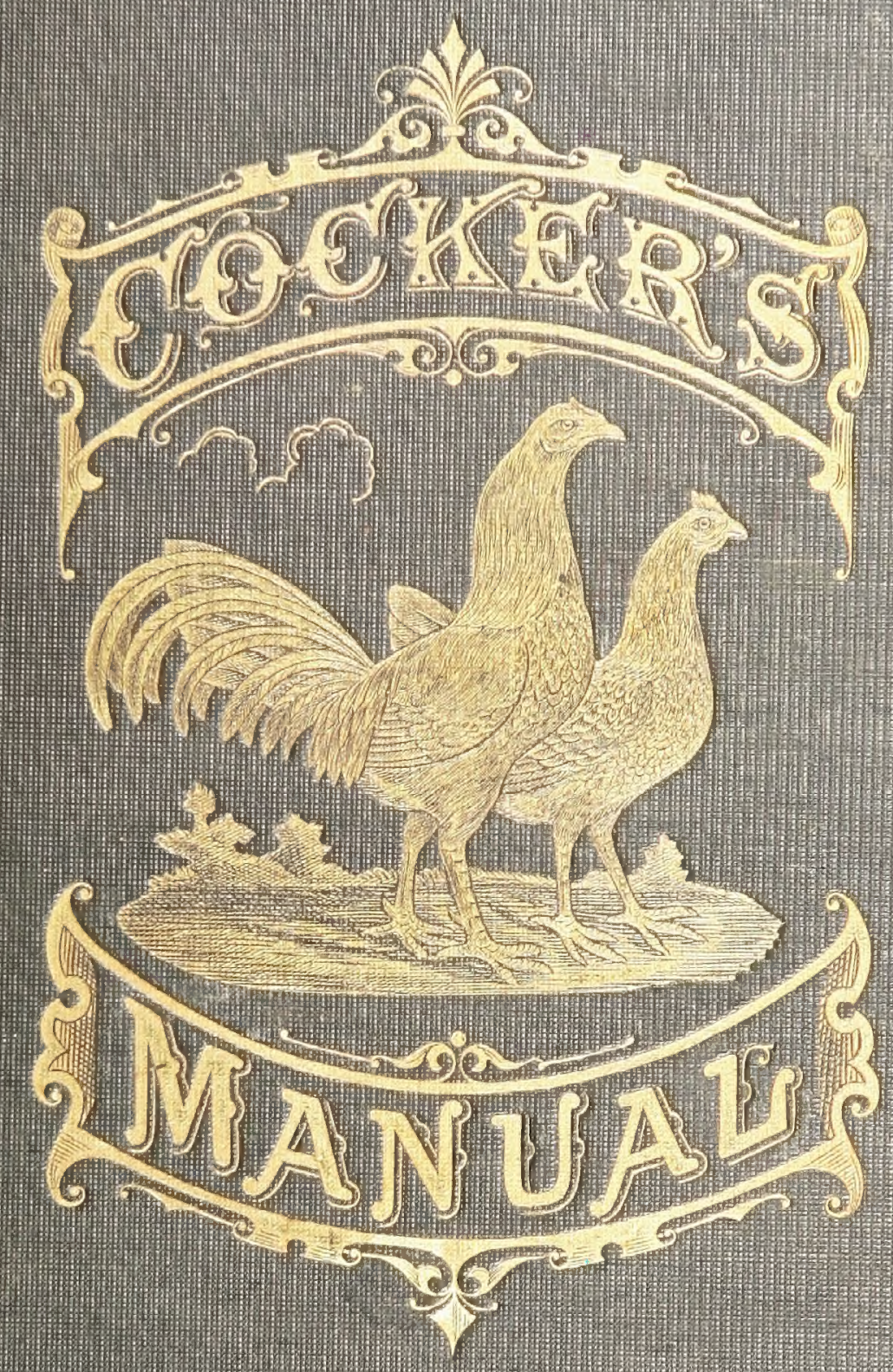




\section{From the Personal Reference Library of PAUL IVES

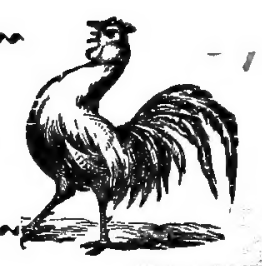

ALBERT R. MANN LIBRARY

New York State Colleges OF

Agricuiture and Home ECONOMics

AT

CORNELl UNIVERSITY

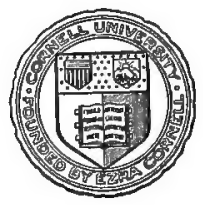

THE GIFT OF

Paul Pomeroy Ives 2D

IN MEMORY OF

Paul Pomeroy Ives 


\section{Date Due}

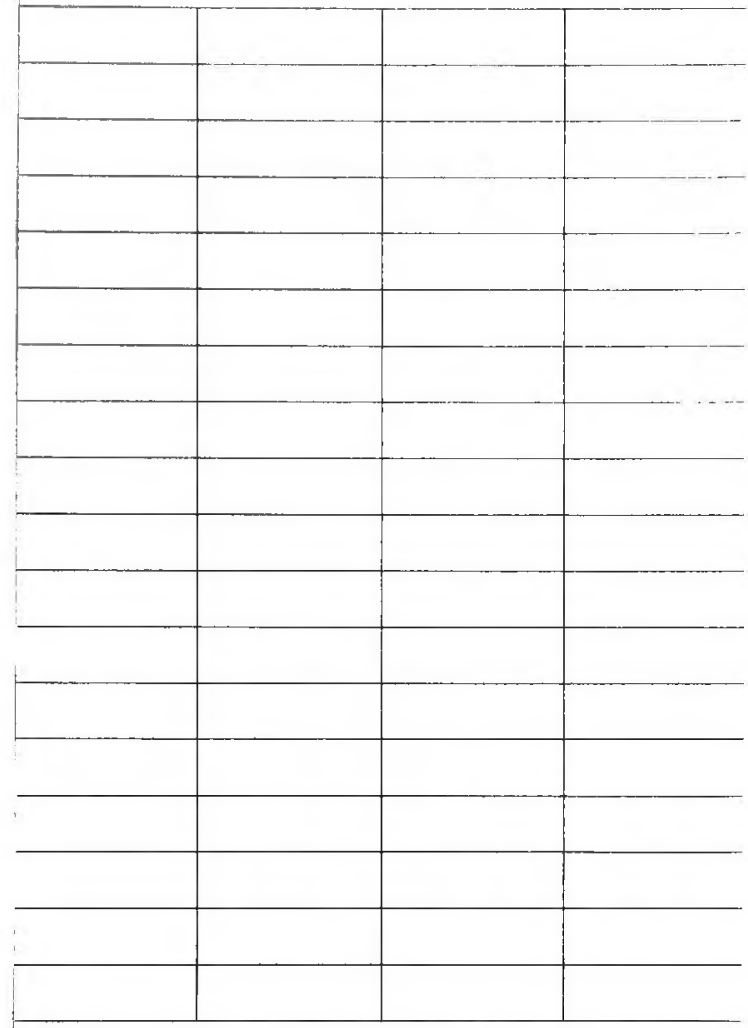

Library Bureau Cat. No. 1137 


\section{Cornell University Library}

The original of this book is in the Cornell University Library.

There are no known copyright restrictions in the United States on the use of the text. 




\title{
Cocker's Manual,
}

DEVOTED TO THE

GAIME FOOTI,

THEIR ORIGIN AND BREEDING

RULES FOR

FEEDING, HEELING, HANDLING, Etc.,

Description of the Different Breeds,

DISEASES AND THEIR TREATMENT.

\author{
SECOND EDITION (Revised), \\ $-\mathrm{PY}$ - \\ F. II. GTATY. \\ PUBLISHED AND SOLD BY THE AUTHOR. \\ 1878.
}




\section{E 6505}

Entered, according to Act of Ceugrews, in the year 1876, by F. H. GRAY,

in the office of the Librarian, at Washington. 



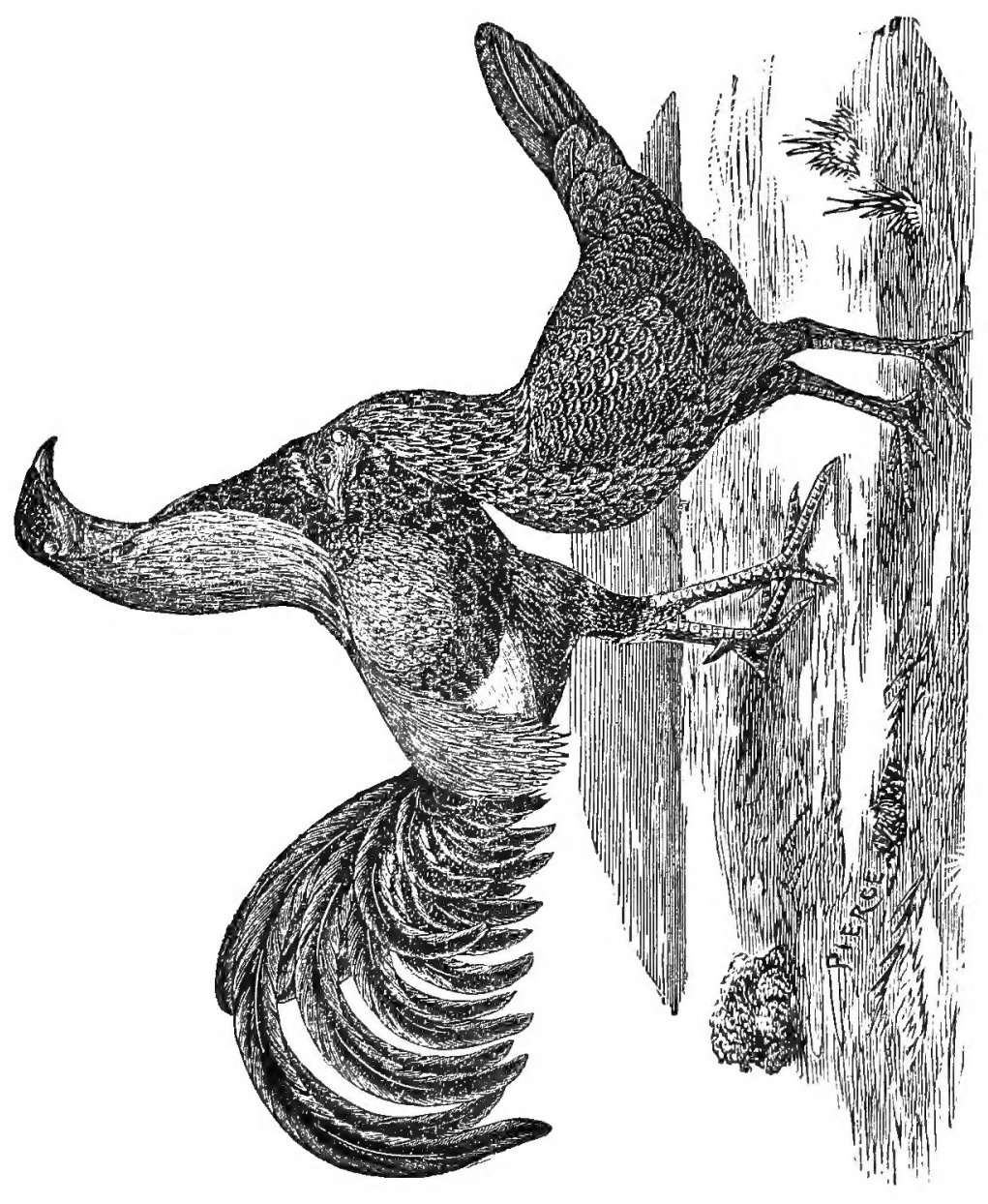




\section{CONTENTS.}

PAGE,

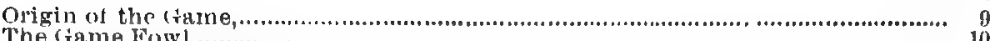

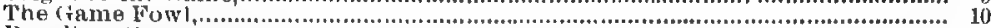

Breeding (tamtes, ...................................................................................... 16

Felection of Breders, ........................................................................................... 18

I'ire of Breeders, ............................................................................................... 19

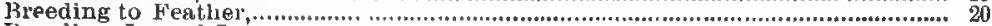

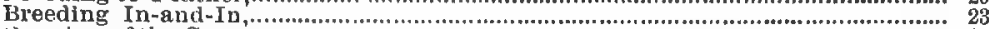

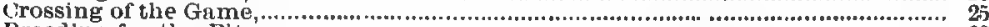

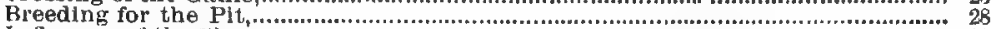

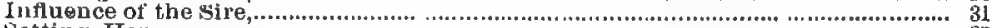

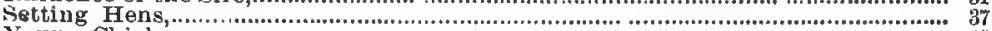

Young Chicks, ... ...................................................................................... 40

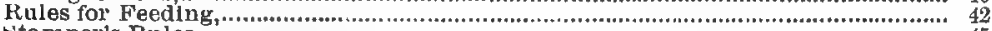

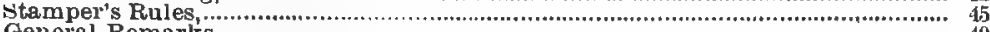

General Remarks, ............................................................................... 49

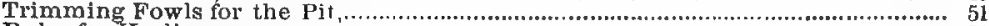

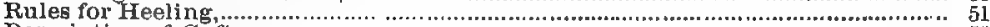

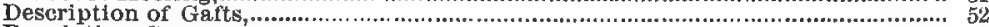

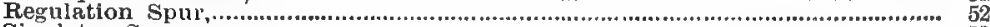

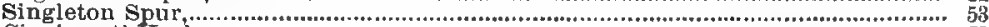

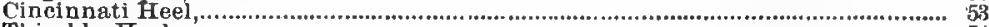

Thimble Heel, .........................................................................................

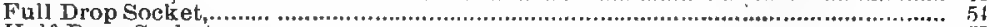

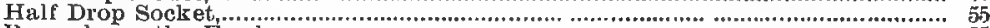

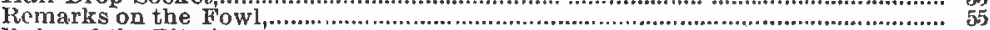

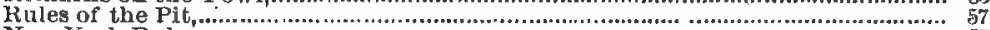

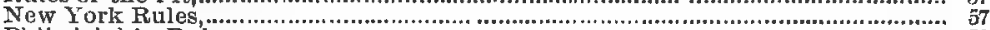

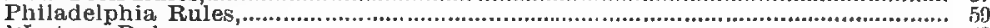

Western Rules, ...................................................................................... bit

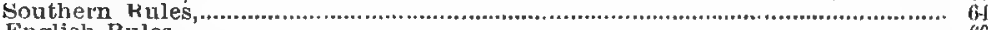

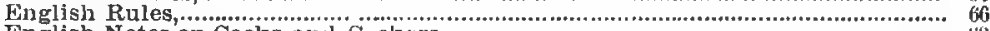

English Notes on Cocks end CAckers, ........................................................... thl

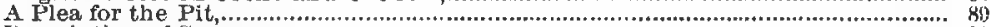

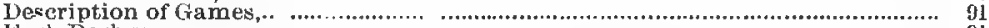

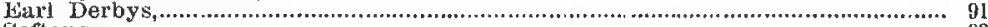

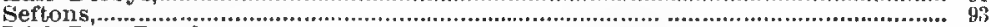

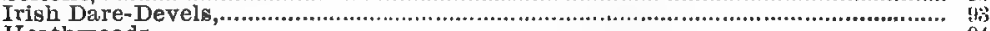

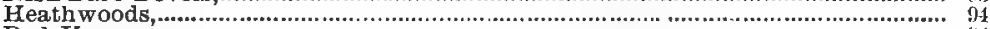

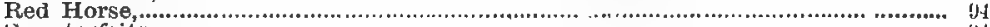

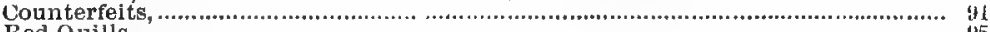

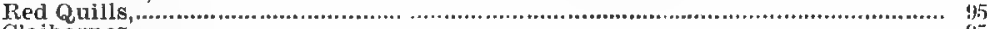

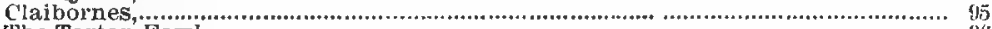

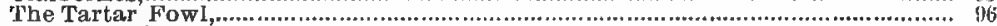

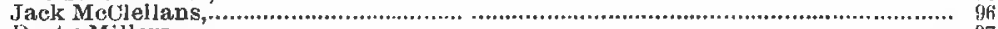

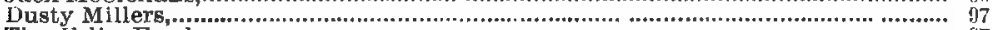

The Eslin Fowl, .........................................................................................

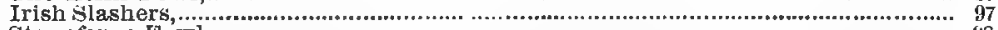

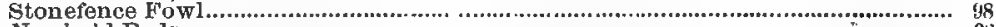

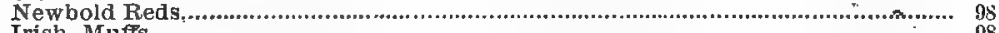

Irish Muffis,.............................................................................................. 98

Baltimore Tassels, .................................................................................... 99

Rattlers, ................................................................................................... 99

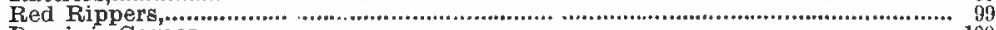

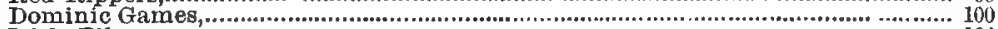

Irish Piles, ................................................................................................... 100

Brass Back Games................................................................................................ 101

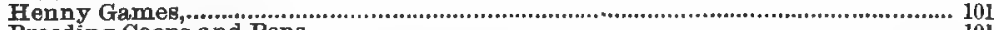

Breeding Coops and Pens, ............................................................................ 101

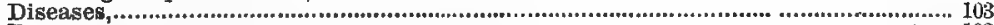

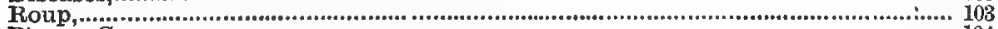

Pip, or Gapes, ............................................................................................ 104

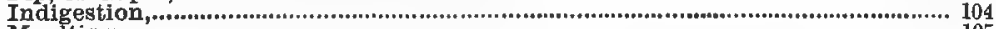

Moulting,.......................................................................................................... 105

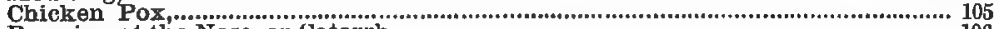

Running at the Nose, or Catarrh, .......................................................................... 106 
Diarrhcea, or DJuentery, n...me..................................................................... 107

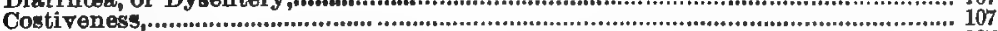

Limed Leg, .......................................................................................................... 107

Rheumatifm, .................................................................................................. 107

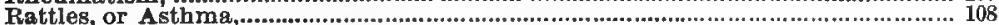

Fever, ...................................................................................................................... 108

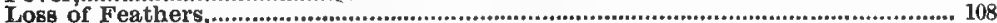

Eating their Feathers, ................................................................................ 109

Inflammation, or $\$$ welling of the Eyes, ........................................................... 109

Melancholy and Moping,................................................................................. 110

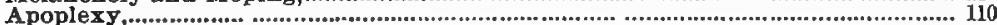

Corns, ........................................................................................................... 1110

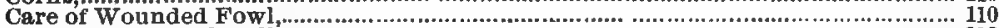

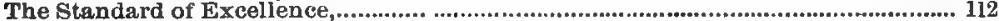

Black-Breasted Red Games......................................................................... 112

Brown-Red Games, ............................................................................................ 115

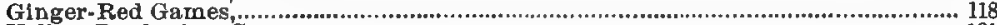

Yellow Duckwing Games, .......................................................................... 121

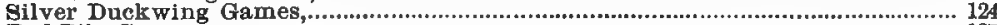

Red Pile Games, .............................................................................................. 127

White Plle Games, ..................................................................................... 130

White Games, ......................................................................................................... 182

Black Games, ,............................................................................................... 135

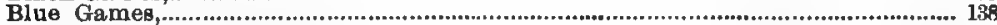

Gray Games, ................................................................................................. 1440

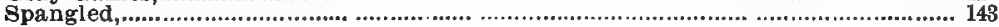

ILLUSTRATIONS.

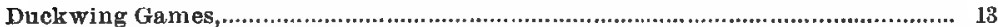

Dominic Games, ............................................................................................... 21

Brown-Red Games, ......................................................................................

Yellow Duck wing Games, ........................................................................... B

Black-Red Tartar Games, ........................................................................... 47

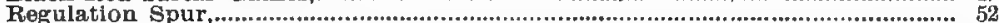

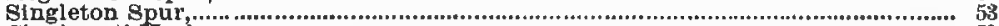

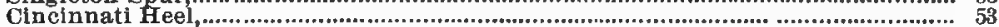

Thimble Heel ................................................................................................. 54

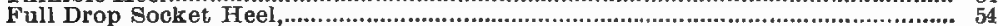

Half Drop Socket Heel, ................................................................................ 55

Red Pile Games, .................................................................................................. 61

Brown-Red Games, ................................................................................................. 67

Black-Breasted Red Games,............................................................................ 77

White Georgian Games, .......................................................................... 83

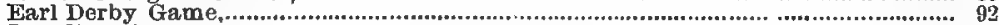

Breeding Coop,.................................................................................................... 102

Tartar Game Gock, ..................................................................................... 111

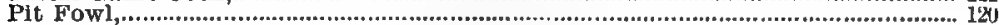

ADVERTISEMENTS.

H. H. Stoddard, Hartford, Conn , ............................................................. 147

Wm. J. Healey, Mineral Point, Wis.,............................................................. 148

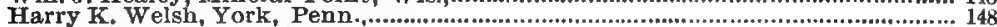

Louis Sendker, Parker City, Penn.,...................................................................... 148

L. E. Sinsabaugh, Syracuse, Nebraska, ................................................................. 149

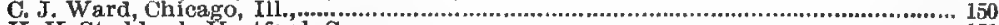

H. H. Stoddard, Hartford, Conn.,.......................................................... 151

F. H. Gray, Battle Creek. Mich., .................................................................. 152

Daniel Allen, Galt, Ontario, Canada,............................................................ 15

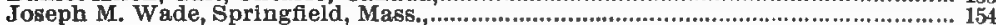

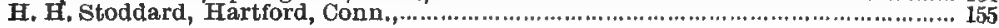




\section{PREFACE.}

With respect to the present work, it has many advantages over that of the first addition. Everything has been treated in so plain a manner that all may understand it. The rules laid down by the best sportsmen have been carefully attended to. With the author's practical knowledge of the different subjects he has advanced, nothing but what he knows to be consistent, and the fancier will meet with more accurate ideas of the subject, while his practice will give him daily proofs of its utility. As such it is presented to the public, without a doubt but that it will meet with a candid and favorable reception. We feel obliged to acknowledge an indebtedness to those who have favored us in many particulars, and by their contributions have materially lightened our labors, and those manifesting an interest in our welfare have our best wishes. In closing, it is but just to say, in our work we have been aided by many standard and reliable works on poultry, to all of which we have given due credit. 



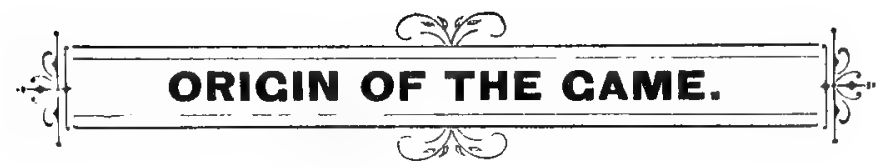

The origin of the Game Fowl is a point that would involve am immense amount of labor and considerable time without leading us to any practical conclusion. It has proved a most perplexing question notwithstanding naturalists, historians, and game fanciers have written much concerning it, and still no one theory has been accepted by all as correct in every particular. We find almost every known part of the globe has been honored with their origin. Many refer to India as the original country, and possibly aver from thence they were carried over the world. Others to the contrary, forcibly assert that England, or the Isle of Rhodes, or some other place were their orignal countries. In this way, perhaps, we could go on and give article upon article yet be no nearer their origin than we were at first, and we do not intend to furnish many new ideas upon this subject as it would only be filling our work up with what many care so little about.

In closing we simply say, by permission we have been allowed to publiş extracts from a short letter written us some time since upon this subject, and we have no hesitation in saying the writer has written more concerning Game Fowls than any other person living, having traveled in all parts of the globe and seen every variety he speaks of in their natural state. We cannot do otherwise than take his ideas for granted, knowing full well that he is conversant with what he is writing about: "As for all Game fowls coming from India, it is nonsense ; but one yellow and willow-legged sort come from that country. The white, brown, black carp and blue-legged are the old British sorts, but as the whole of their ancestors of both Britons and Saxons came from Persia in Asia originally, it is probable that all our white-skinned game fowls are of Persian origin, and that all the yellow-skinned sorts 
are of Indian origin, and also the gypsy-combed and dark-faced will be from there too. There are five colors in India still : First, Blackbreasted Reds, legs willow, eyes red and comb red. Second, Ginger Reds, legs yellow, eyes red and combs red. Third, Gingers, legs yellow, eyes yellow and combs yellow. Fourth, Brown-reds, legs dark willow, dark eyes and dark faces. Fifth, Ginger-brown Reds, legs dark willow, dark eyes and dark faces. All of these colors are to be found, small and quite wild, and are all originals. All the others are made-up colors, except perhaps the Red Duns or Ginger Blues, which some say are original. Duck Wings and all grays are made-up colors, though many will say the contrary. White Piles and Blacks are the most artificial colors of all and took much trouble to make up."

\section{THE GAME FOWL.}

For the present type of the Game Fowl we are without doubt indebted to the contests that for centuries incited that strife among the breeders of it, which has in this way given so good results. The English Game Fowl as now seen is unequaled in form and carriage and is everywhere regarded as the highest possible type of gallinaceous beauty. Just before the abolishing of cock-fighting in England by law, we find Newcastle, Cheltenham, Chester, Gloucester, Norwich, Lancaster, Stamford and other smaller places were noted for their fighting strains of Games, and at one time the cockers of Newcastle challenged the world. This was just subsequent to one of their last meetings, at which over two hundred cocks were fought. Cock-fighting in England is greatly on the decline owing to stringent laws. We also have the same in this country, but from reading the reports of several mains the past few seasons we should judge it was more on the increase, as seldom before has such large sums been placed on each side or mains been more frequent. In consequence a demand has been excited for a game fowl greater than ever before known, and not only is attention being paid them by fanciers and cockers alone, but other breeders of fancy poultry whose yards are now considered incomplete without one or more varieties.

In this country, fanciers believe more in crossing, and for this reason many of our best games cannot be claimed as any particular strain, but 
generally take the name of the breeder or some fancy name, given them by him for some known fighting quality, and among such persons are they to be found in the highest degree of perfection, and can be shown of various colors. Every country has its games, as we have stated, and just so long as they are grown so long will more or less of them be obliged to endure the severe tests well known to cockers in one or more hattles.

We do not intend to treat at any length upon the subject of cockfighting, as perhaps the views we might express would be unpopular with some and the same time do us no real good. Every cocker will as readily bet on his own fowl as a lover of a good horse will upon his animal. All kinds of sport has its admirers, and each one will stand up for his just as strong as the other will cry it down, consequently we shall not point out the cruelty of it nor speak of any of the charges brought against it.

Games compared with other fowl look small, but on handling it will be found they are larger than they look, and are more than the average size, but owing to their quarrelsome dispositions are a hard fowl to manage; still, they will often run peaceably together as soon as one becomes master. Game fowls often reach as high as eight pounds in weight, and yet the cock will appear as light and active as an ordinary fowl will of smaller size. A true game fowl should be of bold carriage, the eye large and bright, the beak well shaped and strongly made, the body should be broad between the shoulders, gradually tapering to the tail, the breast should be broad, full and straight, the thighs short and well turned, the legs stout, the foot flat and strong with a long claw and the spur rather low on the leg. For the game cock to show fight well he must be in the best of health, for though possessing superior qualities physical weakness and general debility will sometimes cause him to seek flight. Activity, determination, willingness to encounter, force in fighting, etc., are the distinguishing characteristics of the game. No other fowl possesses to so great an extent these peculiar qualities. Not only are they noted for their bold carriage but for their disposition to receive severe punishment in a rnost courageous manner.

We find in the Journal of Horticulture the following article upon this subject, written by one of the oldest and most reliable breeders in England, which we consider worthy of notice: 
"Game fowls have not gained their popularity as other breeds, by" one class of admirers only. Many breed them for table purposes, justly preferring their delicate white skin and flesh, round, plump appearance, and rich nutritious game-like flavor, both of flesh and eggs, to all other poultry. Others breed them for the beauty of their elegant muscular symmetry and brilliancy of feather; whilst a few of the old school still breed them for those points so ominous of sudden death, and every Englishman admires their unrivaled courage. Now, how far do exhibition birds supply either of these requirements? Certainly not as a table fowl, as fully ninety per cent. of show birds have dark legs and skins, although the purest and best Game fowls ever seen in England, consequently in the world, have had white legs; and in shape a roasted or boiled exhibition Game fowl more nearly resembles a Heron in its na:row shape and length than a true Game fowl, whilst for tenderness and flavor of the two breeds, well, you can dine on oneand try to on the other.

"As for symmetry the true Game fowl was bred so as to have the greatest possible strength and activity, combined with the lightest weight possible to go to scale with. The show bird is bred with a beak and head as long and weak as a snipe, yet we are asked to believe with all this want of leverage he can hold and tear like a hawk; he is thin, long.necked, has long legs, and is stilty upright, consequently has not the least spring or force to fight if he wished-has no forehand; in fact, a cup-winner is out of all proportion, for if a 5-1b. cock has one quarter inch too much length of body, leg or head, he must necessarily be so. As to color, the original Black-breasted Dark Red has not been seen in a show pen since the first few shows at Birmingham, and is as different in color to our present Black-breasted Reds of the show pen as they are to Brown-breasted Reds, which are also a new-made color, being totally unknown to the old frequenters of the Royal cock pit.

"As to their fighting it scarcely requires a word. They were never intended for it, and it would be a cruelty to put them to what they either will not or cannot do. Mr. Wright has seen both breeds, and 'Duckwing' has bred both, I have bred both, and used them successfully for each purpose, and I quite endorse 'Black Red's' opinion.

"I do not write with the spleen of a disappointed exhibitor, as I am sure I can compare results favorably with any exhibitor in England 


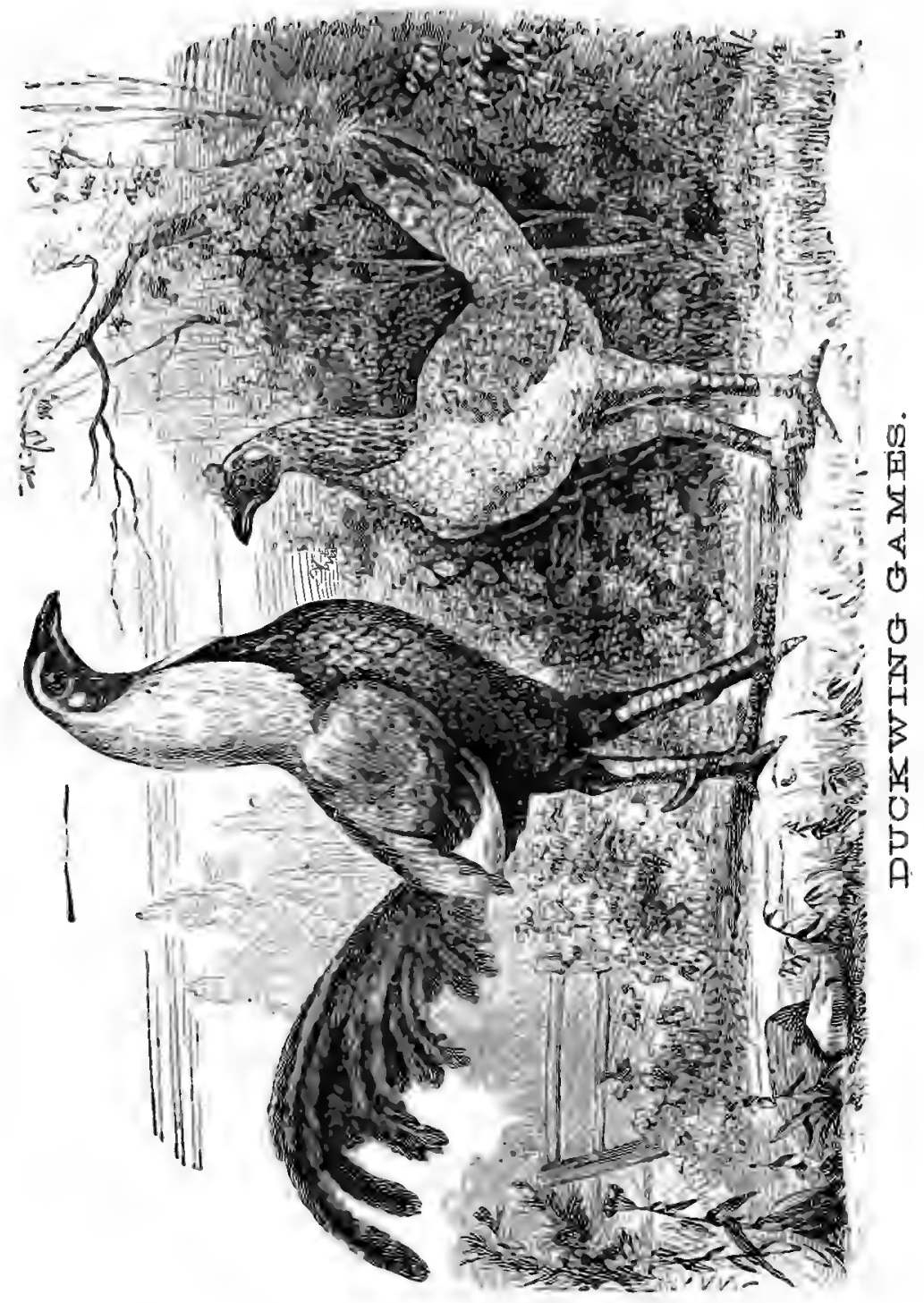



with the same number of entries, and I am not quite ignorant of the fighting bird, having fought my first main in public, with the parish constables keeping order in the pit, about the same time as 'Duckwing' began breeding, and have seen a score or two of cocks judged by merits in private since he wrote his article in the Journal asking for the points of the Malay in our exhibition birds. I would ask where the whip-tail came from, carried as only a Malay and a craven does carry? What is the first thing a bad-bred one and a craven does, when intending to fly the pit? (I am sure 'Duckwing' knows, as I think we have had some conversation on this subject), and is it not to fold his flag and put it in true exhibition posture? whilst the up and spread tail belongs only to the true Game cock. 'Duckwing' must surely in varied experience have seen half-bred Malays awarded cups, and on the second and third days of the show seem so ashamed of their deception that they would neither crow nor fight. I knew a sporting American colonel to take thirteen cocks to America from our best shows, and after journeying 3000 miles with them found all were dung. hills, except two low-priced despised yellow-legged ones. I have just received a letter from a breeder and shipper of Game fowls in America, asking me to try to get him something better than the trash exhibited in this and his own country. Our Journal stated that many of the birds at the last Birmingham show were as much Malays as game, and an old and able correspondent of this Journal, 'Newmarket,' wrote me to the same effect, and no one knows a Game cock in or out of condition better than he does. I recently wrote for a brood cock to a gentleman who has long bred and shown as good Game fowls as any man in England, and he requested me to see a bird he was sending to a show in my district. It was awarded the cup, but I thought it the coarsest bird of the Malay type I had ever seen him exhibit, wrote him to that effect, and his reply informed me that he fully anticipated my verdict, saying that he had purchased this one not to please himself but the judges; and as this bird has taken as many, if not more cups than any other bird shown this season, it would seem he has been very successful in doing it.

"As to length of head, I know an exhibitor who has a stag only three removes from a prize Malay hen, whose head for mere length would beat most prize-winning show birds; and of the many birds I have known so manufactured for the show pen, a judicious se- 
lection has obviated all trouble in molding the head into the required shape. Not only does every poultry show contain these mongrels in abundance, our judges encourage them, and even the illustrations of our modern poultry books would pass muster for improved Malays, and are mere caricatures of real Game fowls, such as are seen in 'Rural Sports,' from a good painting by Marshall, of one of the most perfect cocks ever seen: It took centuries of careful breeding to gain that perfection, and the trial was often for a fortune, thousands depending on the prowess of a single bird. Now, we are told a few years' breeding them to be shown a score together for a few shillings or a cup has improved them, and readers are asked to believe it. I shall give them Punch's advice to those contemplating marriage and say, 'Don't.' "[CoRnish Duckwing.

\section{BRERDING GAMES.}

The breeding of Games is just as much a science as the breeding of other fancy poultry, and it is a mistaken idea of fanciers to think as they have purchased perhaps at a large expense a pair or trio of Games from some noted breeder's yards that it is all that is required to produce a nu nber of fine fowl; but care, time, and a large amount of patience will also be needed. They can be just as easily raised as other breeds of fowls and at no more expense to the breeder, and as he grows in experience so much less will be the work, as each season will teach him something new. They being hardy can be confined in very small runs, and for this reason can be bred in small places as they have a strong constitution. We find them in their prime when two years old, but as a general thing the cock wears out faster than the hen, although the hens at an old age only lay about one clutch. We now have a cock in our possession which is over twelve years of age, and as far as we can notice appears as young as a two-year-old, and his stag's comb as strong and vigorous as any we raise. But very few Game fowl ever live to this age, as owing to their quarrelsome dispositions sooner or later they die by accident or some disease caused by fighting. 
Stags bred to pullets will produce good chickens, but as a.general thing full grown or two-year-old birds bring the best.

A writer in the Journal of Horticulture says, "In crossing colors in breeding the following cases-first, when there are more than six hens to each cock; second, when the hens are dark with dark legs and the cock light; third, when the hens are full grown and the cock not full grown; also in breeding games from hens with a barn-door cock the the progeny will be gamer than if breeding from a game cock and barn-door hen. The fighting qualities are, however, inherited more directly from the cock than from the hen. In breeding Game fowls together, which made the best breeders for the pit in general, more careful of their brond cocks than of their brood hens. In all animals of both sexes those taking the most after their sires are considered to be the strongest and most spirited. As a rule, breeding from fowls not full grown is a great mistake, as even if they produce quicker birds (which some say, though contrary to my own experience), they at any rate produce weaker, smaller and softer birds both in bone and flesh."

It is a well known fact that every breeder has his own ideas and no amount of talking could induce him to change it. One of these is not dubbing his breeding cocks, as they select their finest stags and keep them undubbed, putting them on a walk alone with a few hens only. When our stock has been bred in-and-in too long they begin to be slower in their motions, the hens do not lay as well and also moult later each season and feather more slowly. In this case they should be crossed with a strong, healthy brood cock, as all birds from a first cross are more vigorous if the cross is good; and also best for the pit. Each succeeding cross grows less vigorous and spirited. By keeping two distinct breeds a first cross can always be had when wanted. It is said the first laying hens never breed the best birds, i. e., hens that lay in winter are not the best to breed from, having exhausted themselves before the proper season.

Breeders for the pit generally allow three hens to the stag, and five to the cock, but we are convinced from our own experience that the best stock can be bred from a single cock and two good hens; still it is often the case that two hens will not prove sufficient and others will have to be put in. But as a general thing we like to breed from two hens if possible. Successful breeders avoid breeding in-and-in, and it 
is shown many good breeds have been ruined by so doing, although they were once very successful. To avoid this American breeders breed twice in and once out, while it is said the English breeder's rule is once in and once out. Our advice is, if you have a good winning strain take good care of them and breed from them the best shape and most active and healthiest, and do not destroy their good properties by constantly crossing and changing them.

\section{SELECTION OF BREEDERS.}

As the selection and mating of our breeding stock is not attended without some difficulty much care and patience will be required to be successful. Fanciers who select their cocks from one yard and hens from another must not expect to raise fowls that are reliable, although their chicks will not be related. As the hens give us size and shape too much care cannot be taken in selecting them. Each fancier has his own ideas as to what his breeding stock should be, yet we often see some very poor fowls on such breeders' yards. Some fanciers prefer small birds, others medium size, and again others extra large ones, and each one will show his own individual preference for one over the other. Perhaps there are some grounds on this point for question, but for us we have no hesitation in giving our judgment for the larger bird, as we can then get all the smaller ones we want without breeding especially for them, as we contend that a good large one is better than a good small one, and one of extra size with all the other good qualities should not be disposed of but be highly prized as one of our breeders. Another wrong is also done by some fanciers in letting their old and well tried stock run out and breeding some new breeds they know nothing of when, perhaps, they find they do not equal their old favorites and then lament for not breeding from them. They are too apt to be taken up with some new breed and each season trying something new, and for this reason the breeder should understand his stock thoroughly. It is a well known fact that good qualities in parents will become fixed in the offspring if care is shown in the selection of the breeders. The age of the breeding stock is an important consideration. Some fanciers claim no hen should be selected as 
a breeder until she is two years old, as pullets' eggs have a tendency to produce weakly chickens, and also claim the same in breeding from too young a cock. We always have our breeding stock full grown if possible; if not we prefer to breed cocks to pullets and hens to stags. If the fancier's object is breeding to feather, great care should be taken in selecting his breeders or otherwise the object sought will not be obtained. If it is desired to preserve a particular color, the hen selected for the purpose should be the same in color as the cock hut of different blood, that is to say, not closely or nearly related. Some claim the principle in breeding to be observed is, "like produces like," but still this is not an unerring guide as we can breed from any stock of fowls, and not unfrequently an extra fine specimen will appear, and by breeding such specimens or pairs we cannot obtain their like in all cases, at least a portion of their progeny will possess the qualities distinguishing the originals. If, however, we select the best prodaced by such fowls as breeders and continue from season to season selecting the best samples we shall in time arrive at our desire and obtain a permanent improvement on the original stock. If size and strength are desired the selections should include large hens or pullets with good build, legs and general make. If intended for the pit special attention should be given to abtaining a breed of good size with large bone and muscle-the cock well set upon his legs, broad at the shoulders, wing strong and of good length and a tough wiry feather, one that continually urges the battle and gives his adversary no rest, and a stock whose gameness you have often seen tested. With such a cock placed with hens selected for the many fine points which they possess, being good layers and setters, the chickens will be noted for their courage and gameness. Some like a cock to be full of motion while in hand and continually talking and chatting, with his legs drawn close up to his body.

\section{CARE OF BREEDERS.}

All fanciers must bear in mind that great care and attention must be paid to our breeding fowl during the breeding season. Particular attention should be given to our breeding cocks, as they must be in 
the best of feather and health, as it is well known that breeding from diseased fowls result in chickens with weak and sickly constitutions, small in leg, boue and muscle. We do not believe in too expensive coops for our breeding pens, but light and roomy, as we use ours only during this season; but if intended for winter as well as summer use more expense will be added in making them. Care must be taken in feeding them and not supply too much food, as the birds may become fat and thus defeat our object. It is not well to keep them confined to one kind of food but a change should be given them often; fresh water must be supplied them daily, and if extremely warm weather at least twice each day. If a cock takes a dislike to a hen she should be removed at once as it would be useless to endeavor to breed from her and would result in her death, or at least her injury. The eggs should be collected regularly each day, marking the name of breed and day on each. If this plan be adopted great disappointment will be prevented in the hatching of the eggs.

\section{BREEDING TO FEATHER.}

Since our Poultry Standard has come into existence and our poultry shows more numerous we find much attention being paid to breeding games to feather, caring more for exhibition birds than our old pit fowl which, owing to the stringent laws now in force has done much to put them out of use. Yet, notwithstanding this fact, we find that many old cockers discard breeding to feather, caring more for the action and fighting qualities of the cock than for his appearance. Among the cockers this class are greatly in the majority. A fancier, however, whose object is to breed exhibition or prize birds gives close attention to breeding to feather, to do which successfully several things are necessary to be observed. Just as much science will be needed in breeding fowls to feather as for any other purpose, and in breeding for this point it is generally expected that we will produce fowls of the same feather, but experience shows all will not be the same, and so it is with standard birds. Many chapters have been written in which are given various rules and instructions for breeding to feather if this or that advice is followed. But there are many important points 


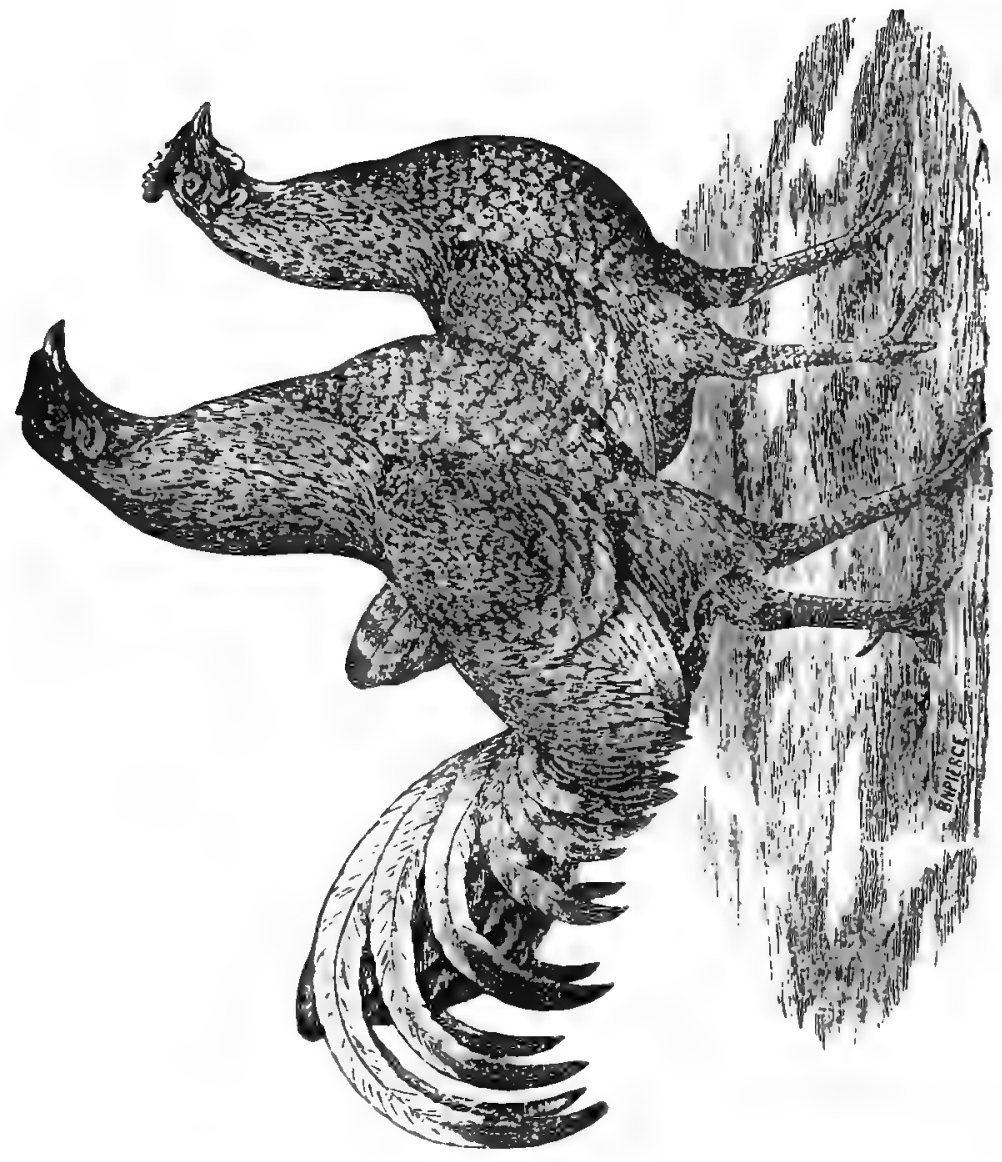



besides these which must be considered as well as plumage, although it is one of the main objects in judiciously mating for breeding to feather, yet we have other well known points that we must not overlook but have an eye on form, size, vigor and action, as while we are breeding to feather none of these other qualities should be lost sight of. Select only your best birds, mate them carefully for color, avoiding as much as possible breeding brothers and sisters together, keeping our selected stock closely by themselves. By carefully following the course suggested you will succeed in getting a larger number of chickens of the right color and the more valuable for breeders.

\section{BREEDING IN-AND-IN.}

It has long been a disputed point whether the system of breeding in-and-in or the opposite one of crossing had the greatest tendency to maintain or improve the quality of the breed. Both systems we find here have able and earnest advocates, each confident of being in the right. As a general thing in-and-in breeding is not looked upon in this country with as much favor as in England, still we now and then find some old cocker who perhaps brought with him a trio or pair of some favorite breed of games, and has kept breeding them together ever since in order to keep his breed pure, and to his sorrow he gives them up as worthless for fighting. There has been much written upon this subject the past season. We find one English breeder of some reputation holding to it as if it were his only hope, showing how it worked in animals, why not the same in game fowls? No doubt they can be inbred for a number of years, but in doing so intelligence on the part of the breeder is required, also great care and study in the selection of his breeding stock. It is almost impossible nowadays to obtain a breed of games pure. You will find when you breed them that they have one or more crosses, and sooner or later this will show itself, and yet this in-and-in breeding will produce bad results when practiced by an inexperienced breeder, and to do it successfully must understand his fowl. It is a well known fact that some of our finest horses, cattle and sheep have been produced by this in and-in breeding. To preserve certain characteristics an amount of close breeding is necessary, 
but for strength of constitution the less the better. When our fowls have been bred in-and-in too long they begin to be slower in their motions, the hens do not lay as well as before, and they moult later and slower each season.

"The question of in-breeding has never been settled by the uniform custom of any considerable number of breeders. The practice in England appears to be once in and once out, avoiding incest, while the American practice leans to the practice of twice in and once out. Some of the best English authorities have recommended the custom that prevails in this country, though it is not reduced to anything like uniformity among American breeders. By in-and-in breeding is understood to imply the union of near relatives, avoiding kindred of the first degree. Long continued in-breeding would tend to diminish the bone and reduce the dimensions of the muscular form and proportions. It therefore becomes necessary to breed out to strangers, to keep up size and bone. As soon as this end is accomplished, we can breed back to kindred, and refine bone and muscle. By this simple process of enlarging and refining, we get the most substance in the least comfass.

"The wild horse, in promiscuous intercourse, avoids consanguinity, or continued in-breeding in the highest degree, by the simple law of nature. It is a wise provision, designed to perpetuate the race. The strongest of the male species govern the flock and perpetuate their kind. The king of the harem soon gets displaced by some young, courageous rival, who usurps the throne, and holds dominion through his day and generation. He is succeeded by' some other rival, who holds dominion over the flock till his successor becomes qualified, by brute force, to displace him. We have here the system of in-breeding and out crossing agreeable to the laws of nature. The deductions from the wild horse, roving at large, are decidedly in favor of inbreeding. It would be a natural conclusion from the common course of things, that when we have the best possible form and action matured in the breed, not to lose half the benefit of superior excellence by crossing out to strangers except to enlarge the reservoir to hold more substance. We must keep all the improvement we have got, and get all we can.' 


\section{CROSSING OF THE GAME. .}

There can be no doubt that crossing as practiced by the more experienced and cautious breeders is of real benefit as it hardens up the feather, increases the size and gives us more bone and muscle, and also helps lessen the amount of superfluous flesh, the last being one great point for an old cocker as a less amount of work is required to prepare him for pit fighting. The game fowl is unlike many others, consequently the benefits of crossing can be realized in a single season, the results of which can well be shown, perhaps in some of our fowls in days gone by, but well remembered by many old fanciers and who still speak with as much pride of their Claibornes, Heathwoods, Baltimores, etc, as our great horsemen do of their Longfellow, Bassett, etc. Here the benefit of crossing was shown in its full force, as no fowl was ever produced that excelled them in an old cocker's eye, as determination and force in fighting could here be found. Many think as they have two strains of games that is all that is needed to make a cross, consequently their fowls in time show much worse than their old ones. Nothing can be gained in crossing without regard to form, size and general characteristics of your breeding stock. Experience of old and reliable fanciers everywhere have shown this, and all breeders should seek to be as near perfect as possible. We believe it cannot be disputed that old cockers have made the game what they are, giving him his ferocious disposition, hardness of feather and perfect build, and it never could have been done without care and study in breeding them.

By crossing is meant the mixing of breeds, and if two towls of different breeds cross a third is invariably produced different from either and partaking to a large extent of the qualities of both is frequently and it may be invariably said better than either. The follcwing article upon this subject was written by Newmarket in the Journal of Horticulture :

"Some breeders assert that in crossing, color and form or shape are derived chiefly from the cock, and that size, vigor and constitution: come from the hen. I would not, however, "give much for any brood cock that did not impart all qualities to his pregeny in excess of the hen. ******** As to crossing and mixing the different colors I think that Piles and Red Duns cross best of all, both being of 
a light red. Reds will always spoil the color of grays, giving them a tinge of red and brown, but grays do not spoil the reds. The best colored Duckwings are bred from the dark gray cross though this spoils dark grays. It is well known to all good breeders that crossing colors is very injudicious, as a rule all the best breeders liking each sort to be exactly alike both in shape, in feather and in blood, and disliking all mongrel mixed colors and crosses. $* * * * * *$ In crossing colors when the hens are of a stronger and harder color than the cock, most of the cock chickens will be the color of the hen and the pullets the color of the cock. For instance, in crossing brownred hens with a willow-legged black-breasted red cock most of the cocks will be brown-reds and most of the pullets of the partridge color. This. however, is not a good cross."

Darwin says: "There can be no doubt that crossing, with the aid of rigorous selection during several generations, has been a potent means in modifying old races, and in forming new ones. Lord Orford crossed his famous stud of greyhounds once with the bull-dog, which breed was chosen from being deficient in scenting powers, and from having what was wanted, courage and perseverance. In the course of six or seven generations all traces of the external form of the bulldog were eliminated, but courage and perseverance renained. Certain pointers have been crossed, as I hear from the Rev. W. D. Fox, with the fox-hound, to give them dash and speed. Certain strains of Dorking fowls have a slight infusion of Game blood; and I have known a great fancier who on a single occasion crossed his turbit-pigeons with barbs, for the sake of gaining greater width of beak.

"In the foregoing cases breeds have been crossed once, for the sake of modifying some particular character; but with most of the improved races of the pig, which now breed true, there have been repeated crosses-for instance, the improved Essex owes its excellence to repeated crosses with the Neapolitan, together probably with some infusion of Chinese blood. So with our British sheep; almost all the races, except the Southdown, have been largely crossed; 'this, in fact, has been the history of our principal breeds.' To give an example, the 'Oxfordshire Downs' now rank as an established breed. They were produced about the year I 830 by crossing 'Hampshire and some instances Southdown ewes with Cotswold rams;' now the Hampshire ram was itself produced by repeated crosses between the native Hamp- 
shire sheep and Southdowns; and the long-wooled Cotswold were improved by crosses with the Leicester, which latter is again believed to have been a cross between several long-wooled sheep. Mr. Spooner, after considering the various cases which have been carefully recorded, concludes, 'that from a judicious pairing of cross-bred animals it is practicable to establish a new breed.' On the Continent the history of several crossed races of cattle and other animals, has been well ascertained. To give one instance: The King of Wurtembery, after twenty-five years' careful breeding, that is after six or seven generations, made a new breed of cattle from a cross between a Dutch and Swiss breed, combined with other breeds. The Sebright bantam, which breeds as true as any other kind of fowl, was formed about sixty years ago by a complicated cross. Dark Brahmas, which are believed by some fanciers to constitute species, were undoubtedly formed in the United States, within a recent period, by a cross between Chittagongs and Cochins. With plants I believe there is little doubt that some kinds of turnips, now extensively cultivated, are crossed races; and the history of a variety of wheat which was raised from two very distinct varieties, and which after six years' culture presented an even sample, has been recorded on good authority.

"Until quite lately, cautious and experienced breeders, though not averse to a single infusion of foreign blood, were almost universally convinced that the attempt to establish a new race, intermediate between two widely distinct races, was hopeless. 'They clung with superstitious tenacity to the doctrine of purity of blood, believing it to be the ark in which alone true safety could be found?' Nor was this conviction unreasonable: when two distinct races are crossed, the offspring of the first generation are generally nearly uniform in character; but even this sometimes fails to be the case, especially with crossed dogs and fowls, the young of which from the first are some-. times much diversified. As cross-bred animals are generally of large size and vigorous, they have been raised in great numbers for immeconsumption. But for breeding they are found to be utterly useless; for though they may be themselves uniform in character, when paired together they yield during many generations offspring astonishingly diversified. The breeder is driven to despair, and concludes that he will never form an intermediate race. But from the cases already given, and from others which have been recorded, it appears that pa- 
tience alone is necessary; as Mr. Spooner remarks, 'nature opposes: no barrier to successful admixture; in the course of time, by the aid of selection and careful weeding, it is practicable to establish a new breed. After six or seven generations the hoped-for result will in most cases be obtained; but even then an occasional reversion, or failure to keep true, may be expected. The attempt, however, will assuredly fail if the conditions of life be decidedly unfavorable to the characters of either parent-breed.

"It is scarcely possible to overrate the effects of selection occasionally carried on in various ways and places during thousands of generations. All that we know, and, in a still stronger degree, all that we do not know, of the history of the great majority of our breeds, even of our more modern breeds, agrees with the view that their production, through the action of unconscious and methodical selection, has been almost insersibly slow. When a man atteuds rather more closely than is usual to the breeding of his animals, he is almost sure to improve them to a slight extent. They are in consequence valued in his immediate neighborhood, and are bred by others; and their characteristic features, whatever these may be, will then slowly but steadily be increased, sometimes by methodical and almost always by unconscious selection. At last a strain, deserving to be called a sub-variety, becomes a little more widely known, receives a local name, and spreads. The spreading will have been extremely slow during ancient and less civilized times, but now is rapid. By the time that the new breed had assumed a somewhat distinct character, its history, hardly noticed at the time, will have been completely forgotten; for, as Low remarks, 'we know how quickly the memory of such events is effaced.' "'

\section{BREEDING FOR THE PIT.}

We do not find at the present day as much attention paid to breeding Games for the pit as in times gone by, still many old cockers take. as much pains as ever and show just as much care and attention in. breeding as in an earlier day. The best breeders fur the pit consider the cock as ahead of all the qualities, consequently show great care in selecting them, as in breeding for this special purpose we must not 


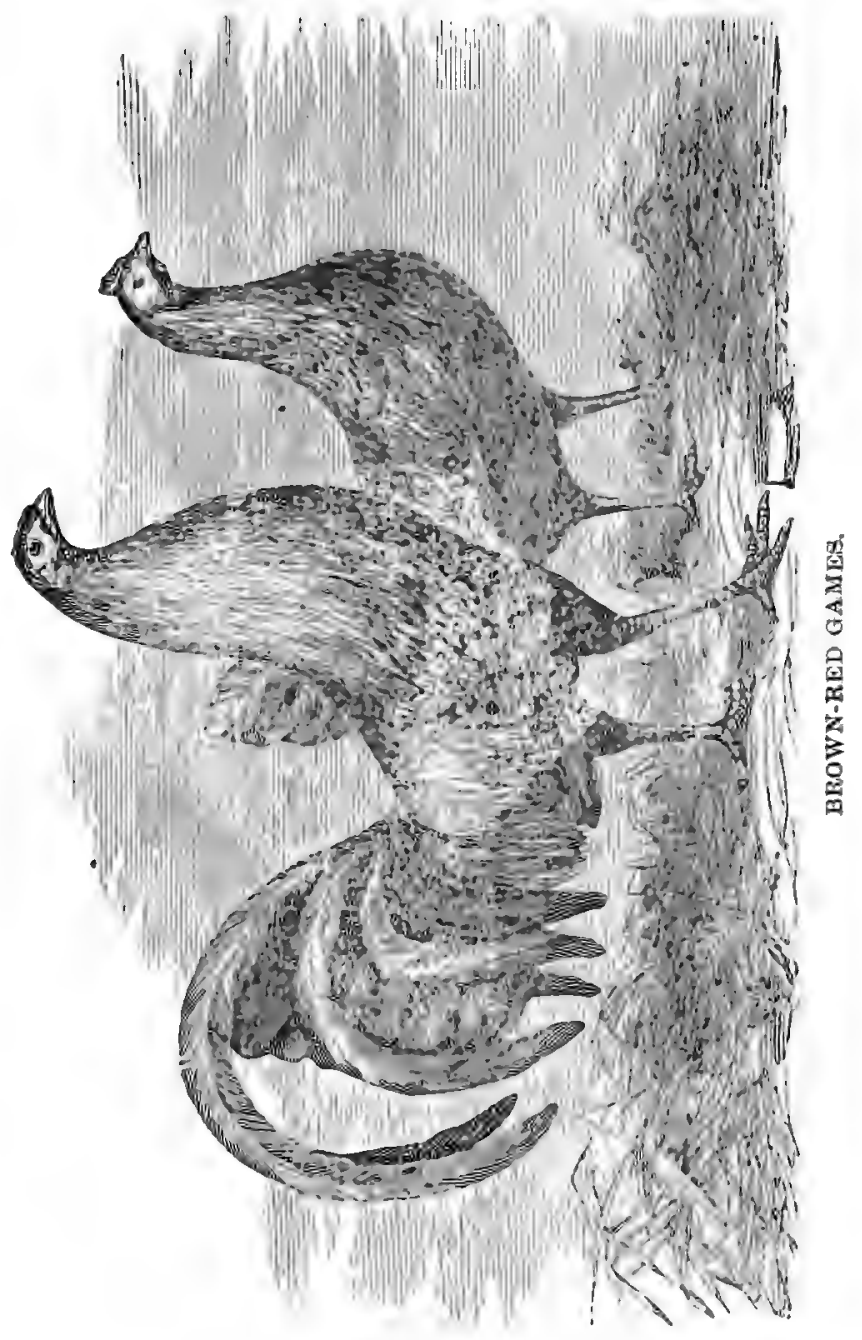



seek color but strength and endurance with all the good fighting qualities. Color, as will be observed, is of secondary importance and should not be preferred to the essential requisites for the pit. It is generally considered that a cross fowl is best for this purpose and for this reason the breed selected to cross with must be equally as good and better if possible in their fighting qualities than those possessed: by the breed intended to be crossed. In the selections made it is hardly needful to be remarked that great caution should be observed, for it is frequently the case that some games are good billers but very poor strikers, and such it is hardly desirable to breed from. A selection should be made of a well tested cock of a reliable breed, a good biller and striker, a savage and inveterate fighter, quick in movement and who shows no quarter to his antagonist. Breeders for the pit generally allow three hens to a stag and five hens to a cock. Some, however, prefer only two hens to a cock.

\section{INFLUENCE OF THE SIRE.}

It is still an unsettled question as to the length of time it is necessary to keep a hen after a cock has been changed before the eggs can be set with a certainty of getting chicks sired by the new cock We have seen statements to the effect that a permanent influence resulted from copulation in the case of fowls-that absolute purity of blood could not be depended upon if the hen at any time had run with a cock of different breed. On the other hand, we find with many a cominon impression that impregnation takes place but a short time before the egg is laid. If we wish to be doubly sure we should not breed from a hen until she had finished laying her litter and wishes to set, then we would place her with a cock we desired to breed from. In this way we think we could be more assured that we had the breed we most desired.

The following was written by a well known western breeder, who has given the subject much careful attention, and which we consider worthy of mention :

"A correct answer to this question is important to the breeder of high-class poultry, to enable him to know when a breeding hen should 
be confined or removed from the cock to maintain purity in her progeny; also, what number of eggs, being laid by one hen, are fertile after the cock has been removed from the yard. I shall not attempt to answer this question fully, but give such observations as have come to my notice.

"In examining some of the leading works on poultry, such as Wright, Tegetmeir, aud others, I find the chapters on eggs, their formation, etc., do not touch upon the subject, but slip out of it easily, and fail to give a hint tending to a solution. All the answers $I$ have ever seen have appeared in periodicals, and were written by breeders who gave their individual opinions, just as the subscriber is now doing. Their answers are that the period at which a cock can be removed from the hen and still have the eggs she may produce fertile at four, six, eight, ten or more days, and I believe one man had such wonderful hens that the characteristics of a certain cock were seen in their progeny, although they had been removed from him the year previous. For fear of contamination, or for effect, some persons advertise that they keep their various breed's separated the entire year. This carefulness is well enough, but fully shows the ignorance of the breeder, who seeks to make reputation by such proclamations.

"After the yolk has fully matured, the sac which contains it is detached from the ovary, and passes in to the oviduct or egg-passage. It is in the egg passage, in my opinion, that the eggs becomes fertilized; That at different seasons more or less eggs are so maturing in this passage; and that all the eggs so maturing, which have not become enveloped with the skin which we find next to the shell, are impregnated if the hen comes in contact with the cock. Hence, as production goes on faster at one period than at another, it is impossib?. to fix any given number of days that one impregnation by the cock may last.

"It is well established that a pure-bred hen may remain with cocks of other breeds with safety to the purity of her progeny at another time than during the producing seasons. It is also well established that her eggs may be fertilized by a cock of any other breed and only produce cross-bred chicks from a limited number of eggs. Physiologists maintain that in most breeding females, the first male by which they are impregnated influences their subsequent progeny, no matter by what male it may be produced; and that such a female absorbs into her own blood, through the offspring, some of the characteristics of 
the male. In fowls this rule or trait does not seem to obtain, and may be, perhaps, an indirect evidence that the yolk is vitalized or impregnated after it has become detached from the ovary.

"If this opinion is well founded, then, the exact number of days which must elapse before preserving eggs for hatching, after the hen has been placed with her cock, no definite answer can be given, as it is impossible to know the number of eggs in process of formation in the egg-passage of a living hen, and in all cases, it will be safe to wait long enough, say two or three weeks, especially so if the eggs are designed for sale."

Again we notice in the Fancier's Gazette, London, the following article upon the subject, which we consider of interest to all breeders :

"How long after the cock's removal does his productive influences continue to affect the hen is a question more easily asked than satisfactorily answered. Our forefathers who bred their old fighting strains with a hundred times more care for the pit than we are wont to do, for the show pen, contended that a hen was never clean, i. e., free from the influence of the cock she first laid to after moulting until she moulted again. There are others who as positively affirm that every hen is clean on becoming broody, whilst not a few assure us that the influence of the cock only extend over the limited space of three or four days. Are they all right or all wrong? I am not so egotistical as to say, but would rather, with your permission, state a few facts which may assist your readers in drawing their own conclusions.

"Every experienced breeder will have often observed chickens of one clutch showing the distinctive points of two cocks when it has happened that two cock birds have been running on the brood walk at one and the same time, or when a cock of one breed has been substi tuted for another during the laying of the hens. For instance, I have often required a brood cock from the walk for some purpose, say a full-feather plain head, and have placed with the hens a Tassel or hen cock, the result is that the laying hens then produce chickens closely resembling both the plain heads and Tassel, or full-feathered and henfeathered cock; but the question is, 'How long is it after the introduction of a fresh cock before this change of parentage takes place?' Last autumn a poultry-killing sheep-dog so bit and mutilated a brood cock-one of the handsomest I ever saw, presented to me by one of the 
oldest and best ureeders in Cheshire-that I had great difficulty is keeping him alive. I determined to breed from him this spring notwithstanding his injury, so I placed six brood hens with him in November, and not until March, after sitting several nests of eggs by him without producing a single chick did I become satisfied that he had totally lost all procreative power, as all the eggs were marked with the date they were laid and all set. I found the eggs became prolific on and after the fifth day from the introduction of another stag and not before. Again, I had occasion to take a cock from a brood walk early in the spring. A black hen was then running with a brood of young chickens, and after leaving them she laid away privately in the woods, and nine weeks and two days after the cock was taken away she appeared with a brood of eleven strong chickens. There was no possibility of her getting with another cock, no other fowl being kept within a mile of the place. Requiring a few game fowls of a particular color for some friends in Australia, I last year placed a gray pullet with a brown-red cock, both having been carefully bred in-and-in and to their respective feathers, for many years previous, the produce being exactly what I required, viz: blotch breasted dark grays with marigold-shouldered cocks, and a more uniform brood in color, shape and style it would be difficult to find. Being so successful I this year placed with the cock three other sisters to the pullet which had never perviously heard a cock crow. The produce of these bear the closest resemblance to those hatched last year, but their sister (mother of last year's trial brood) has hatched nine chickens, all quite undistinguishable from true brown red and good brown reds, too. Is this caused by any latent influence of the brown-red cock from last year? And will her sisters $j$ left with the same cock until next year produce brown-reds instead of grays? I have noticed variations of colors causen by change of constitution, water, soil, and especially by food. I had a weakness in my boyish days for breeding from any strange cock I saw distinguish himself in a main, and the motley colors I often got were a sight to see, even when the hens happened to match the cock through the hot meals and stimulating food which the cock had been fed on during his preparation for battle, but none of these things can have affected the birds in question in the least, and although I have my own opinion as to the cause, I shall be glad to have that of some more competent person." 


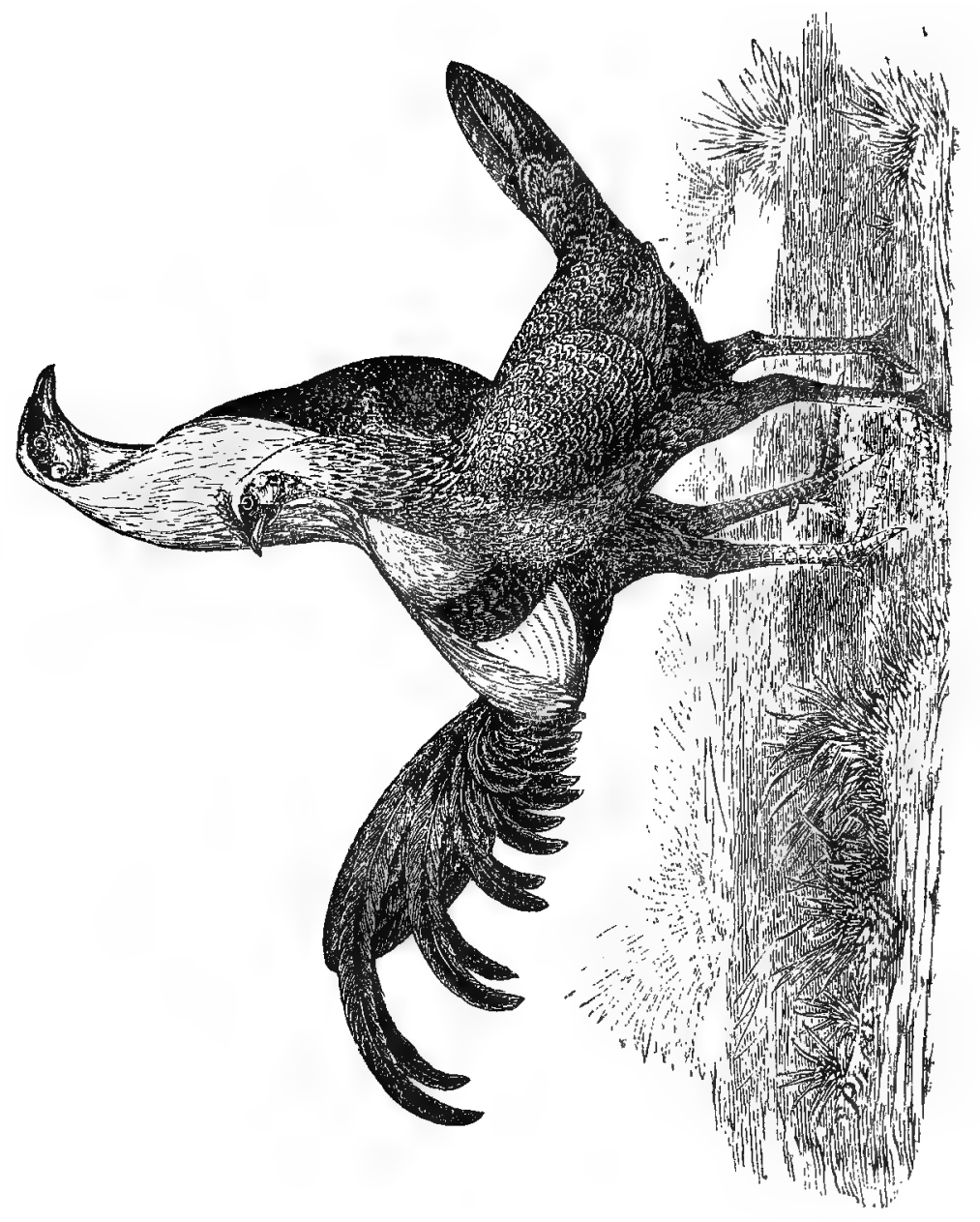





\section{SETTING HENS.}

In setting hens only the largest eggs should be selected, and in no instance should a misformed egg be used for this purpose. The hen should be set in a clean dry place, so situated that other fowls cannot disturb her. She should come off regularly for food and water, both of which there should be a plentiful supply within reach. Thirteen eggs is the average setting; frequently more than this number are set, but the study of the fancier should be rather as to the number of chicks the hen can cover than the number of eggs. During the time of setting the eggs should not be molested but nature should be allowed to take its course. The time required for hatching, as a general rule, is twenty-one days, but with good and continual setting the chicks will come out in twenty days. If the eggs used are fresh they will hatch within a few hours of each other; if not fresh they require at least twenty-three days and should not be destroyed before the expiration of that time. Marking the eggs is conducive to convenience and certainty as it forms the means for knowing whether any have been laid since the day of setting. It is also well, though not of course necessary, to mark the day of the month. The state of the weather should be taken into consideration, as we find that a hen capable of setting and hatching a certain number of eggs in the warmer months, cannot give an equal share of heat to more than two-thirds the number in the early part of the season.

Another consideration worthy of notice is sprinkling the eggs with water. This process undoubtedly assists the hatching, from the fact that the chicks receive an increased supply of fresh air, and in the summer season prevents, to a great extent, the inner membrane of the egg from becoming hardened and contracted. So in moderately cold weather, as in the spring of the year, by a careful sprinkling the egg is in a great measure prevented from chilling. Setting hens occasionally desert their nests. The causes of such desertion are quite numerous, principal among which could be mentioned the irritating effect produced by lice. When these are found the eggs should be carefully removed, the nest' thoroughly cleaned, and fresh straw sprinkled with sulphur and ashes placed therein, after which carefully replace the eggs sprinkled with sulphur. The hen also should be sprinkled with sulphur, though sparingly. We know of many cases 
where this method has been used, and can recommend it as likely to produce beneficial results.

"When several hens sit nearly at the same time, if any accident should happen to one of them her eggs may be distributed among others, provided they had not too many eggs in the first instance. The best time to make such a transfer will be when the hen is off the nest, lest she be dissatisfied at receiving them."

Some cockers raise many objections against setting eggs under dunghill hens; but these objections are really entitled to no weight, and in fact are only false notions, for such hens are much less inclined to be quarrelsome and less apt to be disturbed by other hens. It has been the experience of many breeders that chickens so brought up do not partake of the qualities of the dunghill, and now it is not unusual to find cockers wanting two clutches from the same hen, setting the first under a dunghill and the second under a game hen.

An early writer on this subject has the following: "The desire to sit is made known by a particular sort of clucking, which is continued until the chickens are full grown; and a feverish state ensues, in which the natural heat of the hen's body is very much increased. The inclination, or, as physiologists term it, the 'starge,' soon becomes a strong and ungovernable passion. The hen flutters about, hangs her wings, bristles up her feathers, searches everywhere for eggs to sit upon, and if she finds any, whether laid by herself or others, she immediately seats herself upon them. These signs of an inclination to set ought generally to be indulged in all hens: but those are best adapted for setting which have rather short legs, a broad body, large wings, well furnished with feathers, and their nails and spurs not too long nor sharp. The setting hen will sometimes exhibit impatience at her close confinement, and want to get frequently off the nest. When this is observed, one-half of the food that usually forms her meal should be withleld, and, when she has had only half her due allowance, replace her on the nest, and hold out to her in the hand some hemp or millet seed. This second meal has the effect of reconciling her to sit constantly without deserting her eggs. With the same view some put food and water so near the nest that the setting hen may feed without leaving her eggs for any great length of time; while others hold that this is not so conducive to health as the more natural method of letting her come off to enjoy good water and food at some 
little distance. Undoubtedly it is important that setting hens should have a little exercise, as well as that the eggs should be exposed to the circulation of air, to carry off any stagnant vapor which has been proved by experiments to be deleterious and destructive to the chicks still in the egg. We have ourselves remarked that setting hens are as fond of rubbing themselves in the dust as they are of food and water; and we have always indulged them, evidently with benefit, in this habit. Other hens will sit so closely and long that they are in danger of starving themselves for want of food. Of such it has been said they have been known to faint outright, as if dead, and which, when the chickens were hatched, were so exhausted as scarcely to be able to attend them. It is recommended that such should be fed on the nest."

We find in the April number of the Fanciers' Journal a well written article upon this subject and of interest to all breeders:

"Burn out every nest-box, new or old, before and after using. The charred surface will not favor the lodgment of vermin. Fill each nest-bottom with freshly cut sod slightly hollowed towards the center, covering with fine straw. Sprinkle nest and hen with carbolic powder. Don't use too much sulphur ; in fact if carbolic powder is obtainable don't use it at all. Let your hen get accustomed to the nest before trusting her with the eggs; then give the eggs, to her, quietly inserting them under her rather than giving her to the eggs. 'Make haste slowly.' Don't give her more than she can cover and care for well. Mark the eggs with INk, giving kind, if necessary, and date of sitting, preserving a duplicate record in a book kept for the purpose. Examine the nest daily. If an egg is broken, or even cracked, remove it. If the remaining eggs have any trace of the disaster, clean them from it by washing then carefully in tepid water. The contents of an egg are alive or dead. If alive they must have air. If the pores or air-ducts of the shell are closed, the contents die of suffocation. The grave is made and hermetically sealed. It is our plan to moisten the eggs and nests three times during the last ten days of incubation when the nest is in a dry, warm situation, and the hen not permitted the freedom of out-of-doors. We have found it done most easily and effectually by a fine rose sprinkler, using tepid water. If a chick must be helped from the shell, give it aid in the form of warmth, and warmth only. Insert the pipped or unpipped egg if you are assured that it contains life, in warm water, being careful to keep the opening 
of the pipped shell above the surface. It is wonderful how quickly new life will be infused, and the little bird gain strength to help itself. If in the course of hatching it is necessary to examine the nest and its. contents, remove the hen, then the contents. Allow the hen to return to the nest, then give chicks and eggs to her; she will carefully tuck them away where they shall not be injured. Mark the chicks when taken from the nest in a web of the foot either with one of Scribner's steel punches, or with a darning needle filled with coarse twisted silk, leaving the silk in the hole until it is healed. Make record of the mark and its purpose. Do not teed the chicks for the first twenty-four hours after hatching, then give hard boiled eggs or bread and milk." The best brood of chickens we ever saw were never fed mixed or 'artificial' feed of any kind, but simply broken grains, coarse corn-meal, oat-meal, and bird seeds. It was an experiment, and a scccess. Examine each chick's head for the long lice that are so often found there. Kerosene oil is an excellent remedy, simply applying it with the finger, the lice are exposed to view, and they generally yield to the first application. Give young chicks every care and attention. Do not let them be stunted by exposure to cold, dampness, or lack of food. Feed often, but not more at a time than will be eaten up clean. Reinember that chickens are early asleep and and early awake, and prepare food for them to find as soon as they are out in the morning, at daylight, instead of allowing them to chirp around half-starved for two or three hours. If you can manage to give them a late evening feed, they will thrive under it. Any one caring to make the experiment will be astonished at the difference in the growth of chicks fed early, often, and late, and that regularly, and those fed, as they too frequently are, without any system-'when I happen to think of it." "'

\section{YOUNG CHICKS.}

If possible the feed for the first week should consist of hard boiled eggs, oat meal, bread crumbs, etc. Where a large number are raised this system of feeding would perhaps be attended with too much trouble and expense; but even where such is the case efforts should be made to give them at least two or three feeds as above. Chicks 
under two weeks old should be fed as often as every two hours during the day, and no more should be given at each feed than they can eat up clean. They should be kept at a distance from the house to prevent them from drinking muddy or filthy water. Oftimes it will not do to allow several hens with their chickens to run upon the yard at the same time on account of their quarrelsome disposition and liability to kill each other's chickens, etc.; and when from any cause they are confined in coops they should be plentifully supplied with fresh water and green feed. Green grass chopped fine, lettuce, cabbage, etc., should be mixed with their food. A little meat two or three times a week is also good. Wheat screenings are very good for chicks five or six weeks old. In no case should bread soaked in water be fed as it soon sours in the stomach, and is productive of disease. A little camphor put into the drinking water will be found to assist greatly in keeping the chicks in good health. It is bad policy to allow spring ' chicks to roost before they are three or four months old, as before that time the tendency is to produce crooked breast bones, so frequently seen in young fowls.

Respecting the care of chickens Mr. Bement says: "We are certain more chickens are destroyed by over feeding than are lost by the want of it. We have remarked also that hens which stole their nests generally hatched all their eggs; and if suffered to seek the food for her chickens, if the season was somewhat advanced, she would, unless some casualty occurred, raise the whole brood, while with too much kindness or officiousness not half would be raised. All watery food, such as soaked bread or potatoes, should be avoided. If Indian meal is well boiled and fed not too moist, it will answer a very good purpose, particularly after they are eight or ten days old. Pure water must be placed near them, either in shallow dishes or bottle fountains, so that the chickens may drink without getting into the water, which by wetting their feathers benumbs and injures them. After having confined them for five or six days in the box, they may be allowed the range of the yard if the weather is fair. They should not be let. out of their coops too early in the morning, or while the dew is on the ground ; far less be suffered to range over the wet grass, which is. a common and fatal cause of death. Another cause of the utmost consequence to guard them against is sudden unfavorable changes of the weather, more particularly if attended with rain. Really all the 
diseases of gallinaceous fowls arise from cold moisture. At the end of four weeks, the hen may be allowed to lead her little ones into the poultry yard, where she will soon wean them and commence laying. again. The feathering of chickens demands attention inasmuch as with them it is a most trying time. If chickens feather rapidly when very young they are always weakly, however healthy in other respects, from the fact that their food goes to sustain their feathers instead of their bodies, and they frequently languish and die from this circumstance alone; but if, on the other hand, they feather slowly the food in early life goes to nourish and sustain their bodies until they become more vigorous and old enough to sustain the shock of feathering without detriment. Chickens which feather rapidly must be kept perfectly dry and warm, however strange it may appear, or they will die ; while naked chickens, as they are called, or those which feather at a more advanced age and very slowly, seldom suffer from the cold from the fact that their down is very warm and their blood is hotter and circulates more rapidly, as their food principally goes to blood, flesh and bone, and not to feathers."

In closing we will only say, don't try to raise too many, for a place that will accommodate a large number when chicks will be found much too small when grown. Close quarters cause vermin and disease. We think these instructions and the aid of a little common sense will insure you success.

\section{RULES FOR FEEDING.}

Nearly every old cocker has rules for feeding of his own which he follows, often producing good results ; but our object is to give rules which have been extensively used and which on that account can be regarded as standard authority, and the following if carefully observed will result in marked success :

The first thing to be provided is a coop of sufficient size, and suitable for a cock to exercise in. Probably one two and one-half feet wide, three feet high and three feet deep, with a roost running through the middle, would be sufficient. Another requisite is a.place with sufficient light and air. Put up your cocks in the evening two weeks 
before they are to fight; if stags ten days will do. For the first three or four days let the feed be mush and molasses. If your cocks be very fat mix a little vinegar with the evening food. After the third day physic them with one ounce of Epsom salts to three ounces of butter, mix well tugether, and at night be sure that they have no food in their coop. Give each cock a pill the size of a marble. The next day let them have as much water as they will drink. The first feed after giving the physic should be mush and milk, one tablespoonful to each cock, and one feed of the white of hard boiled eggs chopped fine and mixed with barley. During the last week do not feed any barley but feed bread and eggs in the morning, and cracked corn and eggs in the evening. Wash their feet once a day and sponge their heads with rum reduced with vinegar; equal parts. should be used. Before feeding in the morning exercise for a short time, increasing the length of time each feed. To give them their exercise, toss them on a bag stuffed with straws or a soft cushion until they become tired. If you have a very fat cock give him extra exercise and immediately after sponge and wipe dry; then place him in the coop and do not give Him drink until he has become sufficiently cool. Be careful to examine each cock before cooping, to see if there are any signs of disease about him; and if so remove at once. If possible let the drink be spring water, and that only to be given once a day, at noon; two or three swallows are sufficient. If the cock is very thin in flesh, beat np the white of an egg with a little boiled milk, and give two swalluws twice a day. The utmost care must be taken to keep the coops clean. It is best to remove the straw every morning and put in fresh. Frequent use of the weights is necessary to show the order and condition of the cocks. Extra fat cocks will require longer exercise and others proportionately. If a fowl is extremely eager to drink, it shows too much fever; in this case give a little nitre with the water, and the fever will be reduced in a short time. This should be repeated until the desire for drink subsides. In no case feed a cock unless his crop is empty. Large fat cocks can be reduced from eight to fourteen ounces; smaller ones from three to eight ounces.

The following is to be found in the Edinburg Encyclopæedia:

"The fowl is supposed to come from his walk in good condition, in which case he will be too fat for fighting and will have no wind until ne is reduced. To effect this medicine and abstinence from food are 
required for seven or eight days before he can be brought to the hit at least such is the regime pursued hy our first feeders and is pretty generally as follows: His tail and spurs being cut short he is put into his pen, and the first day received no food; second, he has his physic, consisting of cream of tartar or jalap, or both united, in the dose of about five grains of each; or if it be a very fat and large fowl, the dose may be increased to ten grains of cream of tartar. These are given him mixed in fresh butter; this generally purges briskly and scours out the intestines. Immediately after the physic is given and before it affects him he is placed on loose straw or a grass plat with another cock and allowed to spar with him, the boots or muffles being previously tied on their short spurs. In this way he is exercised till he is a little weary; he is then returned to his pen. Before putting him up it is necessary to examine his mouth to see if he has been picked or wounded in the inside, as such wound is apt to canker. To. prevent this it is washed with a little vinegar and brandy. $\mathrm{He}$ is now allowed his warm nest to work off his physic. This is a diet made of warm ale or sweet wort, and bread in it, with a little sugar candy, or bread and milk and sugar candy, a large tea cup full. $\mathrm{He}$ is then shut up close till the next morning, or about twenty-four hours. If the weather is cold the room should be made warm, or a blanket placed over the pen; if in warm weather he may be clipped out for fighting; but if the weather is cold this should be left till the time of fighting. The room should be kept dark except at feeding. Early on the following morning, that is about the third day, his pen must be cleaned out from the effects of the physic, etc., and clean dry straw put in; this should be done every day. His feet should be washed and wiped clean before he is returned to his pen. If his feet feel cold his pen should be made warmer. $\mathrm{He}$ is next to be allowed some bread; that is, a sort of bread made of. ingredients in the following proportions: about three pounds of fine flour, two eggs, four whites of eggs and a little yeast; this is kneaded with a sufficiency of water for a proper consistency, and well baked. Some add, as a great secret, a small number of annis seeds or a little cinnamon. Of this bread as much as would fill a tea cup, cut into pieces, is given him twice that day; no water is allowed him then, as it is considered highly injurious at the early part of the feeding. On the fourth day early in the morning he should receive half a tea cup of good barley and a little 
water, in which a toast has been steeped some time. Having eaten this clean his pen, etc., and let it be uncovered for about an hour while he scratches and picks the straw Some think it is highly advantageous to prepare the barley for them by bruising it, and thus take away the sharp points of the barley and the husky shell or covering which is blown away. In the afternoon the same quantity of barley may be repeated, but no water. On the fifth or next day he may have the bread as before, but three portions of it and no water. On the sixth or weighing day very early in the morning give hirn the bread as before. He is then to be weighed, and afterwards a good feed of barley and water should be given. Some hold it a valuable secret to give them flesh, as sheep's heart, for this and the succeeding day, chopped small and mixed with the other food. On the seventh day or day before fighting, early in the morning let him have the same feed of barley; in the afternoon bread and the white of an egg boiled hard and a little water. On the eighth or day of fighting he may have a little barley, as about forty grains."

We give below Stamper's rule (a well-known Southern sportsman, who, many years ago met with great success through the Southern States), which was presented to us by F. E. Grist, of Blakely, Georgia, who had a personal acquaintance with him:

\section{STAMPER'S RULE.}

Ten days before the cock is taken up from his walk to be prepared for battle he should be carefully examined to see that he is a sound fowl, his feathers should be glossy, hard, and lie close; if you are fully satisfied from this examination of his soundness you can then spar him with a cock of his own weight until he becomes wearied; should he turn black in the face turn him out, as it will be impossible to get him right in time for the contest. If he does not show any sign of disease, give him a dose of the following physic: Six grains cream tartar and six grains rhubarb made into pills with unsalted butter or lard. After giving the physic, flirt him a few times, then give him a warm mash of bread steeped in sweetened water or boiled rice and milk; leave him for twenty-four hours and this will have acted sufficiently; he can now be turned out. Give one feed of boiled rice and milk. For the balance of the ten days feed on such grain as he may 
have been accustomed to, giving an occasional feed of raw meat chopped fine, which will be of great advantage should it agree with him.

11th. Having been prepared as above suggested, the cock will now be taken up preparatory to being fed and drilled for the pit. Cut off his spurs, which should be done with a small saw made for that purpose, leaving about half an inch. Flirt him until he seems tired, then give him warm sulphur water. I ate that evening physic as before directed, spar him, then give him a masis of barley or oat bread and milk to work off the physic.

12th. At twelve o'clock to-day feed boiled rice and milk, late in the evening flirt him then give warm sulphur water.

$3^{\text {th. Clean }}$ out your coop well, then wash your cock's mouth, legs and feet, wipe dry and put him back into the coop. His first feed should be barley or oat meal bread moistened with skimmed milk or water. Give him three feeds of this, and his drink should be barley water three times that day. Flirt him.

I 4th. Feed oat bread and scalded barley mixed; at twelve o'clock oat bread and the white of a hard boiled egg; late in the evening exercise by flirting, feed with scalded barley and corn bread. Give him free-stone water three times for drink.

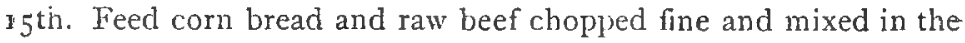
morning, oat bread and the white of a hard boiled egg at twelve o'clock, flirt him in the evening for exercise, feed oat bread and scalded barley; give barley water cool three times and let him roost. at night.

r61h. Feed oat bread and raw beef chopped fine and mixed in themorning; at twelve o'clock feed with rorn bread and the whiteof a hard boiled egg. Exercise him in the evening by flirting, and. feed him oat bread and scalded barley. His drink should be spring water and milk. Let him roost at night.

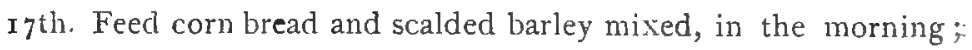
at twelve o'clock feed on oat bread and the white of a hard boiled egg. In the evening flirt him for exercise, and feed corn bread and scalded barley mixed. His drink should be barley water three times. Let him roost at night. 


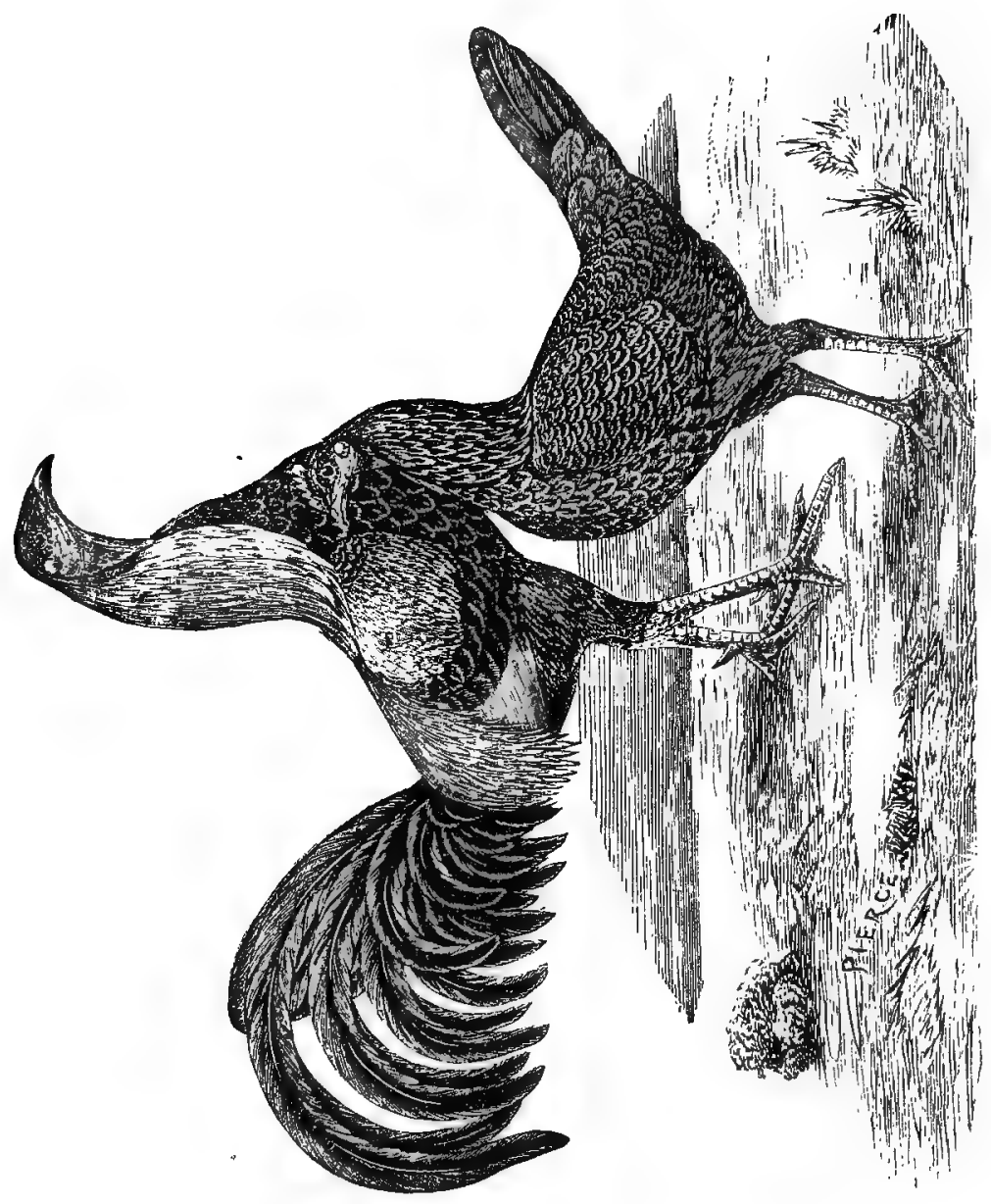




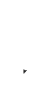


I 8 th. Feed barley bread and the white of a hard boiled egg in the morning. At twelve o'clock feed corn bread and the white of a hard boiled egg. Flirt him in the evening and feed on oat tread and scalded barley. Let him roost at night.

I 9 th. Feed corn bread and scalded barley. At twelve o'clock feed oat bread and the white of a hard boiled egg. Flirt in the evening, and turn loose for a few minutes in a room, but not one in which he cannot get FRESH AIR. Feed corn bread and scalded barley.

2oth. This being the day of battle, give him a light feed of oat bread early in the morning, and in about one hour a drink of spring water and milk.

\section{GENERAL REMARKS.}

Some cocks will need physic twice when taken up, others only once; this can only be determined by the feeder. The feeder should be provided with a good pair of scales that weigh down as low as half an ounce, and he can only feed intelligently by their frequent use. Fat cocks require long sparring or flirting, and when much wearied let them rest. As long as their appetites are good you need have no fears of over exercise or over feeding. Let them have what they will eat at night, keeping their flesh down by exercise; but should you not be able to keep them down in flesh feed sparingly with barley bread and scalded barley. If they should become too much reduced and wanting in appetite, let them have such food as they are most fond of; a raw egg or two will probably restore it. When they incline to dris k too muct it is a sign of heat, and sometimes happens at the latter part of the keep; then they should have a little sorrel or plantain leaf cut and mixed with their food. Give them also milk and cool spring water with a little fine rectified spirits of nitre in it to drink, which will cool and moderate their heat. This ought to be repeated until their thirst or desire for drink subsides. In no instance give a cock water after being heated by sparring or otherwise. When cocks begin to purge give them new milk well boiled with barley bread, warm, and their drink ought to be warm toast and spring water. In giving cocks drink do not let them have more than four dips at one time, which ought to be eight and eleven o'clock in the morning and three o'clock in the evening, and never feed a cock unless his crop is empty. 
Give him drink and exercise and it will soon go off. Reducing the weight of the cock depends entirely on the size and order when they are put up. Large, fat cocks should lose from ten to sixteen ounces, a cock in medium order should lose from six to ten ounces, smaller ones: in proportion. Lean cocks will lose one or two ounces but will nearly gain it in feeding, and every cock when fought should be rather in the rise in weight. If the weather is warm they should be trimmed the day before the fight, but must be kept warm that night. Be careful and not cut their wings and tail too short.

Care should be taken to keep the cocks clean; shift the straw at. least once in two davs in their coops. Every evening, three days before the fight, wash the head, legs and feet in chamber lye, and in the morning in water not too cold, and wipe dry; this will heal the bruises about their heads and the cracks in their toes.

Stags ought to be put the ninth day before they are to fight, and ought to have but one sparring afd one purge. They are to be treated in other respects as an old cock.

Sulphur water is made by a pint of boiling water on half an ounce. of sulphur and pouring off as it cools.

The scalded barley is prepared by pouring on scalding water and not letting it stand more than ten minutes, then pour it off and spread the barley on a table to dry. The water that is poured off serves for their drink, which ought to be made fresh every morning. It is best weak, a slight taste of the barley being sufficient; otherwise it is rather heating. In mixing milk and water for their drink, observe not to put more than one-fourth skimmed milk to three-fourths spring water; a greater proportion of milk is not so cooling. The different sorts of bread for feed, such as oat, barley or corn-meal, must be heated and ought to be baked the day before they are used. They are made in the following manner: take equal measure of the white of eggs and milk, beat well together, then add as much meal as will make up for bread, which must be well worked up and baked, care being used to prevent the crust from burning. In no instance must sour milk be used, for it will cause them to purge, which is very hurtful. When raw beef is recommended, if it should be found to purge discontinue its use. 


\section{TRIMMING FOWLS FOR THE PIT.}

Known among cockers as "cutting out," is done by the handler immediately after weighing and tends to give the cock greater force and activity in the pit. This practice has been in vogue for years among handlers, and consists in cutting or trimming the neck and hackle feathers close from his head to his shoulders and clipping off all the feathers from his tail close to his rump. The more scarlet appears the better state of health he is in. Then take his wings and extend them; from the first feather clip the rest sloping, leaving shar points, that in rising he may endanger the eyes of his adversary. This practice, we are glad to say, is not followed as much at present as in former years, as most fowls are required to be shown in full feather.

\section{RULES FOR IEELING.}

Holding the fowl on either side fit the heel tightly to the stub, having the point just pass the outside or back of the leg and fasten it while in that position. Holding onto the leg just heeled, turn the fowl and proceed to heal the other in the same manner, with the point occupying a similar position. Fowls heeled in this manner will be found to do good cutting in the body and neck and frequently will bring down their opponents with either a broken wing or leg. A towl fighting for the head and neck exclusively require a much closer heeling, to accomplish which, if the heel is to be placed on the right leg, set it so that the point will be on a line with the center of the slight hollow perceptible in the upper joint of the right leg. The point of the heel on the left leg should be placed on a line with the outside of the upper joint of the left leg.

On this subject Dr. Cooper advises as follows: "Let your fowl be held so that the inside of the leg will be perfectly level, then take your thumb and fore finger and work the back toe of the fowl. While doing this you will see the leader of the leg rise and fall at the upper joint. You will set the right gaft on a line with the outside of the leader at the upper joint of the leg, and the left gaft you will set on a line with the inside of the leader at the upper joint. Be careful not 
to set the gaft too far in, as it would cause the cock to cut himself."

The spurs should be sawed off when the cocks are put up for feeding, and should be left with a length sufficient to reach nearly through the socket of the gaft. Thin paper folded and dampened, or soft buckskin can be used to fit the spur to the socket of the gaft. The two methods given above are extensively practiced, and when followed cannot lead astray. Yet, perhaps nothing connected with the handling of birds depends so much upon undivided preference as heeling; and nearly all fanciers have original methods for heeling, and by no means quietly affirm their methods superior to all others known.

\section{DESCRIPTION OF GAFTS.}

For the benefit of those unacquainted with the different styles of Gafts we give illustrations of all the leading kinds now in use. To the old cocker they would be of little use, but there are many fanciers who are not acquainted with them who have asked for a more careful illustration, which we trust we have given.

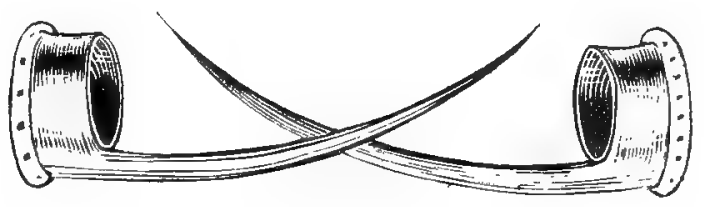

REGULATION SPUR.

The fairest and best heel in use for all purposes, being nearly straight and perfectly round from socket to point, with a short round socket, varying but little from the Singleton, which is also very much in use and a farorite with many. 


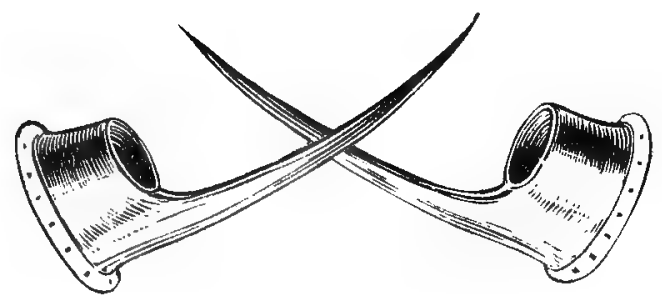

SINGLETON SPUR.

The Singleton Spur is now extensively used by heelers. The socket is light, short and round, with the spur nearly straight, running from the lower part. This is considered one of the fairest heels in use, is highly finished, finely tempered, not easily broken, and can be obtained of any desired length.

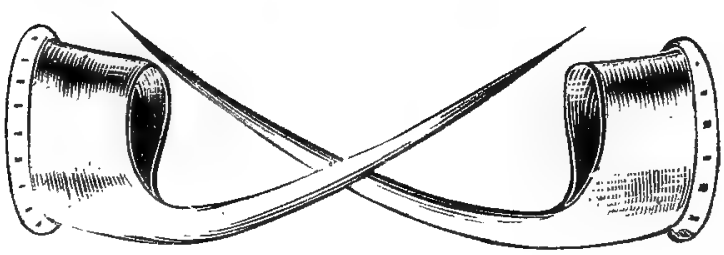

CINCINNATI HEEL.

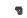

The Cincinnati Heel differs from the Singleton heel in many particulars. The socket is heavy; long and deep, with the spur curved upward from the bottom of the socket. This spur is deservedly a favorite among all heelers, and cannot be barred from any pit, being. perfectly round, like the Singleton spur, from socket to point. 


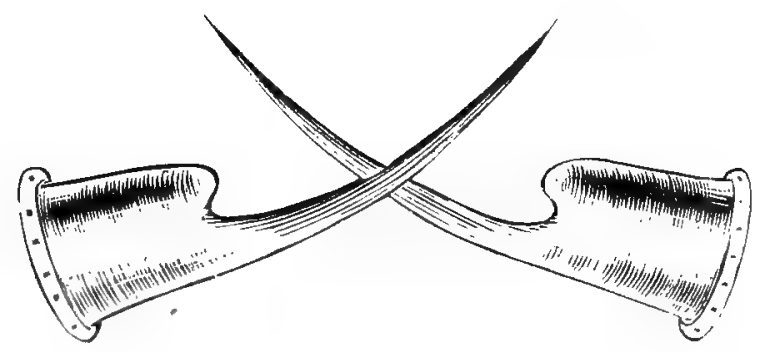

THIMBLE HEEL.

The Thimble Heel is extensively used, and many of the advantages claimed for it are possessed by no other spur. The socket is thimble-shaped, with no opening at the end, constituting the only essential difference from other heels. It is claimed that by filling up the socket the heel is removed farther from the leg, giving the fowl greater purchase.

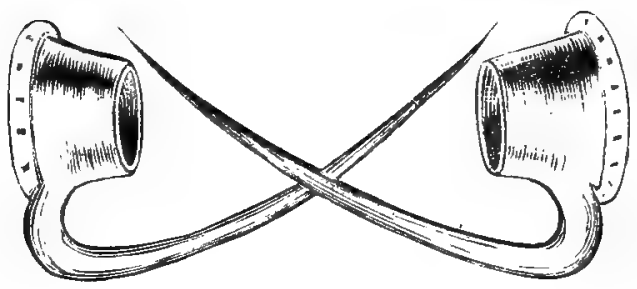

FULL DROP SOCKET.

Full Drop Socket Heel was a favorite among heelers of an early day. As will be noticed the blade comes directly from the back and lower part of the socket, and dropping almost throws the spur even with the foot. Leather is frequently placed on the under part of the socket to make the drop greater. 


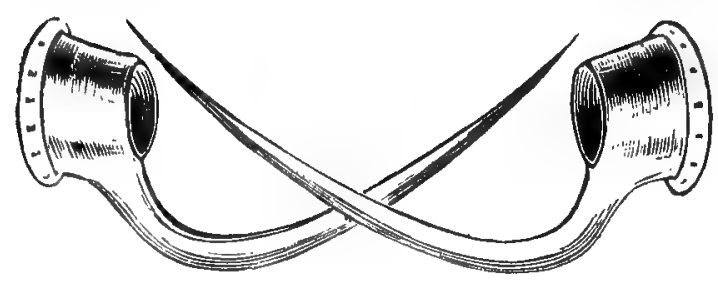

HALF DROP SOCKET.

The Half Drop Socket differs from the Full Drop in having the blade come directly from the front part of the socket with a less long and deep drop. Drop sockets can be obtained of any desired length. The revised rules of the pit however declare drop socket heels unfair, and consequently if used a special agreement will be necessary.

\section{REMARKS ON THE FOWL.}

HEELING, HANDLING, ETC.

No general rule can be laid down for handling, yet a few special semarks concerning the qualifications of handlers and what they observe may be made. The handler never should allow himself to become excited by the remarks or actions of the opposite pitter, who will undoubtedly seek to get him confused, but remaining perfectly cool should give an undivided attention to his bird during the count. In handling do not allow your opponent to over-bill for the purpose of fatigueing your bird. If it becomes necessary to give either cock the wing it should be done in a gentle manner and not with force sufficient to throw him upon his feet. If one cock becomes fast in the other, the pitter should at once advance and see to the drawing of the heels. Immediately after the fight see to the weighing of the birds. Handlers should be men capable of maintaining the utmost composure, endowed with quick perception and thoroughly conversant with the rales of the pit. They should strive for every advantage possible 
within the rules. A good handler is a man of many resources. Numerous fights have been won more by the handling than by the heeling or the fighting qualities of the birds.

As regards heeling we remark that many fowls are close hitters, while others are wide. The latter should be heeled more closely, in this respect differing greatly from the manner of heeling close hitting birds, with whom the greater caution is to be observed to prevent them from cutting themselves. Every heeler should be thoroughly acquainted with his fowls before he attempts to heel them. The amateur after heeling should try the cock, and following this practice will learn the proper way of setting the heels.

Never pit a fowl that is sick or out of condition, for no matter how. good a heeler you have you can hardly be successful; in fact, condition is everything, as otherwise the fowl will lack wind, muscle, will be weak, and his style of fighting will not be determined but extremely feeble. The fowl that is in the best condition invariably wins the battle, although through chance his opponent will get in a blow that will disable him. It has been our experience that condition and style of handling is of greater importance than the heeling, for if in poor condition the fowl can hardly use the heels to advantage.

The pit should be either sixteen or eighteen feet in diameter, and can be made with either six or eight corners, or if preferred can be of circular form. It should be from sixteen to twenty-four inches in height in order to prevent the cock from breaking his heels should he while fighting force his opponent too near the side of the pit. It should be lined with some cheap material, dark color preferable, with a stuffing of either cut hay or straw, making a soft cushion the entire distance around it. In all regular pits the bottom is covered with carpet or other suitable material, a mark being made as near the center as possible; two other marks are drawn one foot each way from the center. 


\section{RULES OF THE PIT.}

\section{NEW YORK RULES.}

ARTICLE I. - The pit shall be a circular pit, at least twelve feet irs diameter and not less than sixteen inches in height, the floor of which shall be covered with carpet or some other suitable material. There shall be a chaik or other mark made as near as can be to the center of the pit. There shall also be two outer marks which shall be one foot each way from the center mark.

ART. 2. - The pitters shall each choose one judge who shall. choose a referee. Said judge shall decide all matters in dispute during the: pendency of the fight; but in case of their inability to agree then ite shall be the duty of the referee to decide, and his decision shall bet final.

ART. 3.-Chickens shall take their age from the first day of March ${ }_{2 w}$ and shall be chickens during the following fighting season, to-wit : From the first day of March to the first day of June the following year.

ART. 4.-It shall be deemed foul for either of the respective pitters: to pit a bird with what is termed a foul hackle; that is, any of thefeathers left whole on the mane or neck.

ARr. 5 - No person shall be permitted to handle his fowl after he is fairly delivered in the pit unless he counts ten, clear and distinct. without either fowl making fight, or shall be fast in his adversary, ox: fast in the carpet, or hung in the web of the pit or in himself.

AkT. 6.-Any fowl that may get on his back the pitter thereof shal turn him off it, but not take him off the ground he is lying on.

ART. 7.-Whenever a fowl is 'fast in his adversary, the pitter of thefowl the spurs are fast in shall draw them out, but the pitter of a fow has no right to draw ot: his own spur, except when fast in himself, $0 .-$ in the carpet, or in the web of the pit.

AR'T. 8. - When either pitter shall have counted ten tens successively: without the fowl refusing fight, making fight, again breasting then: fair on their feet, breast to breast and beak to beak on the center scors: or mark, on the fifth ten being told, and also on the ninth ten being 
told, shall have won the fight. The pitters are bound to tell each ten as they count them, as follows: once, twice, etc.

ART. 9.-No pitter, after the fowls have been delivered in the pit, shall be permitted to clean their beaks or eyes by blowing or otherwise, or of squeezing his fowl, or pressing him against the floor during the pendency of a fight.

ART. I0. - When a fowl is pounded and no person takes it until the pitter counts twenty twice and calls three times "Who takes it?" and no person does take it, it is a battle to the fowl the odds are on; but the pitter of the pounded fowl has the right to have the pound put up, that is, twenty dollars against one, should not this be complied with, then the pitter shall go on as though there was no poundage.

ART. Ir.-If a fowl is pounded and the poundage taken, and if the bird the odds are laid against should get up and knock down his adversary, then if the other bird is pounded and the poundage not taken before the pitter counts twenty twice and calls out "Who takes it?" three times, he wins, although there was a poundage before.

ART. 12.- It shall be the duty of the respective pitters to deliver their fowls fair cn their feet on the outer mark or score, facing each other, and in a standing position, except on the fifth ten being told, and als on the ninth ten being told, when they shall be placed on the center score, breast to breast and beak to beak, in like manner. Any pitter being guilty of shoving his bird across the score, or of pinching him, or using any other unfair means for the purpose of making his bird fight, shall lose the fight.

ART: r 3. - If both birds fight together, and then if both should refuse until they are counted out. in such case a fresh one is to be hoveled and brought into the fiit and the pitters are to toss for which bird is to set to first; he that wins has the choice; then the one which is to set to last is to be taken up but not carried out of the pit. The hoveled bird is then to be put down to the other and let fight, while the judges, or one of them, shall count twenty, and the other in like manner; and if one fights and the other refuses it is a battle to the fighting bird; but if both fight or both refuse it is a drawn battle.

N. B. - This rule is rarely carried into effect, but any pitter can exact it if he thinks proper to do so. 
ART: r $_{4}$ - If both birds refuse, fighting until four, five or more or less tens are counted, the pitter's shall continue their count until one has refused ten times; for when a pitter begins to count he counts for both.

ART. I5- - If a bird should die before they are counted out, if he fights last he wins the battle; This, however is not to apply when his adrersary is running away.

ART. 1.6. - The crowing, or raising of the hackle of a bird is not fight, nor is fighting at the pitter's hands.

AkT. I7.-A breaking fowl is a fighting one, but breaking from his adversary is not fight.

ART. I 8. - If any dispute arises between the pitters on the result of the fight, the birds are not to be taken out of the pit, nor the gafts taken off, until it is deribled by the judges or referee.

Akr. 19.--Each fowl within two ounces of each other shall be a match; except blinkers when fighting against two-eyed birds, an allowance of from three to five ounces shall be made; when blinkers are matched against each other the same rule to apply as to two-eyed contestants.

ART 20.-Any person fighting a bird heavier than he is represented on the match list shall lose the fight, although he may have won.

AR'T. 2 I. - In all cases of appeal fighting ceases until the judges or the referee give their decision, which shall be final and strictly to the question before them.

ART. 22. - When a bet is made it cannot be declared off unless by consent of both parties, all outside bets to go according to the main bet.

ART. 23.-Each pitter when delivering his fowl on the score shall take his hands off him as quickly as possible.

ART. 24.-Any person violating any of the above rules shall be deemed to have lost the match.

\section{PHILADELPHIA RULES.}

ARticle r.-The pit must be a ground floor, unless otherwise agreed to.

ART, 2.-The cock or stag must be weighed enclosed in a small bag, and then two ounces deducted for the weight of the bag and feathers. 
A stag figliting a cock has an allowance of four ounces in weight, a blinker cock fighting a two-eyed one has four ounces; a blinker cock and a stag of one weight are a match.

ART. 3 -The cocks being weighed and matched, you will cut then out; you must cut the hackle with all the shiners off; you can use your own pleasure about cutting out other parts of your cock.

ART. 4.-Your cock now being cut out you will heel him; you can heel him with paper and water and nothing but that; if you do you' will lose the battle if the opposite party finds it out.

ART. 5.-Your cock being heeled, you will bring bim in the pit for battle; you will bill the cocks one minute, and then put them down behind your scores for their battle.

AkT. 6.--In fighting a battle, according to Philadelphia Rules, when you deliver your cock on his score, you must stand back of him and not lean over him to hide him from the other cock.

ART. 7.-A cock breaking with another cock is fight, and a cock picking at any time when on the ground is fight; but picking while in your hands is.not fight; he must make frght after you deliver him. out of your hands.

ART. 8. - When the cocks are fast, you must handle by my drawing. your spur out of my cock and you drawing my spus out of your cock, you then have thirty seconds to nurse your cock; the judge will call "down cocks;" then you must strictly obey and put your cock down to renew the battle. In case one of the cocks gets disabled, you can count him out; you can lay your cock down on his wing on his score, and count ten without the other cock making fight; you can handle him again, and so on until you count five tens; then you can get ready to breast your cocks; you must put them down on their feet and breast to breast, and if the crippled cock refuses to fight while the opposite handler counts twenty more, he has lost the battle.

ART. 9.- You are not bound to lay your cock on his wing, you can use your pleasure whether to lay him on his wing or on his feet; if it is to your advantage for your cock to fight, put him lown on his feet and let him fight.

ART. Io.- - In counting a cock out, after you breast the cocks and you are counting twenty, if the cock should get in the disabled cock, you dare not put your hand on them unless the disabled cock makes 


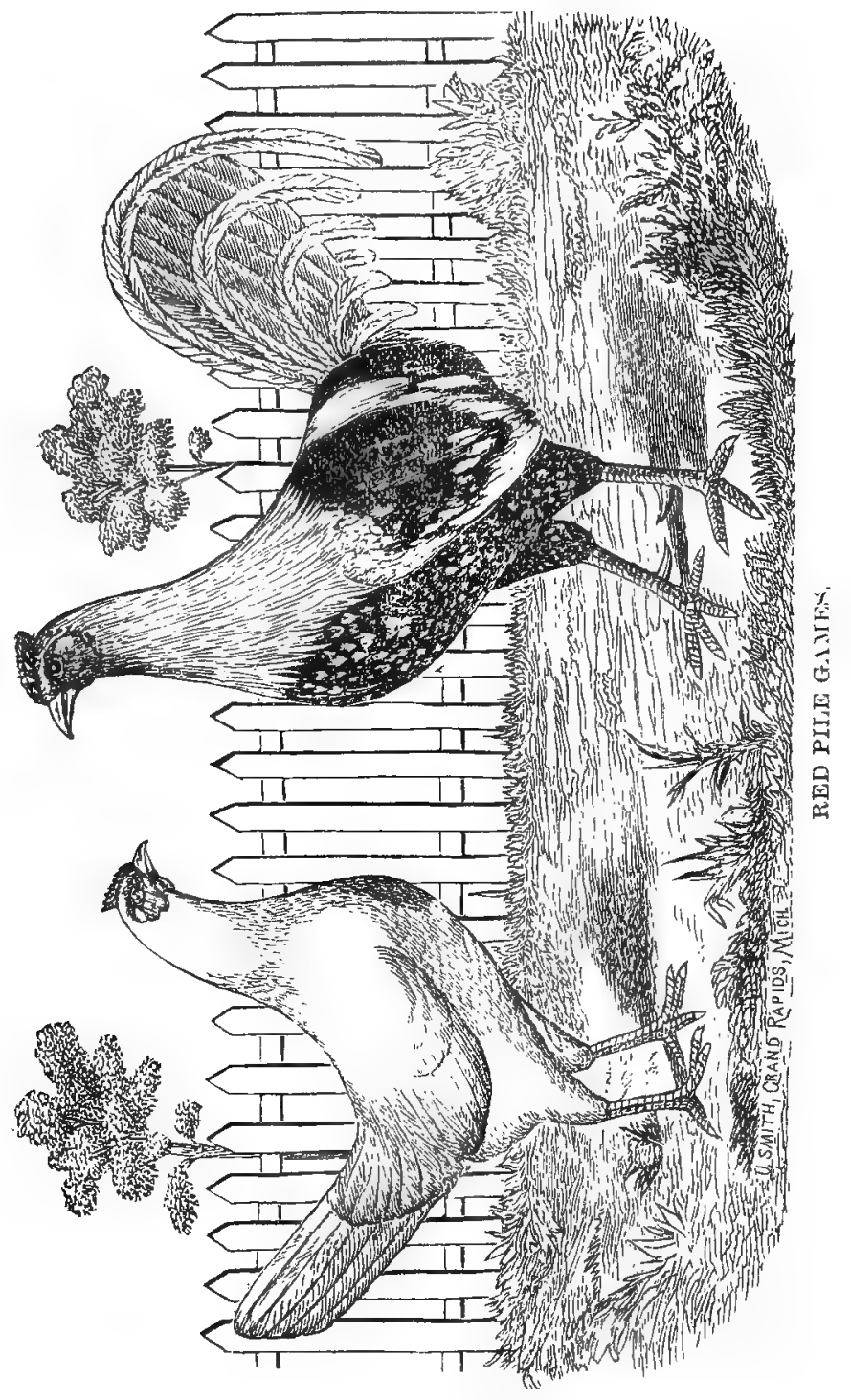



fight; and if he does make fight, you can handle, and by his making fight it will renew all the counting from the first, and if the disabled cock should make fight lase it is his count.

ART. Ir.-The judges cut the heels off, and if all is right you must get seady for the next battle; you, are allowed twenty minutes to be in the pit with the next cock. The judges are to keep the time.

APT. 12. - All outside bets go as the main stakes.

ART. I3.- Any man not paying bets that he lost will not be allowed in any pit in Philadelphia hereafter.

\section{WESTERN RULES.}

RULE T.-All birds shall be weighed, give or take two ounces, shall be a match or otherwise if parties see fit to make it so.

Rule 2.-All heels to be fought with shall round from socket to point, or as near so as can be made.

RULE 3. - When a stag is matched against a cock, the stag will be entitled to four ounces advance in weight.

Rule 4,-It shall be fair for handlers to pull feathers and sling blood, or any other thing to help the bird between handlings.

RULE 5.-It shall be foul for A or B to touch their birds while fighting unless one is fast to the other, but if a bird should unfortunately fasten himself with his own heel it shall be fair to handle, but on no other consideration, and either handler violating or deviating from the above rules shall lose his fight.

Rule 6.-Thirty seconds shall be allowed between each and every round.

Rule 7.-In counting, the bird showing fight last shall be entitled to the count, but if his handler refuse to take the count the opposite handler shall be entitled to it.

Rule 8.-The handler having the count shall pit his bird in his respective place when time is called, and count ten, then handle three more successive times; when time is called again, the birds shall be placed in the center of the pit, breast to breast, and forty more counted, and if the bird not having the count refuse to fight, the one having it shall be the winner. 
RuLE 9. - A peck or blow at the opponent's bird, and not at hi thandler, will be considered fighting.

RULE ro.-When time is called the handlers must let go their birds from their respective places fair and square, for it shall be foul for either handler to pitch or toss his bird upon his opponent's, and *ither one violating the above rule shall lose his fight.

RULE Ir.-Each party shall choose a judge, and the judges chcose a disinterested party as referee. No referee will be competent who has bet on either side, or is otherwise interested.

RILE I5.--It shall be the duty of the judges and referee to watch all movements of the fights and judge according to the above rules. The referee will be confined to the opinions of the judges only, and ihis decision final.

RuLE ${ }_{3}$ 3. - It shall be the duty of the referee to keep time between the rounds and notify the handlers to get ready at twenty-five seconds, then call time at thirty seconds, when the handlers must be prompt in pitting their birds; and if either handler refuse to do so, he shall lose the fight.

\section{SOUTHERN RULES.}

Fraclele I. - When the cocks are in the pit the judges are to ex.smine whether they are fairly trimmed and have fair heels. If all be right and fair the pitters are to deliver their cocks six feet apart (or ithereabouts) and retire a step or two back; but if a wrong cock should Tre produced the party so offending forfeits that battle.

ART. 2.-All heels that are round from the socket to the point are allowed to be fair; any pitter bringing a cock into the pit with any ather kind of heels, except by particular agreement, forfeits the battle.

ART. 3. - If either cock should be trimmed with a close, unfair back, rahe judge shall direct the other to be cut in the same manner, and at the time shall observe to the pitter that if he brings another cock in the like situation unless he shall have been previously trimmed, he shail forfeit the battle.

ART. 4.-A pitter when he delivers his cock shall retire two paces back, and not advance or walk around his cock until a blow has passed. 
ART. 5- -An interval of -- minutes shall be allowed between the termination of one battle and the commencement of another.

ART. 6.-No pitter shall pull a feather out of a cock's mouth or from over his eyes or head, or pluck him by the breast to make him fight, or punch him for the like purpose, under penalty of forfeiting the battle.

ART. 7.-The pitters are to give the cocks room to fight, and are not to hover and press on them so as to retard their striking.

ART. 8. - The greasing, peppering, muffing, and sooping a cock, or any other external application, are unfair practices, and by no means admissible in this amusument.

ART. 9.-The jndges, when required, may suffer a pitter to call in some of his friends to assist in catching the cock, who are to retire immediately when the cock is caught, and in no other instance is the judge to suffer the pit to be broken.

ART. IO.-All cocks on their backs are to be immediately turned over on their bellies by their respective pitters at all times.

ART. Ir.-A cock when down is to have a wing given him if he needs it, unless his adversary is on it, but his pitter is to place the wing gently in its proper position, and not to lift the cock; and no wing is to be given unless absolutely necessary.

ART, 12.-If either cock should be hanged in bimself, in the pit, or canvas, he is to be loosed by his pitter; but if in his adversary, both both pitters are to immediately lay hold of their respective cocks, and the pitter whose cock is hung shall hold him steady while the adverse draws out the heel, and then they shall take their cocks asunder a sufficient distance for them fairly to renew the combat.

ART. 13.- Should the cocks separate and the judges be unable to decide which fought last, he shall at his discretion direct the pitters to carry their cocks to the middle of the pit and deliver them back to back, unless either of them is blind; in that ease they are to be shouldered, that is, delivered with their breasts touching, each pitter taking care to deliver his cock at this, as well as at all times with one hand.

ART. I4. - When both cocks cease fighting it is then in the power of the pitter of the last fighting cock, unless they touch each other, to demand a count of the judges, who shall count forty deliberately, 
which, when counted out, is not to be counted again during the battle. Then the pitters shall catch their cocks and carry them to the middle of the pit and deliver them beak to beak; but to be shouldered if either are blind as before. Then if either cock refuses or neglects to fight the judge shall count ten, and shall direct the pitters to bring their cocks again to the middle of the pit and pit as before; and if the same cock in like manner refuses, he shall count ten again and call out "twice refused," and so proceed until one cock thus refuses six times successively. The judge shall then determine the battle against such cock.

ART. 15.-If either cock dies before the judge can finish the counting of the law, the battle is to be given to the living cock, and if both die the longest liver wins the battle.

ART. I6.--The pitters are not to touch their cocks whilst the judge is in the act of counting.

ART. 17.--No pitter is ever to lay hold of his adversary's cock, unless to draw out the heel, and then he must take him below the knee. Then there shall be no second delivery, that is, after he is once delivered he shall not be touched until a blow is struck, unless ordered

ArT. 18.-No pitter shall touch his cock unless at the time nientioned in the foregoing rules.

ART. 19.-If any pitter acts contrary to these rules the judge, if called upon at the time, shall give the battle against him.

\section{ENGLISH RULES.}

1. That every person show and put his cock into the pit with a fair hackle, not t so near shorn, or out, nor with any other fraud.

2. That every cock fight as he is first shown in the pit, without shearing or cutting any feathers afterwards, except with the consent of both the masters of the match.

3. When both cocks are set down to fight, and one of them runs away before they have struck three mouthing blows, it is adjudged no battle to the persous who bet.

4. No persons to set-to but those who are appointed by the masters of the match. 


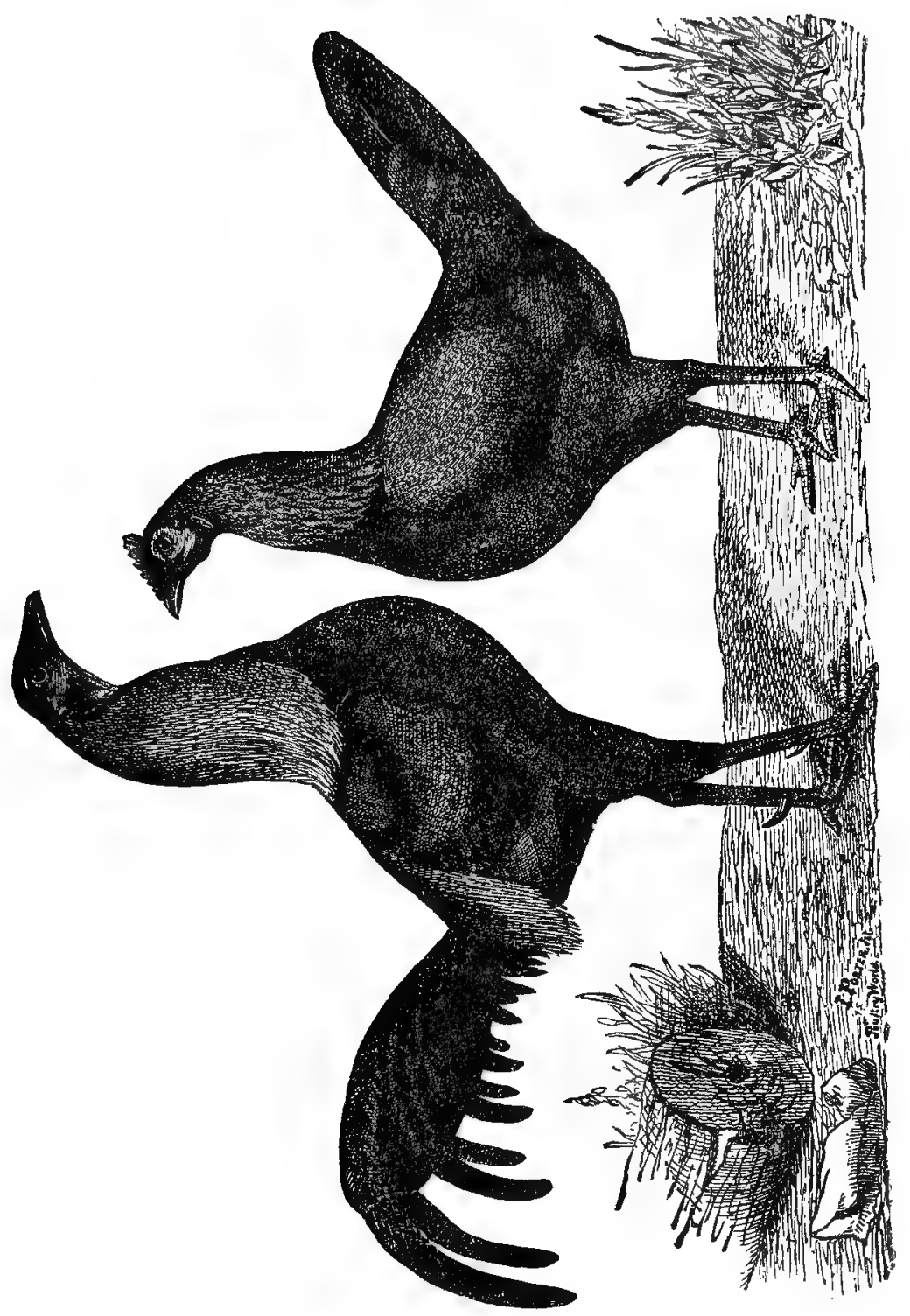


5. When a cock shall come setting-to, and both cocks refuse to fight ten times successively according to the law, then a fresh cock shall be hoveled, and the masters of the match must agree which of them shall turn the cock down; after that, if both fight, or both refuse, to be deemed a drawn battle; but if one should fight, and the other refuse, the battle to be allowed won by the fighting cock.

6. After the person appointed by the masters to tell the law shall have told twice twenty, the cocks to be set-to, beak to beak if they both see, but if either be blind, then the blind cock to touch; and on their refusing to fight, the person appointed as before is to tell ten between each setting-to, till one of the cocks has refused to fight ten times successively.

7. When ten pounds to a crown are laid on the battle, and not taken, after twice twenty is told, the battle is determined as won by that cock the odds are on.

8. That no person shall make any cavil or speech about matching of cocks, either to matchers or owners, after the cocks are once put together.

9. A master of a match has a right to remove any person out of the lower ring.

IO. No person can make a confirmed bet void without mutual consent.

II. Bets to be paid on clear proof by creditalule witnesses, even though they have not been demanded immediately after the battle is over.

12. It is recommended that all disputes be finally determined by the masters of the match, and two other gentlemen whom they shall appoint; and in case the four cannot agree, then they shall fix on a. fifth, whose determination shall be final.

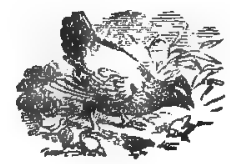




\section{ENGLISH NOTES ON COCKS AND COCKERS.}

The following brief notes on the past and present cocks, cockers and cocking in England were furnished at the request of the author by J. Harris, who has been enthusiastically devoted to the sod from a child, and who has not merely had a local experience of a few birds and men, but has assisted and also fought many of the best cockers all over the kingdom:

The origin of the game cock is enveloped in considerable obscurity, for whilst many naturalists affirm that it is the reclaimed wild jungle fowl, as still found in India, many others who have given the subject much careful consideration and research are of an opinion that our game fowls were originally from Persia, where they deem it probable that a race of white-legged birds were very early reclaimed, but whose originals, like many wild animals, have long since become extinct, and their sporting history dawns in this country of Persia and the early records of China, although most books, etc., point us to Themistacles as the first cocker known to fame, who, some authorities state, received an omen of the success of the army he was leading from the crowing of the cocks, but Aolieu, the author cited, says he saw the cocks fighting: Yet Idomeusus long before that time bore on his shield the effigies of a cock as a martial bird. History informs us that they were bred for fighting in the reign of Crosus, king of Lydia (A. M. 3426). The ancient Dordanii had representations of cock. fighting on their coins. The fighting cock was one of the principal gods of the Lyrians, and the learned Hebrew, Dr. Rahbi David, interpreting the I $7_{\text {th }}$ chapter of and Kings, verses 30 and $3 \mathrm{I}$, says "Nergel" was a cock for war or fighting, or champion cock, and by the Samaritans worshipped for a god.

A volume might be written on this subject of interest to the antiquarian, but enough has been said to satisfy the sportsman that this sport will bear favorable comparison with any other in point of antiquity. Its introduction into England has been attributed to the Romans who, history informs us, were called on to witness cocking in their own country in order to incite them to deeds of bravery and courage, previous to their departure to conquer our tight little isle, 
but from a fair translation of Julius Ciesar's words, the natives reared fowls for pleasure and diversion, although it was unlawful to eat them. It requires no great stretch of imagination to suppose that the spert was practiced here previous to the Romish invasion, It is true early English history is very reticent on cocking, as well as many more important matters, and but little information can be gleaned from that source, until the ath century, when it was so common as to be practiced in schools, as we find it has continued to be up to almost the present time. As recently as I $868 \mathrm{Mr}$. L. G. Fitch, one of the assistant school inquiring commissioners, called attention to the fact that the almost obsolete custom of cock fighting is at this moment a pretext for charging a guinea to the head master and a half guinea to the usher from each scholar at the Ledburgh school in order to provide cocks at Shrovetide for the entertainment of the boys and their parents, adding that the boys have ceased to require any sport from their masters as an equivalent, and that at other free schools a similar rule prevails. This gratuity has from time immemorial been know as the cock-penny, but in many schools and countries the penny has been transformed into a more valuable coin, as at Ledburgh, or in the statistical account of Scotland (Vol. 3 Edinburgh, I 792), the schoolmaster at Appleross, in county Ross, is mentioned as having, amongst other perquisites, the cock-fight dues, equal to one-quarter payment to each scinclar. Welsh princes sometimes made presents of game cocks to the English princes and nobility and which were much valued, and within the present century a single county in Wales has publicly challenged all England to fight an annual main for five successive years for a large sum. I have seen a great many mains fought in Wales and very few plain cocks, a bad one never.

Early in the $4^{\text {th }}$ century cocking became a royal musement, and was carried on to that extent that it had to be introduced in the royal household. In the accounts of Henry the VII. is found the following entry: "March 2 nd, $7^{\text {th }}$ Henry; item to Master Bray for rewards to them that brought cocks to Westminster at Shrovetide, twenty-five shillings. In the early part of the $x 6$ th century a royal pit was added to the palace at Whitehall for the more magnificent exhibition of the sport. Although prohibited by Henry the VIIL., as well as by that prince of hypocrites, Oliver Cromwell, a fac simile of whose seal and fprohibition I now have before me. Cocking as well as all other sports 
was much patronized in the days of glorious Queen Bess, who ruled too wisely and generously to interfere with the sports of her loyal subjects. James I. was so fond of the sport that he publicly attended it twice a week, and Charles II. was a great patron of the sod, and introduced the Pyles (so-called) from the very distinctive colors of white and red, and derived from ancient English game of Cross \& Pyle. At this time so enamored of the sport were the people that cocks were very frequently fought in the public streets of London, notwithstanding there were in London several cock-pits beside the royal pit. In after times when the latter was taken down, another bearing the same designation was immediately erected by subscription in Tufton street. Derby Lane theatre was originally a cock-pit, and many provincials were under the patronase of their respective corporations. The Canterbury corporation pit was an apartment of a splen-. did gateway that formed part of St. Augustine Monastery, and some of the olrl rules and regulations that we have seen for the government of those pits prove that amateurs of those days had to conduct themselves with all the gravity of cleportment and language becoming a church congregation of our own time as no loud talking, swearing or unseemly behavior was ever allowed in those places. This would form a striking contrast to the excitement, roars, shrieks, offers to take or lay the odds consequent on the springing from the setter's hand; of a pair of rasping Cornish hen cocks amidst a perfect Babel of tongues indescribable; or yet to the motley groups Hogarth so cleverly depicted on canvas in the royal pit at Newmarket, and on whom that rare cock-feeder, Nan Rawlings alias Duchess of Deptford is looking down so complaisantly and whose characters I would like to portray if space permitted.

Old Frampton was generally acknowledged to be the father of the sod. He was more fond of racing than hunting, and infinitely preferred cocking to either. He was hatched and a very promising chick in the reign of Charles I.; was doubtless a fine crowing stag when Charles II. Pyles were fighting, and was placed in a fine walk by William III as keeper of the running horses to his majesty, a part he retained under ( Queen Ann, George I. and George II. He died in March, 1727, aged 86. From some original letters of his still extant, he not only appeared to have been conversant with many of the modern tricks of cocking, but also to some extent with the method of 
feeding. Cocks were then matched by the length and girth, by the eye and gaip, and not by weight as at present. But he was chiefly noted for breeding a strain of cocks that eclipsed the royal Pyles, and his old Sourface strains were unquestionably the best birds at that time. In color they were known to old cockers as Smittenwing Reds, being either streaky or spotted-breasted reds with dull yellow wings and sometimes saddle also, and white legs. These in turn succumbed to the old Vannihall yellow or orange-breasted grays, on which the popular ditty was written, with the refrain of

\footnotetext{
"Fly up, fly up, fly up,

My bonny gray cock

And crow when it is day;

Your breast is of the burnished gold,

And your wings a silvery gray.'
}

These got whipped by the renowned in-and-in-bred Mealy Grays of Hugo Maynell's and Sir Charles Sedley's, which beat everything that could be pitted against them until crossed after the decease of their masters; even the killing Smocks and light Pyles of the Warburtons, Raylences, Molyneaxs and Egertons, whose heels were wont to bring down death as suddenly as an electric shock, could not live a battle through with them; and only when those ulack-legged warriors of Maynell \& Sedley were opposed to each other did either find their equal, and amateurs witnessed the hardest, cleverest fighting to be seen in England, and by this same system of in-and-in breeding Maynall produced the most perfect pack of fox hounds the world had ever seen, and a keener sportsman all around, never existed. When Sedley's cocks were opposed to his, vast sums of money were invariably staked on the result, as both their cocks and feeders were on a par.

The Earl of Mexborough's beautiful and true feathered grays, with pearl eyes, yellow legs and beaks, looked as handsome and ornamental on their walks when leading forth the half dozen spotless clear white hackle, gray-bodied hens that formed their harem, as they proved dangerous in the pit. There is an old painting of a favorite cock and two hens lying before me as I write this, and look so like life as fairly to threaten to fly out of the canvas-a straw-colored hackle, rich, deep red saddle, up and spread game-like black tail, bright yellow legs and beak, and elegant carriage form a grand contrast to the heavy, dull, inactive, droop-tail, spiritless, so-called game Duckwings we now see in the show-pen at poultry exhibitions. In chickenhood, full feath- 
ered, and when cut out for the pit those birds so closely resemble each other in shape and feather as do wild ducks. The last of the breed was a few years since in possession of a noted feeder who was always wont to swear by them. He left three hens with a gentleman he was in the habit of feeding an annual county main for, and at the decease of the feeder the writer was requested to take the office, and after winning a closely contested main was asked to state his charges, which were expenses and one of those same hens, and since then she has never hatched anything but gray chickens, although she has been mated with a black, brass-back, and a black-red as well as a gray cock. It is said the celebrated Mr. Nunis (or butcher) grays were of this strain, one of which after winning in eleven mains had thirty-six sons fought in a main at the royal pit and only four of them were whipped; so much for blood. A portrait of this bird with particulars was published at the time. Halford's yellow-legged light reds and Elwess' red duns, one of which fought twenty-seven battles, were equally famous, and one of Sir Francis Boynton's won the same number of battles and, was known as the Yorkshire herd. Col. Millish, who the late Duke of Wellington declared was the best aids-de-camp that ever crossed a horse, also bred a wonderful strain of cocks which he backed for fabulous sums. The Dean of York strain and Sir Henry Goodrich's were general favorites with the dark reds of Mr. Green; but all these could scarcely equal the Tassels of John Weightman, known as the Park House Reds. Weightman fought and beat the Lancashire men at Burton with these cocks for the largest amount ever fought for, notwithstanding it is stated in Rural Sports that the main for $\mathcal{E} \mathrm{I}, 000$ a battle and $\mathcal{E}_{5,000}$ the odd, which was won by Gilner at Lincoln, were the largest stakes. I have just seen one (if not the very last) of the pure-bred Parkhouses on a brood walk where he has got fine chickens this season although he is from twelve to twenty years old, and is a real good type of the breed, having a long narrow tassel, short taper head, very strong boxing beak, prominent, quick, fearless red eýe, long, strong, thick neck, short, broad, flat body, white, clean, bloodlike feet and legs, dark, shady breast, light red, with the brightest and glossiest plumage.

The Strokshire Reds and Duns have proved more than a match generally for the very best cocks that could be pitted against them, and the fighting qualities of the Cheshire Piles are proverbial and unsur- 
passed. They have been kept pure and clean from any cross for a number of years by the proudest families of the country, and $\mathrm{Mr}$. Rilands who bred them for a great number of years was so careful on this point that he scrupulously kept the light and dark varieties apart. Mr. Walker also bred and fought against many of them, and all have found when crossed even with Beverly and other noted Piles, leaving out other colors that have invariably been a falling off of their first and grand requisite, the "bloody heel," which has rendered them so notorious. The celebrated Mr. Hetchley, who bred some of the best birds in England upwards of half a century after, tried to cross them but could never reproduce their equals.

The black cocks of Stafford, Lord Veres, were much sought after and were very successful for many years, and so enamored was the noted Nathaniel Monk of them that after seeing a week's main at Boston he fell asleep during service at church on-the following Sunday and startled the minister and congregation alike by peering over the pew with half awakened eyes and shouting at the top of his voice, "I'll have the black cock for a crown!" The Derbyshire striped hackle, dark reds of Mr. Saut, and the Norfolk spangles of Mr. Gurney could always find backers in any company which the Smocks or white cocks of Zealhampton, in Devon, were for a long time annually pitted against the Cornish light reds of Couth. The latter were only an offshoot of the Earl of Derbys, and Mr. Taylor's strains which were one and the same family. Couth kept those birds carefully bred and were very successful for upwards of forty years, when he crossed them to gain bone: With larger bone they were just as unsuccesstul as they had been successful, when he put an old hen of a pure strain, although thirteen years old, with her brother, and the produce brought him back his former successors.

The Earl of Derby strain had been bred at Knowsley a long time previous to the Earl's appearing on the sod. Many cockers objected to their dun eyes. Busley was his lordship's first feeder. On his decease Potter took the office, and was followed by Potter, Jr. But their opponent in feeding, Joseph Gillien, was always too much for either had they not been better cocks. But for a great number of years his lordship's breeder, Roscoe, senior and junior, placed out to walk upwards of 3,000 cock chickens annually, and from this number it was easy to pick mains of cocks faultless in shape and perfect in constitu- 
tion. They were chiefly black-breasted reds, with white legs and a white streamer in tail and flight feathers, although he latterly fought some of a slashing gray strain, and he never bred a finer cock than the Pile of the old Cheshire strain which Pollard printed for him and engraved in 1826, and the Earl's last mains were fought some six or eight years afterwards. Potter always considered his own red duns as superior to his lordship's birds.

Dr. Bellyse, the best judge of a horse, greyhound and cock England ever produced, first bred the Piles of his own country, but soon got an idea that even with their matchless heels their constitutions. were not equal to the punishing preparation of modern feeding, so took to breeding the old dark-red strain, so successfully fought by Gillier, of Warwickshire, as well. He also bred largely from the noted Westgorth cock, and his crow alleys became so much sought after that he was offered fifty guineas for a sitting hen by a visiting nobleman. On handing him the hen there and then and crushing the eggs with his foot, his lordship remarked that he had purchased the eggs as well in the price. "No, or I should have refused a thousand," was the reply. He seldom walked out more than a thousand chickens. a year, but the quality was so superior that at two years old he could always select enough from them to defy all England. Six pullets to their own father, or mother and two or three sisters to her own son was his favorite plan, and he always persisted that he could never breed them too closely. Philips fed a great many mains for him, but whoever fed had to supply them with fresh sod and gravel every third day. Ralph Benson of Stropshire, and Walker of his own county, usually fought him the closest, but beating him was fairly out of the question. There was a suggestion made to one of the sporting periodicals that as no one else had a chance in fighting him that the Earl of Derby should fight him a grand main to prove whether the Doctor was really invincible, as his friends supposed him. But the Earl's. party had too much judgment to avail themselves of the beating that would have been in store for them. His birds were never better than at the time of his decease, and although he lived the allotted space of three score years and ten, age never quenched his love of the sod. If any man ever bred a superior strain of cocks to his it could only have been the late Mr. Clark, of Taunhall, better known as Vaunhall Clark and his phenomenon, that won the Westminster gold cup, besides 


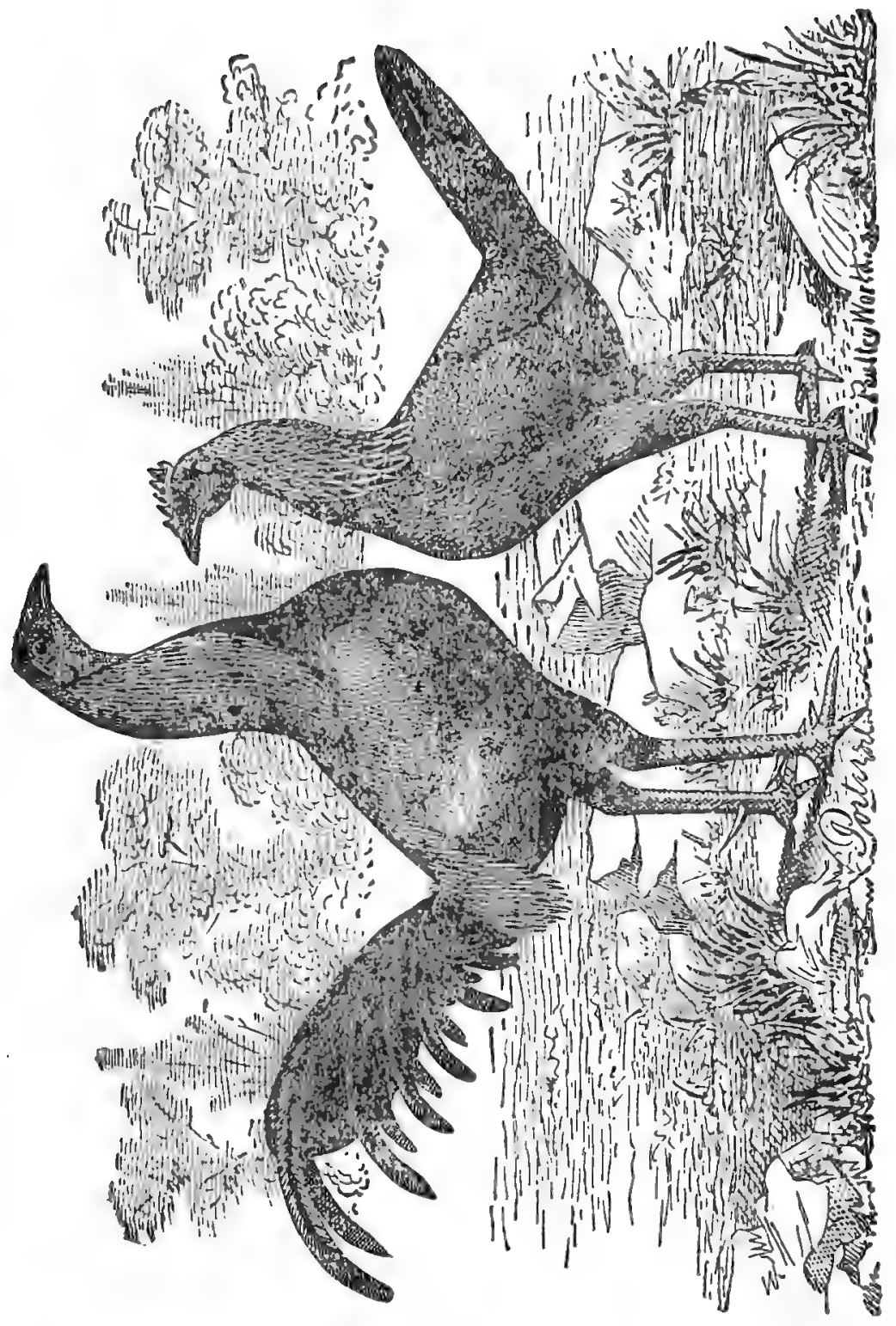


several other mains, was allowed by good judges to be the most clever and terrific fighter ever seen in a pit, often taking his cock and flying screaming across the pit with him, dropping him as dead as a knocker with kicking enough to kill a dozen. But in whatever company his cocks fell it was a foregone conclusion that considerable more than half their opponents would never fight again. Indeed whole mains have been fought against them without scoring a single battle. Sam Chifney, the famous racing jockey, had some of the breed, but he crossed them and so spoiled them. It would be very easy to mention scores of other noted strains that have fought their way into notoriety, as Dr. Waiys, of Leicester, thc Cumberland Muffs, Isle of Wight Yellows, the Devonshire Tassels, and Cornish Hennies, but we have already far exceeded our space, and will just state the colors most valued in the pit in its palmy days of half a century since. Not that we are color fanciers. A good cock cannot be a bad color, yet no one will deny but that a set of full brothers of similar shape, feather, constitution and fighting qualities are much more desirable in a main than birds bred without any rule or uniformity whatever. Some will be good, some bad, and some indifferent. The principal colors of birds used for the pit were as follows: $x$, black-breasted dark reds; 2 brown-breasted light reds; 3, black-breasted birchen Duckwings; 4 brown-breasted berry birchens; 5, Piles; 6, black-breasted silver grays; 7 , smock or shaded-breasted mealy grays; 8 , black-breasted dark gray; 9, ginger-breasted reds; ro, blacks; I I, brass-backs; I 2,

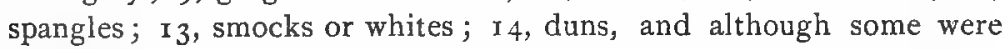
esteemed more than others in different localities, their merits were pretty generally accepted in the order named. The first named is the old true BlackRed of the cock pit, for a description of which we accept the best known and acknowledged authority in England, who has bred and fought more cocks for upwards of fifty years than any other man, is that the bird in question should be a clear, vivid red extending from the hackle to the extremities; the red upon the hackle above and black beneath; the upper converse side of the wing equally red and black, even though surrounding the posterior; the whole of the tail feathers, the tips of the wings, the breast, beak and legs, black. The hen, dark partridge color, with bright red hackle above and black beneath, clean brick-breasted and such to the posterior, with black beak and legs. If a Black Red has any other color than black and red 
he is not a true Black Red. The brown at tip of wings of any blackbreasted Red is not at all admissible. In a true Black Red, or properly dark-breasted Black Red, who has a crow wing, point black and brown, and a Black Red could have no other colored breast or he would not be Black Red, the breast being always named in match bills.

We have not space to enter on breeding more than this. If you have a real good sort be careful not to spoil them by crossing, and a very old cocker has said a failure needs no cross but total eradication, and I would add, the best way to perpetuate any grand qualities is to breed those that have those qualities in the greatest perfection, and if those should be of the same family, which is not likely to be the case, provided they are in perfect health and vigor and are the best you .. know, then by all means breed from the best, although they should be brother and sister. I am aware many will object to this as ridiculous, but here is a fact, that all the crack breeds in England have been so bred that scarcely a breeder in England has become celebrated for a strain of cocks that has not adopted this in-and-in system. How often have we known two of the very best strains that could be put together get very indifferent produce, and it holds good with animals as well. Mr. Balkwell bred his cattle on the same principle, as well as other celebrated breeders of sheep, pigs and dogs, and the best horses we have ever had on the turf are proved by pedigrees to have been bred in the same manner. One thing never lose sight of, and that is, that the brood cock has that first and greatest requisite, heel, for it is that which wins and without which all other fine qualities are useless.

Of feeding I shall say still less. Every feeder thinks his own system best, and has some infallible secret which is jealously kept, and I have some half dozen recipes by me now which have been obtained at fabulous prices from some of our most celebrated feeders by gentlemen of fortune, and there is scarcely one I entirely agree with. Infallible recipes are mostly infallible nonsense, and some that are published in recent works on game fowls in America would insure death in England if followed. There is a vast difference in the constitution of cocks, climate, seasons of the year, fighting in steel and silver, which the best recipes never allow for. I have seen strange things given fowls, and I have never yet seen ${ }_{\xi}$ condition forced into a pen of cocks, 
but I have seen it forced out considerably. When a cock is properly wound up for a battle he should neither be overloaded with flesh, distressed with physic, or wearied with sparring; should be full of fire and vigor, yet fight cool and collected, for a cock rendered hot and mad with unnatural treatment has little chance with the cool, hardhitting cock in condition. Centuries of careful observation has resulted in giving that condition to the game cock surpassing all animals. Even our severest contested races fail to put condition to the test so much as the game cock in the long battle.

Spurs have been made of very different shapes and material, but Clay's silver spurs are more valued than any other. They are now become very scarce, and there is but one maker in London, although Cockspur street was so named from the trade being carried on there. Men are still living who recollect $\mathrm{Mr}$. Vincent keeping several men constantly at work making. Smith was the riext best maker and succeeded Clay. Gatesfield was a reliable maker, as was also Toulman of the Dial and Crown stand. We found a beautiful box of the latter make at a gentleman's house the day after Doncaster won the last derby. A few cocks were on the walks, and after dinner it was proposed to have a battle or two, but we had no spurs. One of the domestics said there was a box in the library, and produced a splendid box that appeared not to have been once used since fresh from the maker's hand, say fifty years before, and on the inside of the lid was coupled with the maker's address the following lines :

\footnotetext{
"As curious artists different skill disclose, The various weapons different temper shows: Now curving point too soft a temper bear, And now too bard, their brittleness declare:

Now on the plain the treacherous weapons lie,

Now winged in air the shivered fragments fly:

Surprise, chagrin, the incantious feeders gaze,

And Smith alone in genius artists praise."
}

Toulman refers to his method of making, being the same as the noted Smith. Green made some very strong spurs and good turns, but were often heavy and always yellow, very different from the silverlike spurs of Clay and Smith. A well turned out pair of silver spurs were worth three guineas, and no mains of any importance were ever fought except in silver. An old friend of the writer, Mr. Faultless, of London, gave ten guineas for a recipe supposed to be two hundred years old for mixing the alloys, making, etc., and his assistant the late W. Chalden, of Sussex, made some nice turned spurs but they 
would never stand, and as he never knew how to mix the alloys properly, and as Faultless obtained his recipe under secrecy he would not divulge it to him. Their sort of spurs was made of steel and washed over with silver to pass for silver spurs. They often broke, and $\mathrm{Mr}$. Bald Houghton once lost a main to Lord Derby by the spur breaking in the last battle. The very best maker of this class of spurs was Singleton, of Ireland. These can be made very good at present in England, although no cocker would trust the best silversmith in London to make a pair of silver spurs and fight a battle for money in them. Steel spurs were made very good in Ireland by Singleton and others, but the largest quantities were made in Sheffield, and generally were very reliable; although the best maker of steel spurs was a resident of Exeter in Devonshire, who has been dead some thirty years; his name was John Wattling, and at present his spurs are much sought after, and half a dozen pairs of any other make can be gotten for a pair of his, for in addition to their being a very killing spur, no cock can either break or bend them, although they are so light and elegantly made.

Main bags were made of different colored silk velvet embroidered in gold and silver lace, were used to carry the birds into the pit, and this alone was often worth the entrance fee.

There was a difference in mains, but a long main and those generally fought was that each county and party should show and weigh sixty-one or more or less cocks between three pounds six ounces and four pounds eight ounces three days before fighting, and as many as fell within one ounce of each other had to fight in the main which began with the lightest pair of cocks on the third day after, and the battles were as equally divided as could be into five or six single or double day's play-a double day being when five or seven battles were fought in the first ingo, or before dinner, and the second ingo of the same number who were fought in the afternoon. But at race mains single day's play or ingo in the morning only were fought, the afternoon being devoted to racing. When the cocks were weighed the colors and marks were most carefully and accurately taken by both parties in order that the birds might not be changed. All birds not falling in one ounce but falling within two ounces of each other were fought by battles for ten, twenty or forty pounds a side. Three pounds six ounces and four pounds eight ounces were the regular fixed 


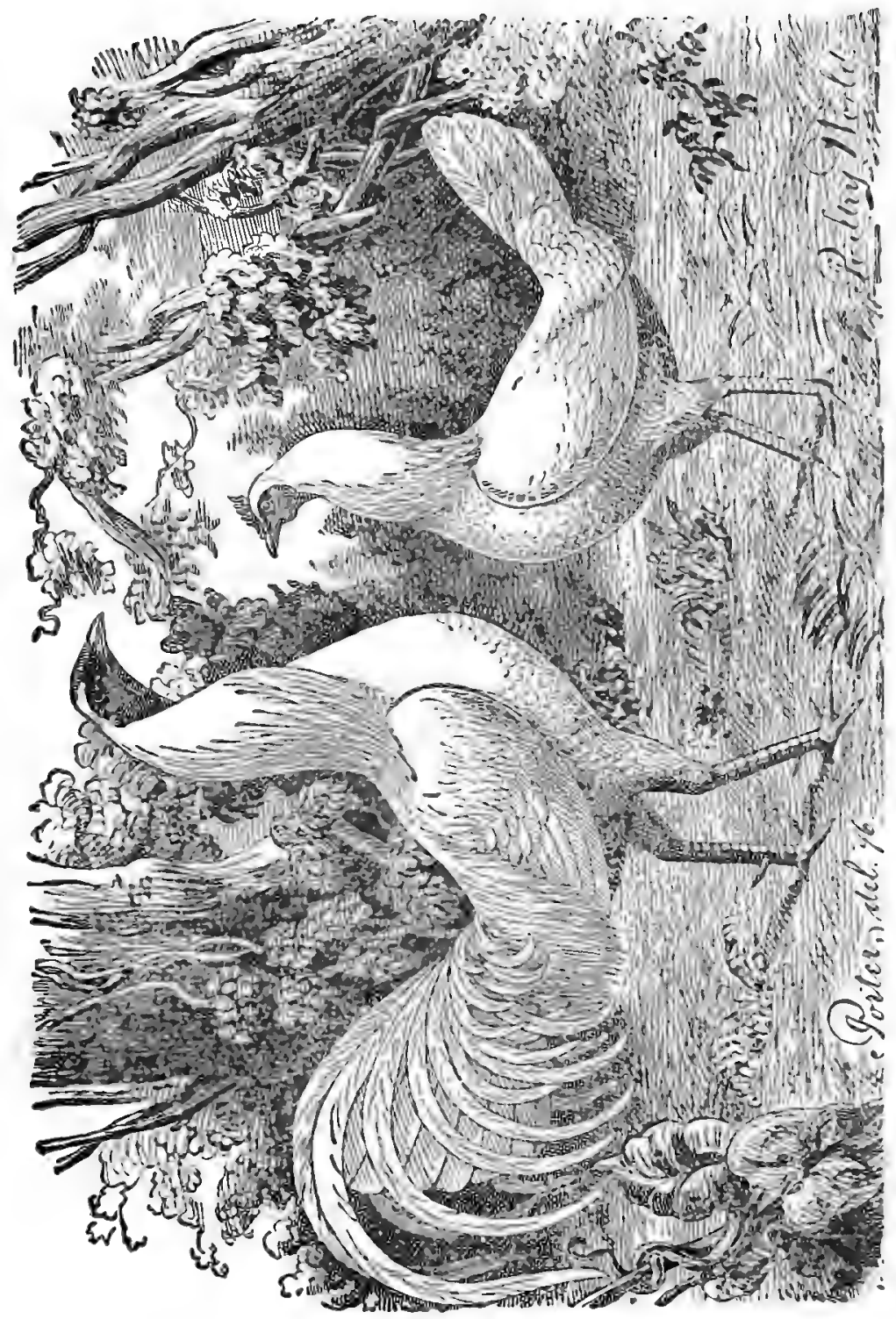



weights of the royal pit, Westminster; all above that weight went for byes, and none less were allowed. 'The lightest birds commenced fighting and proceeded up. When the birds were brought into the pit they were carefully examined to see that they answered the description on the match bill, and if correct the birds were handed the setters to fight, except in the first battle of the main, when it is usual for the masters of the match, i. e., the backers or principal owners of the cocks, to toss the first pair upon the mat or rod. In this case no cocks are weighed after the weighing day, it being left to the feeders to weigh the birds as light as they can, and to raise them as high on the fighting day three days after. Eight days is the usual time for feeding, but the heavy or last cocks fighting in the long main of six days are in fourteen days, and there have been mains fought for a longer time, for a fortnight, in the north, many years since, and which after all ended in a drawn main, and some twenty years since a week's fighting took place at Easter, in the Gallogate pit, where six feeders sat upwards of two hundred and seventy cocks on the mat ranging in weight from three pounds four ounces to five pounds two ounces, and a notice was at the time hung up in the pit that the cocks for the 6th of May main were to come in on the 26th of April and weigh on the $3 \mathrm{~d}$ of May, and of another main to weigh off scales on

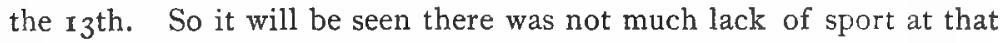
time. Printed lists of the numbers, colors, weights, feeders' names, and winners were at that time published, to be sent to those parties who had cocks there but could not themselves attend on account of business or distance. Many of those lists are now before me as I write, especially one of the mains I have just referred to, Prailey commencing with a winning three pound four ounce furness cock named Mungo, and losing the last battle of the main with a five pound two ounce cock named Waterloo.

Short mains are when parties each find twenty-one cocks, more or less, between a stipulated weight. Each supplies a list of the weights of their cocks to a referee, who compares them and matches all that fall within one ounce under four pounds eight ounces and within two ounces of those above four pounds eight ounces but under five pounds four or eight ounces to fight for the stakes previously agreed upon. The cocks are weighed in the pit, one ounce being allowed for spurs, 
and any cock excluding one-fourth ounce of the weight he was matched for loses the battle.

A set weight main is one where each party names the weight of eleven cocks, more or less between certain specified weights, and his opponent must find cocks to match them. They then toss for choice of weight for odd battle which the loser must match, and they usually meet aud fight fourteen or twenty days after choosing weights.

A Welch main is sixteen cocks under a certain weight are weighed, and the lightest pair matched to fight, and so upwards until eight battles are fought. The eight winners are matched and make four battles, and the four winners make two battles, and the two winners fight for the purse cup or stakes.

A main Royal is when any number of cocks under a certain weight are thrown on the sod together, and the last cock fighting takes the stakes. This, according to the Rev. Dr. Robert Wild, the historian, poet, wit, divine and cocker, is of Dutch origin. The Doctor, although a minister, was an enthusiastic cocker, and wrote the best poem on the subject in the English language. At one time he and another preached probationary sermons for the rectorship of Aynho, in Northamptonshire, and a friend some time after asked him which had received the living, he replied, "We divided it ; I took the ayes and my rival the nays."

There is sometimes fought what is termed a shake-bag or turn-out main. Each party get a specified number of the largest cocks they can and proceed to fight them without weighing. Indeed, weighing cocks at all is of comarpative modern date, as cocks were formerly matched by length, girth, strength, etc.

Setting is the most difficult art in the whole routine of cocking. Hundreds think they can set a cock when they know no more of the art than a cock knows of his father. An old author has said, "A setter should have a ladie's hand, a hawk's eye, a fox's head and a lion's heart." A cock should be handled as tenderly as if he were foam, or some equally as perishable matter. Yet how often do we see men roughly handle cocks in distress. He should not only be quick to see any hurt to his own bird but to his opponent's, and thus reckon where to force the fighting or slacken it. A cool, calculating head is indispensable. From thirty to sixty guineas were formerly paid to some of our cock-setters for a good main, and Stradling, Gladdish, 
Fisher, Eaton, Overton and Lun were thought highly of in this capacity by those great patrons of the sod, Lord Lonsdale, Wexborough, Hamilton, Northumberland, Warburton, Halton, Wharton, Bullock, Halford, etc., as were the feeders Brombey, Lister, Watling, Lauley, etc. I thought to have given something more than the mere names of those past celebrities, but space will not permit, and I would just remark that Owen Prolyn was generally supposed to equal any man that ever entered a pit. Porter, too, was very clever, whilst at the Royal pit Dick Fleming was always supposed to be several battles ahead in the long main of any setter ever entering there, and the old chant, "I've seen Dick Fleming handle cocks," is still remembered by many a sexagenarian. His father was a great feeder and a rival of the celebrated Nash, and both young Nash and Fleming were no mere adepts at that art. But in this line none could be found to equal Joseph Gilliner, publicly pronounced to be the greatest feeder that ever lived. But all these, along with their opponents, Potter Weightman, Philips, Woodcock, and a host of others have many years since passed away, and were succeeded by Bailey, Brough, Parker, Morton, Bootal, Jones, Gillham, Davis, Faultless, Calicott and others.

For some time past the police have been constantly on the alert to stop all fighting in England, so that it has to be carried on in private. The Society for Prevention of Cruelty to Animals hound them on, and many good men amongst them think cocking a most cruel sport, whilst they are practicing much worse cruelties every day. All of Nature's laws are cruel, from the spider that ensnares the fly to the hawk that pounces on the bird, but vain man would be wiser than his maker, and it is one of the wise laws of the Creator that this battle of life should be carried on, we will suppose a cock in his native wilds is armed with spurs more fatal than even with steel, for with them two strong combatants die, whilst with the steel one would probably come off scathless. I would ask, what are those spurs provided by nature for? When the old cock becomes infirm he is engaged by a younger and more lusty rival and soon falls a victim; and well it is so, as he is thus saves from decrepitude, hunger and a lingering death, while his younger rival's progeny keeps up nature's standard of excellence, and it is no more cruel to. look at two fowls that are only following their own natural instincts and inclinations and in which they cannot be forced than it would be were they to fight in their natural wild 
habitation. There is a vast deal of difference between this natural inclination and gratification and the cruel back-door work of staking, baiting and ill-using creatures, entirely under our own control, and tried in the balance of reason. I am sure cocking is the least cruel of all sports, but $I$ am passionately fond of fishing, lauded as one of the most innocent amusements without considering the pain inflicted on live baits-worms, frogs, etc.-on barbed hooks, and the playing and torturing the fish into weakness to enable me to land it. I have never got over the pang given the beautiful trout when drawing the hook from its throat and gills. The same with shooting. How many maimed, injured birds escape the gunner to die a lingering death from hunger, mortification and dreadful wounds. The glorious chase and the exciting race-course are not without their drawbacks.

All countries have merged from a state of barbarism to a state of civilization, thence to a state of luxury, and then certain and mere effeminacy, and there is at present an amount of mock humanitarianism, dandyism and effeminacy disgraceful to the name of Englishman. Even the sports of our fathers are denounced as horrible, coarse, vulgar, whilst the amusements of those condemning them are profligate and effeminate to the last degree. I accompanied a Cheshire county squire to the opera the night succeeding the last Derby, and a more philanthropic. kinder-hearted man does not exist, notwithstanding he had attended the Derby, seen a few cocks fight, and is never so happy as when following his hounds. After looking at the half nude creatures that came on the stage for a short time, he turned, thoughtfully, and leaving, said: "This, John, is a most miserable sight with all its glare and glitter ;" and this is one of England's fashionable amusements, and from the pale, sickly youth that frequent those places we are to draw those who will uphold England's glory to a certain extent. In country places magistrates, police, etc, keep down the rustic amusements of young John Bull. The wrestleing ring, cudgeling, stage, boxing, etc., must give place to tea fights, croquet, etc., till England gets in danger, then put a red coat on his back, clap him on the shoulder and say, "you're a fine soldier," but not of that daredevil ilk that Wellington had in the peninsular wars.

A great change has and is still taking place in Englishmen. Some men feelingly but proudly recollect a vessel named the Birkenhead, 
full of Englishmen, and amongst them many enthusiasts of sports. The vessel was found to be in a sinking state. The men were drawn upon deck by the officers, and calmly met their fate as only Englishmen and the bravest of the brave could do. A few months since a vessel was run into full of Englishmen, and the fright and disorder was a strange contrast between the panic-stricken passengers of the Northfleet and the cool bravery of the Birkenhead. That the sports of a country has much influence on a people is abundantly proved in the history of Rome, Greece, etc. However some may contend to the contrary, and if the following lines contain any truth, cocking should take a murh higher stand :

\footnotetext{
And some more martial are, But cocking fits a man for peace or war; It makes men bold and forward for the field, And learns them there rather to die than yield. Cocking does also constancy create, And arms a man to wrestle with his fate. Be it more happy or severe, his mind Is still the same to a brave end inclined.
}

\section{A PLEA FOR THE PIT.}

AN ENGLISHMAN'S ARGUMENT IN FAVOR OF COCK-FIGHTING.

The Hon. Admiral Rous sends a letter to the London Times, from which the following extract is made: A motion in the House of Commons to increase the punishment to Her Majesty's subjects who indulge in the most ancient and royal amusement of cock-fighting induces me to trespass on your columns. It has been argued that it is a wise policy to forbid this sport, owing to its cruelty * On this principle, why not make pigeon-shooting illegal when fat Herods, standing over the traps, slay the innocents? Why not legislate against hunting, coursing, fishing? In the latter amusement, what can be more brutal than impaling worms on hooks or trolling with live bait to catch pike? Playing with a fine salmon on your hook is a pleasant pastime, although the victim differs in opinion. Neither is there much to be said in favor of grand battues, where hundreds of birds and ground game escape mutilated to live a miserable life or to be eaten by rats. 
All these amusements must of necessity'be cruel, but they are sanctioned by the upper classes, and the cruelty is ignored. With respect to the champions of the cock-pit, is it a greater boon for a cock to be well fed and reared to fight a battle, if victorious to be petted for the remainder of his life, with half a dozen little hens for his comfort, or to cut his throat early in life to satisfy the appetite of a carnivorous man.

It must be clear to every man that in this country there is one law for the rich and another for the poor. The snob sticks to the former, but the thoroughbred gentleman stands by the poor man. In ancient times the gamecock was considered an emblem of divinity by the Synans and Greeks. When Themistocles besieged Dalmatia, he commanded that two cocks should be fought in the open view of his army, and exorted them to behave as these stout-hearted creatures fought. Pomponius Mela, the historian, asserted that the Roman empire did not begin to decline until cocking had fallen into disrepute among its governors. He proves that Serverus was not able to conquer Britain until he had rendered his principal officers passionately emulous of glory by exhibiting a main of cocks every day before them. The soothsayers warned Mark Anthony to take heed of Cæsar, because his cocks were always beaten by him. The great Gustavus told the King of Denmark he had no cause to fear the Imperialists, since they had given up cocking and were devoted to drinking and dancing. Christian, king of Denmark, said: "Were I to lead an army against the great infidel of Constantinople I would choose none but cockers for my commanders, and none but lovers of the sport for my soldiers." Our Henry VIII. built a stately pit in Whitehall, where he often disported himself among his most noble and loving subjects. The dying speech of Sir T. Urquhart, who was wounded at the battle of Naseby, was: "My king and a good cock I have ever loved, and like a good cock in my sovereign's service I gladly now expire." A Mr. Wilson, in the last century, advised all men who take delight in this pleasant and delicious pastime never to forsake or alienate themselves from it, so long as it shall please the Almighty to bless and prosper them; and he adds that we are bound to encourage cock-fighting among ourselves and discourage it among all foreign nations. If cocking, which formerly was a great sport with the great nobles of this kingdom, be now a sin, I am an old and hardened sinner. In 1827: in command of 
the Rainbow, I brought ten English-bred cocks from Sydney to Malacca, and fought ten battles with a Chinese merchant who had defeated all the Malays. We won every battle, and I would go two hundred miles to see a main between the Cheshire Piles and the Lancashire black-breasted Reds, if there was no legal prohibition. Any amusement which creates alliances and augments friendly acquaintance adds to the strength of the empire, for united we stand; and the monotony of human life is relieved by every salutary diversion.

\section{DESCRIPTION OF GAMES.}

Owing to the numerous breeds, strains and crosses of the Game Fowl it would be quite impossible to notice all of them, therefore if we fail to mention any well known variety we would not be understood as considering them unworthy of notice.

\section{EARL DERBYS.}

This breed of games, for many years noted in England for their courage and almost universal success in battle, is esteemed by all cockers and fanciers throughout the land. It is generally understood that by skillful breeding and crossing this breed was kept in all its purity for over a hundred years. Many stories are written concerning their history, and many disputes concerning their importation to this country. Upon this subject we have the following, written by one of the oldest and most reliable cockers in England, who has fought many battles against the Derby fowl, and he says: "Many believe that Derby's fowls were the most successful fighters in England. Although he was the most extensive breeder, walking annually from three to five thousand cocks, he could from this number select many good ones, buit many breeders who never bred so largely but bred more good ones were equally successful in their mains. But from so many it is an easy matter to pick mains of cocks faultless in shape and perfect in condition. His chief success was mostly to be found in numbers rather than in excellence, as for years Potter had a pick of three thousand two-year-old cocks, and even in that great choice of the Earl's 
cocks he many a time found that old Joe, with Mr. Leigh's birds, carried off the cash and had won the majority of the battles at the end of the week's fighting. It was once proposed to match a great main of those cocks, ten years before the Earl gave it up, against Bllyse, at Chester, but the Earl and his friends would never risk the beating that was pretty sure to be given them, as it had for a number of years

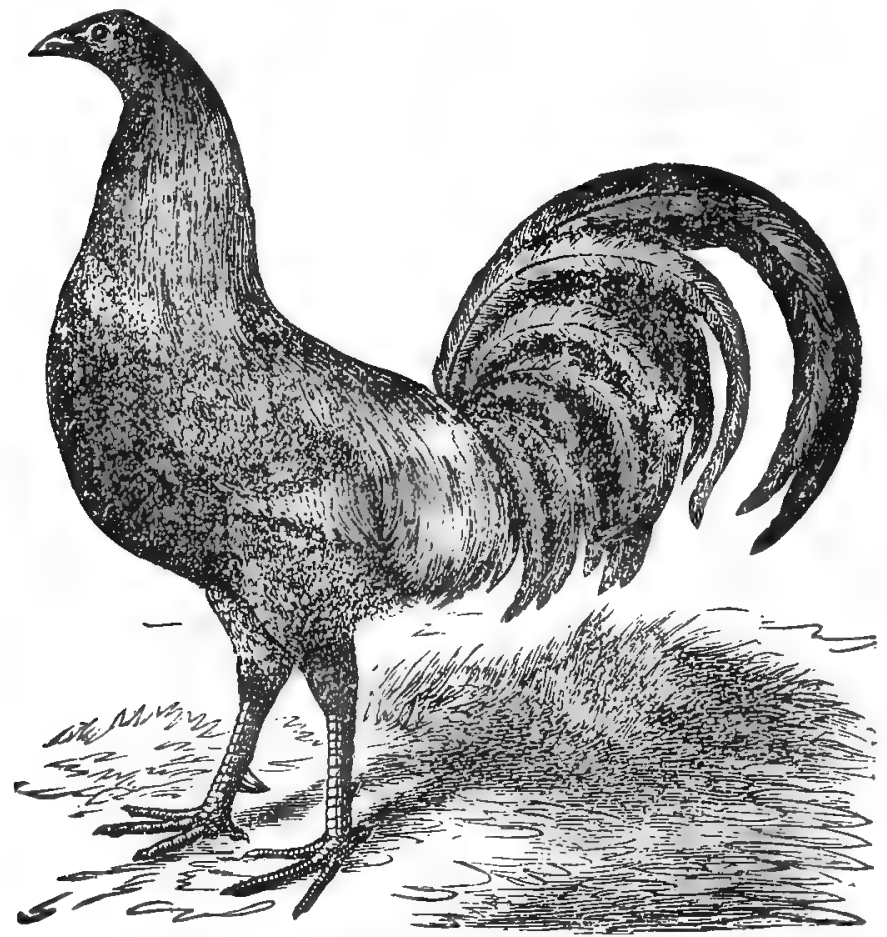

EARL DERBY GAME.

to all comers, both from England and Ireland, including the noted birds of Benson, Walker, etc. In fact, when or wherever Bllyse fought he proved invincible. Philips cheerfully fed for him, and he seldom put out more than one thousand chickens a year, or only onethird the number of the Earl. Clark's birds generally made short work of all that came against them, and when pitted against the Derbys it was always two to one on Clark. Again, many who ought 
to know assert that a pure Derby cock was never sent to America. You might as well have asked the Earl for a church living as one of his brood stock; it would have been the least favor of the two. Some twenty years since we applied to Old Roscoe (who had charge of the cocks as his father had before him) for some of the breed, being some eighteen years after the Earl had fought his last main, and all that Roscoe could then find of the pure breed was some half dozen, and he was most anxious to get them for us as we were an intimate friend of his. I am aware this assertion will not be credited with you, but I would take long odds that one-half dozen real Derby's were never sent to America, if it could be proved, but those that kncw best in this country will quite endorse my opinion. Scores of half-breeds that answer to feather, marking, size, etc., have been sent there as Derbys, as well as hundreds that have been sold and are kept here as such. It has been proven that the white-legged black-reds were bred in this country hundreds of years before the Earl was born; therefore their origin cannot be claimed to have originated with him as he only kept a variety of them. His fowls were chiefly black-breasted reds, white legs and a white streamer in the tail and flight feathers, although at a late day he fought a strain of gray cocks, which were extra good ones.

\section{SEFTONS.}

This is also another breed of English fowls, but have long been known in this country. They were never so noted as the Derbys and never, as claimed by some, the principal contestants of the Earl's fowls. The originals generally bred ginger-reds with green and yellow legs, and are of good size, well shaped and strongly built, with large bone and muscle, and are still a much coveted fowl in certain quarters, and are sought after by many cockers who have been fortunate with them.

\section{IRISH DARE-DEVILS.}

This is one of the largest and best of the Irish varieties. They are, in our opinion, the best class of fowls ever imported for general use. In color a black-breasted red with yellow legs and red eyes. The hens are buff, with yellow legs. This breed has made its mark, are good fighters and dead game. They are greatly in demand, owing to 
their beautiful plumage and hard, rapid style of fighting. The cocks run in weight from five to seven pounds, and very frequently have proved winners against strong odds. The hens are good size, good layers, and take great interest in their young.

\section{HEATHWOODS.}

A noted strain of games named in honor of Thomas Heathwood, a celebrated cocker and breeder. They breed various colors, weigh from four and a half to six pounds, and are bred for the pit only. For many years they were the principal winners in many of the large mains fought in our eastern cities, and were so highly prized that extravagant prices were asked and paid, but they now have become more numerous and can be found on many a fancier's and cocker's yard. They are remarkably quick fighters, fighting with force and vigor, stand up well, and are liberally possessed of bone and muscle.

\section{RED HORSE.}

A fowl long known to old Southern cockers, breed black-brown and ginger-reds, with dark legs, and are considered one of the best of the Southern varieties. They have long been fought in the principal mains in Maryland and Virginia, and no pains have been spared to " make them reliable. They are strong, fast fighters, and invariably force the fighting, are quick in their movements, and are an excellent fowl for yard or pit purposes. In certain sections they have many admirers who breed them largely for pit purposes. The hens are of a dark brown color with dark hackle and dark legs, are compactly made and of good size.

\section{COUNTERFEITS.}

A fowl much thought of at the present time, with a handsome plumage and courageous disposition, are a desperate fighting bird, quick in motion, good size, rather low on legs, long wings, good bones, fine eye, in color either brown or ginger-red, with dark legs, are a very hardy fowl and keep as free from disease as any on our yard. The Counterfeit strain of fowls took its origin from a black-red rose-comb. cock weighing five pounds and six ounces. This cock was a very 
beautiful and well-made bird, and a most extraordinary, desperate and rapid fighter. It was these latter qualities which produced the coincidence and drew forth the remark which gave to this cock the name Counterfeit. Some twenty years or more ago, a main of cocks was fought at Gavanstown, Baltimore county, Maryland. One of the battles of the main was between a very celebrated black-white speckled cock, called the Class-Leader, and the then obscure black-red cock whose progeny afterwards became so celebrated. The two cocks came together, and at first, it was said, the Class-Leader had the advantage and struck his antagonist so hard he was crazed. He quickly recovered, however, and attacked the Class-Leader with such fierceness that he soon killed him. The extraordinary fighting qualities displayed by the winning cock led one of the old cockers present to believe him to be his own, and he exclaimed, aloud, in the pit: "Ah! Skipper, that's my cock; that's the one you ought to have sent me, for mine was a d-d counterfeit!" This occasioned great laughter, and the little black-red rose-comb cock was forthwith named Counterfeit. After the battle he was taken to a gentleman named Goss, who used him for a breeder, and this originated the Counterfeit strain. He was, also, the winner of several subsequent battles, and was finally conquered by a War Eagle cock. The original Counterfeit cock was bred by Billy Hoffman, of Carroll county, Maryland, and was from a strain known as the old Charley Martin cocks.

\section{RED QUILLS.}

This strain has an extensive reputation in Virginia and in a few other Southern States, while in others they are comparatively unknown. We have bred them for a few seasons, and consider them one of the best for pit purposes. They have a handsome plumage and lofty carriage. The cock has a small round head, neck full and well hackled, breast full and strong, tail long and well sickled, wings long and low on the shank, legs either yellow or green, and vary in size from four and one-half to five and one-half pounds. They have unflinching gameness, and will soon earn an extensive reputation throughout the West.

\section{CLAIBORNES.}

This is a noted breed of fowl, taking their name from the gentleman who bred and fought them for a number of years in the Southern 
States. They are supposed to be a cross between a good English and Spanish breed, resembling both breeds in many particulars. The cock has a small round head, with neck full and well hackled, black breast, full and strong, tail full and well sickled, wings long and low on the shank, legs either clear white or yellow. The cocks vary in size from four to five and one-half pounds. They are sometimes described as having a small tassel, but we have bred and seen them bred for a number of years, and as yet have failed to perceive the slightest tassel. Perhaps in crossing them formerly with other approved breeds, to increase and keep up their size and strength, they may have lost some of their original peculiarities. They have long been known in the the Northern and Southern States, and will stand all the changes of our northern climate.

\section{THE TARTAR FOWL.}

This strain had an extensive reputation, at one time being considered the best for breeding and pit purposes. Dr. Cooper prizes this breed highly and still continues to breed them in such a manner as to preserve all the general fighting qualities. We obtained the breed some years since from him, and have bred them as large as eight pounds; their average weight is from five to seven pounds. They can be used successfully for producing any desired cross. They breed black and brown reds with black and green legs. We also find them sometimes breeding a blue-red. The cock stands up well, has a large, full breast, large, heavy limb, long claws, and large red eyes. The many battles recorded show plainly that too much praise cannot be given for their unflinching gameness and quick, savage manner of fighting. They have an extensive reputation and can now be found in the hands of nearly every fancier and cocker.

\section{JACK MCCLELLANS.}

This breed of fowls perhaps is little known in the Western States, but stand high in Virginia and Pennsylvania. They originated with John McClellan, of Gettysburg, Pa., one of the most successful cockers in the country. The cock is strongly built, with fine, well set neck, head rather large, bones strong, thoroughly game, and will 
show fight under all circumstances. We have bred them for many seasons, our original stock consisting of an eight-pound dark-gray cock and two dark-brown hens, nearly black, with copper hackles and green legs. Our stock now shows reds, both black and brown, grays, and occasionally a spangle. Their weight varies from four and a half to six and a half pounds. They are hard strikers, tolerable fast fighters, and for shake bags or cross breeding cannot be excelled.

\section{DUSTY MILLERS.}

This breed of fowls are well remembered by old cockers, and have long maintained a high reputation in Kentucky. The stock is highly valued, but difficult to procure, and of late has met with great favor in Ohio and Virginia. The cocks are terrific fighters and sure to win if equally matched. They breed reds, blue-reds, and occasionally grays, from which they take their name. The legs of the reds are white; of the blue-reds, yellow; of the grays, green. The cocks are well stationed, strong and long winded, varying in weight from four and a half to six and a half pounds, are full breasted, full hackled, with extremely long wings nearly meeting at the points. We have bred them for some time and deem them most valuable for the pit.

\section{THE ESLIN FOWL.}

This breed, it is said, originated with the Eslin family, of Washington, D. C. Having bred them extensively, we find them showing black-red, brown-red and blue-red, with green legs. Many consider them the same as the Tartar fowl. They are of fine plumage, remarkably deep, broad chests, short backs, and strong in the legs and bills, are strong, fast fighters, and in our opinion cannot be excelled. The cocks are of good size, weighing from five and a half to seven pounds. The hens are good layers and setters and very motherly in the care of their young. As a general rule they can be depended upon, and their product under favorable circumstances is generally abundant. They are favorites in localities where large fowls are in demand.

\section{IRISH SLASHER.}

Is a fayorite breed, and having seen their gameness frequently tested in the pit and elsewhere, we consider them eminently trust- 
worthy. In breeding they show reds, blue-reds and Piles, with either green or bright yellow legs. The cocks are desperate fighters, fighting as well on their opponent's hold as their own; are well built, of good action, and are inveterate talkers while in the hands. The bluereds have pure blue breasts, light red hackles, with turkey-red saddles, and dark blue tails, legs yellow, etc., making them ornaments to any fancier's yards. The reds have a deep, broad, black-red breast, with yellow legs and a fiery red eye. The Piles have either green or yellow legs with light robin breasts, red saddles, light hackles and tail, and vary in weight from four to six pounds. They are excellent in the pit, mature early, fight rapidly, and have good wind and endurance.

\section{STONEFENCE FOWL.}

This breed is said to have been kept in their purity for more than fifty years by the Arlington family in North Carolina, by whom they were extensively fought, invariably coming off victorious. At the present time this breed is well known throughout the Northern States. They are of various colors, as black with brass backs and gray. The blacks are of good size, well shaped, strongly built, and are good billers and flyers. They are said to carry no superfluous flesh, and are soon put in condition for the pit.

\section{NEWBOLD REDS}

Were imported by Ed. Newbold, a cocker well known in the Eastern States, and from whom we obtained our stock, giving them the name of Newbold Reds. The cocks are of good size and station, stand well up, with heads erect, full breasted, broad across the shoulders, and tapering gradually to the tail. The wings are long almost meeting at the point, the tail full, with long sickles, breast of a brownred colur, the head small, with a large dark eye; most of the cocks have a loud and savage crow. Their weight runs from four to six pounds. They legs are of good size and either a dark green or black color. They are fast becoming favorites.

\section{IRISH MUFFS.}

Frequently called New York Muff, are a breed of fowls fast gaining a valuable reputation for gameness, and when obtained pure have few 
superiors. Formerly they were very numerous, but on account of being bred by fanciers and irresponsible dealers became unreliable. Lately, however, new blood has been imported, and once more in the hands of experienced cockers are fast proving worthy of every fancier and cocker. They show different colors, and run from five to seven pounds. By reference to the sporting papers it will be seen that they have won many a hard fought battle during the past few seasons. They have a rough-and-tumble style of fighting, are good billers and hard hitters, have large bones and are well set upon their pins.

\section{BALTIMORE TASSELS.}

Have large bodies and breed various colors, as blue-reds, reds and Piles, with tassels to match. We have often seen their gameness tested with steels, and find they invariably stand until death. Their weights run from five to seven pounds; are skillful fighters, stand up well, and are frequently taller than other fowls of equal weight, thereby giving them the advantage in the pit. We have bred them for a number of years, and have found them healthy and easy to raise.

\section{RATTLERS}

Are said to take their name from their style of fighting. They breed a variety of colors, with blue or green legs, and for fancy or fighting qualities have few superiors. They are especially desired when light weights are wanted. The cocks are strong fighters, thoroughly game, strongly made, long winded, and as quick as fowls can conveniently be, mature early, and at an early age can be trusted in the pit. The cocks vary in size from four to five and a half pounds. The hens are fair layers, good setters, and show great interest in their progeny. Of the many crosses we have made none show better than the Rattlers and Tartars.

\section{RED RIPPERS.}

This breed we obtained some years since from a well known cocker in southern Georgia, who, if our information be correct, originated them. The name evidently comes from their color, and style of fighting. Our first stock consisted of a fine five pound cock, in color 
nearly white, and two hens of light buff color with yellow legs. We were informed that the cock was formerly a ginger red, but gradually changing his color each moulting became nearly pure white. Since we obtained him he has changed to a darker color, and at present is as fine a spangle as can be found. He has large, pure white legs. $\mathrm{He}$ was said to have been the winner of many battles, and when we received him was cut out for the pit. Although nine years old he moves as quickly as a yearling stag, is very savage and hard to handle. We have been offered large sums for him several times. Breeding him with the hens sent at the same time gave spangles, brass-backs, and pure reds, with white and yellow legs. They make a close fight, are always near or mixed up with their opponents, and force the fighting ; are continually on the move, long winded, very quick in their movements, lnveterate talkers, and are fast becoming great favorites.

\section{DOMINIC GAMES.}

This breed of fowl has long been successfully cultivated in the Southern States and have many admirers. They are quick, skillful fighters, are of good size, well made, and stand up well on their legs, which are either white or yellow. In the Northern States their admirers are less numerous, having a number of times shown a lack of gameness; yet many breed and fight them and consider them equal to their best varieties. They have been successfully fought in a number of large mains in the South, and have always shown great courage and gameness. We see no reason why they cannot be bred as pure at the North.

\section{IRISH PILES}

Are a well known breed of Piles, and generally speaking result from crossing. They are strong, of good bone, and well made throughout, quick in movement, hard fighters, etc. The cocks run in weight from four to five and a half pounds, and have greater endurance than most Pile fowls. They show reds with white grounds and red and white stripes in the hackle, legs yellow, saddle and buts of wings dark red; the feathers of the breast are red and white. 


\section{BRASS-BACK GAMES}

Have a jet black hackle, bright yellow back, long, flowing dark tail, yellow or white legs, are broad breasted, short back, wings nearly meeting at the points, and are a breed much admired. They are good pit fowls, resulting from a cross; are fine billers and strong hitters, stand up well and are thoroughly game. They are of the average weights.

\section{HENNY GAMES.}

This variety was imported from England and Spain at various times, and it is said to be very difficult to find them in their purity. They derive their name from the peculiar feathering of the cock, as he closely resembles a hen in feather but not in size, and when pure never show any sickle feathers, and the hackle feathers of the neck are quite short, like those of the hen. They are of all colors, some white, some Pile, some spangle, and are said to be dead game.

\section{BREEDING COOPS AND PENS.}

Many admirers of fine poultry are deferred from keeping them, thinking they must have large and expensive coops with plenty of room, but this is a mistaken idea, as almost any one can at a small expense build suitable coops and raise as fine fowls as those bred in large and more costly ones. The following illustration shows one of our coops, suitable for breeding four varieties, or can be divided intó two apartments and two runs and so breed two varieties. It has been our experience that cheap and convenient coops are best, which, after a few years, can be torn down and replaced by new ones, and in this way be kept clean and fresh. Frequent whitewashing on the inside is needed, which prevents in a great measure the most troublesome pest fanciers have to contend with, lice. Keep the uests clean; and to be perfect should be so constructed as to be removed quite often, which allows of their being cleaned and whitewashed more easily. Any fancier can build a small house and pen suitable for half 2 dozen hens in a very short time and at a small expense, giving plenty of light and air. We prefer giving it height enough to enter, as you 
can more readily clean it out, the real cost being but a trifle more. Fowls will bear confinement if a change of food is given them often. Fresh cut sod does much to help them along. During the winter season we use plenty of straw. Selecting a place close to our coops

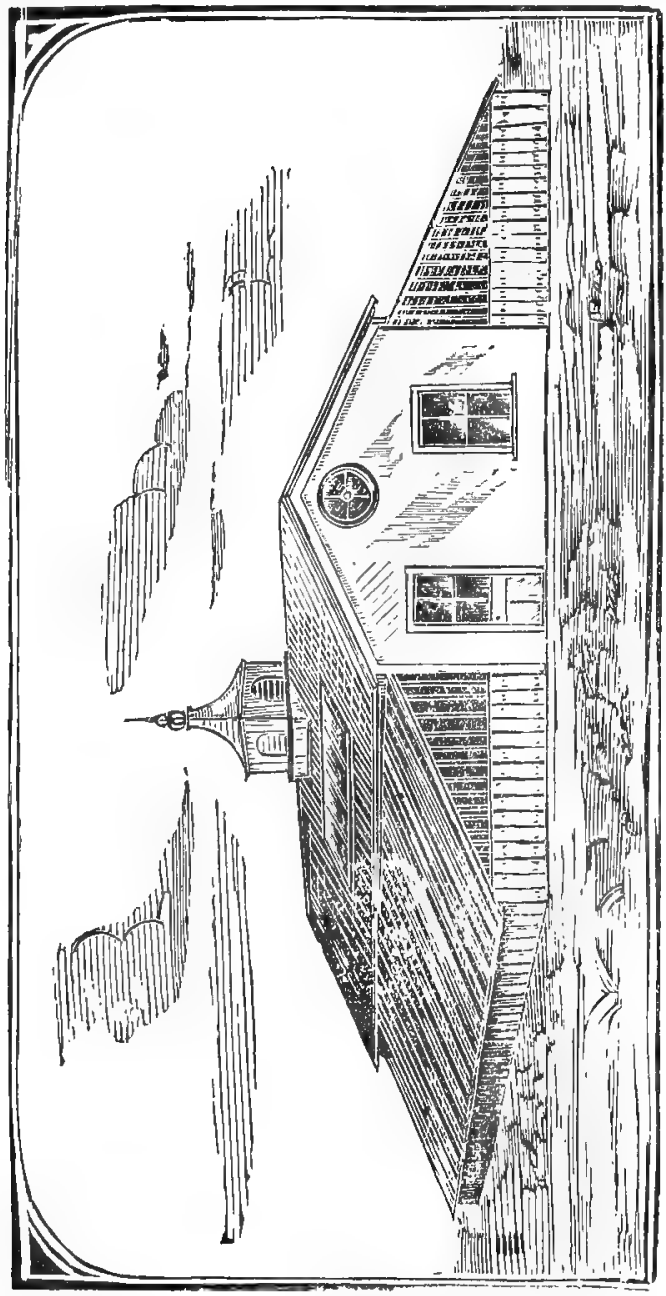

we spread it on the ground quite thick, and whenever it snows take a fork and shake the straw up. In this way our fowls have a place to walk and stand on out of the snow, with no danger of frozen toes and a good place to scratch, which they enjoy. 


\section{DISEASES.}

As it is our purpose to make this manual strictly practical, such complaints will only be mentioned as are most common and with which fowls are most liable to be troubled. The methods of treatment have been more or less practiced, and consequently we feel not the slightest hesitation in recommending them as in every respect reliable and adapted for the different diseases. Without doubt there are many instances when it would be more profitable to kill than to cure the fowl; and an attempt to cure should only be made when the disease with which the fowl is afflicted is well known. Over treatment should be guarded against. It is better to use precaution than medicine; and if fowls are kept clean, are supplied with fresh water and a change of food, they are less liable to disease.

\section{ROUP.}

Perhaps no one disease to which fowls are liable is more troublesome than the roup. It attacks the old and the young. Strong and healthy fowls are less subject, and when attacked are more easily cured. During the continuance of the disease great care should be shown the bird. Dr. Cooper gives the symptonas as follows; "Rising and falling of the wattles at each breath, a whooping sound in the throat, fetid discharge from the nose. In some the head and eyes will swell, then the swollen parts are feverish, and if not soon attended to a yellow matter will form in the eyes, which, if not regularly dressed, will destroy that member. The fowl's appetite fails, his desire for drink increases, his crop feels hard, and his feathers lose their glossy appearance."

Treatment. - As soon as the disease is discerned the fowl should be placed by itself in a clean, dry box, with plenty of straw. The head, neck and throat should be washed, and the eyes thoroughly rinsed with warm water in which common salt has been dissolved; give a half teaspoonful of dry black pepper; supply with soft food-a little bread soaked in ale is beneficial. When a fowl begins to improve place him in the sun for a short time each day. If the bird continues to rattle give a teaspoonful of cod-liver oil, or fish oil. Keep his box clean and supply with fresh straw each day. With good 
treatment and proper care the disease in its worst form can be cured. Nearly every breeder has a method of treatment, but as the difference is not particularly great, one method will answer every purpose. The method given above we have applied in many cases, and invariably with results most favorable. Some authors advise a dose sufficient for a horse, entirely beyond the capacity of a fowl. The method of treatment as given by Bement is: "For roup and all putrid affections take finely pulverized fresh-burned charcoal and new yeast each three parts, pulverized sulphur two parts, flour one part, and water sufficient to mix well; make into boluses the size of a hazlenut and give one three times a day." He also believes in bathing the head, eyes and nostrils with warm milk and water.

\section{PIP, OR GAPES}

Is a very common disease among young fowls, and is particularly troublesome during the warmest months. It is caused by drinking filthy or muddy water, and eating dirty food. Some claim that drinking rain-water also brings them on; and perhaps it were as well to keep them trom it. This disease will be detected by the fowl holding up its head and gasping for breath. We have tried many advised cures and find none so effectual as turpentine administered with a feather. Take a tail or wing feather, strip it within one or two inches of the feathered end, and dipping it into turpentine gently put it down the fowl's windpipe, not his gullet. After turning the feather once or twice draw it out, when it will be found to be covered with small red worms. These as well as those that remain will be destroyed by the turpentine. We would advise as likely to prove beneficial, that camphor be put into the drinking water. A few drops of turpentine mixed with the corn meal with which the fowls are fed will, in general, prevent the appearance of the disease.

\section{INDIGESTION.}

The remarks on this subject we take from the works of Dr. Bennett : "Cases of indigestion among fowls are common, and deserve attention according to the causes from which they proceed. A change of food will often produce crop-sickness, as it is called, when the fowl 
takes but little food and suddenly loses flesh. Such disease is of little consequence and shortly disappears. When it requires attention at all, all symptoms will be removed by giving their diet in a warm state. Sometimes, however, a fit of indigestion threatens severe consequen. ces, especially if long continued. Every effort should be made to ascertain the cause, and the remedy must be governed by the circum. stances of the case. **** General affections of this kind, as in the human species, proceed from over feeding or want of exercise. The symptoms are heaviness, moping, keeping away from the nest and want of appetite.

REMEDY.-Lessen the quantity of food, and oblige the fowl to exercise in the open walk. Give some powdered Cayenne and gentian mixed with the usual food. Iron rust mixed with soft food or diffused in water is an excellent tonic, as indicated when there is atrophy or diminution of flesh. It may be combined with oats or other grain. In England it is said that milk and warm ale have a good effect when joined to the diet of diseased fowls."

\section{MOULTING.}

With young birds the process is easy and the time occupied is not long; but with fowls that have passed beyond the second season the process of renewing the plumage is protracted and exhausting. Much assistance can be rendered by the fancier in varying the diet, and giving tonics, etc. Pieces of meat and fish should be thrown to them frequently, and lime and pepper mixed with their food. An abundance of grass and vegetables should be allowed them. Their drink should be composed of a half teaspoonful of sulphate of iron to one gallon of fresh water; an extra amount of feed should be given them also. After the third year fowls moult later each succeeding season, and frequently it is as late as January before they are in full feather. The fowl should be kept warm and occasionally given a dose of Cayenne pepper.

\section{CHICKEN POX.}

This is the worst disease to which game fowls are subject, and our fanciers may well fear, as it will give them greater trouble than any other disease known. It affects a number of fowls at the same time, 
and generally goes through the entire flock. We find it results principally from fighting, as when the fowl's head has been badly pecked and proper attention has not been given toward healing the wounds. Still we have had it on our yards when no cause was apparent and none could be ascribed. Some years since, being unable to check it, it run through and nearly destroyed our whole stock. Since then wave been more successful, and have found that if taken in time-before canker gets into the throat-it can be cured with but little trouble. Symptoms-small yellowish specks scattered over the head and neck, gradually enlarging until the head and neck become completely covered; the mouth and throat become badly cankered; the eyes swell shut, and in this condition the fowl remains until death ensues. As soon as a fowl becomes affected he should be placed in a coop by himself.

TREATMENT.-Make a strong brine of warm water and salt, and with a soft, fine sponge wash the head and neck; thoroughly rinse the eyes; carefully scrape the mouth with a small, sharp stick, to remove the canker; with the fore finger rub salt well pulverized in the mouth and throat; mix equal parts of sweet oil and turpentine and apply with a feather to the head and neck. No injury will result if the eyes are treated similarly. The fowl should receive the same treatment twice each day, and if carefully attended will grow better in two or three days; the scabs will come off, the appetite will be increased, and soon he will be well. During the sicknes a slight physic should be given, also a light feed of bread and milk. If the fowl refuses to eat force the food down. If the above be followed as recommended the worst cases can generally be cured.

\section{RUNNING AT THE NOSE, OR, CATARRH.}

It is almost impossible at the present day to go on any breeder's yard and not find this disease existing to a greater or less extent. We have noticed it at poultry shows as well as on the yards. Its existence can readily ascertained by pressing gently with the thumb and fore finger on either side of the nostril, when an offensive whitish matter will make its appearance.

Treatment. - Wash the head in warm water in which salt has been dissolved. Pure cider vinegar diluted with water will also answer the 
purpose. Place the fowl in warm quarters and give him a warm feed with a slight physic. This resembles the roup somewhat, and in fact is the first stage of that disease.

\section{DIARRHEA, OR DYSENTERY}

Requires immediate and careful treatment. It is frequently brought on by giving green or soft food, in which case change the feed, as this will do much towards curing the disease in the first stages. Chalk mixed with boiled rice and milk, with a little alum dissolved in the drinking water, will prove beneficial. The disease is accelerated by dampness, cold and wet weather, without proper shelter and care.

\section{COSTIVENESS}

Will be noticed by the fowl's frequent attempts to relieve itself. The cause is continued dry, hard feed, and a limited supply of clean water.

Treatment.-Give a feed of bread and milk, warmed; a small quantity of fresh meat may be safely given, with a change of green food, as cabbage chopped fine; mashed boiled potatoes are also good. If this method be strictly followed a cure will be perfected in nearly every case.

\section{LIMED LEG}

Is first perceived by the whitish appearance of the legs, subsequently becoming sore; the scales enlarge and the toes crack open. Several methods of treatment are recommended, which we have tried with varying success; but advise the following as likely to work a cure as any method used: Wash the fowl with warm water and soap, after which wipe dry and grease with salt butter or lard, or fish oil. Another advised method is, wash the leg with kerosene oil and annoint with salt grease, or rub the parts affected with red precipitate ointment. The white legged varieties are more subject to this disease than others. 


\section{RHEUMATISM}

Arises frequently from confinement in a cold and damp place, without sufficient light or air. It is noticed by the stiffness of the limbs, unsteady gait, and evident pain caused by the slightest movement. The disease can be partially if not entirely removed by placing the fowl in a warm, dry place, and externally applying stimulants, rubbing the legs and thighs, A soft or opening feed will be of service. The large varieties appear to be more subject to this disease than others.

\section{RATTLES, OR ASTHMA.}

A complaint particularly prevalent among young fowls, and is occasioned by colds, or cold, damp weather The premonitory symptoms are a rattling sound in the throat, with a perceptible laboring for breath, occasioned by phlegm obstructing the air cells.

TREATMEnT.-Bathe the head in warm salted water; give a teaspoonful of vinegar each morning, also a dose of dry black pepper. The food should consist of bread and milk; a light physic may be given. A cure is sometimes effected by giving a teaspoonful of codliver oil during the first stages of the disease. Care should be taken to keep the fowl in warm quarters.

\section{FEVER}

Is of frequent occurrence among fowls that have been long confined, over fed, and not given a sufficient supply of water. Fighting also occasions it. Fever is easily cured, but when attending other diseases frequently proves fatal. Symptoms: The head is hot, eyes very red, etc.

Treatment.-Give a light physic, with a little nitre in the drinking water. With light food and change of air the fowl will soon recover.

\section{LOSS OF FEATHERS.}

The following remarks on this subject we take from Dr. Bennett's Poultry Book: "This disease, which is common to confined fowls, is by no means to be confounded with the natural process of moulting. 
In the annual healthy moult, the fall of the feathers is occasioned by the protrusion of new feathers from the skin. In the diseased state, which we now consider, where the feathers fall no new ones come to replace them, but the fowl is left bald and naked. A sort of roughness appears ako on the skin.

"Syмpтомs.-A falling off in appetite, moping and inactivity, the feathers starting and falling off until the naked skin appears.

"REMEDY. - This affection is supposed by some to be constitutional rather than local. External remedies, therefore, may not always be efficient. Stimulants applied externally may serve to assist the operation of what medicine may be given. Sulphur may be thus applied, mixed with lard. Cayenne and sulphur, in the proportion of one quarter each mixed with fresh butter, is good to be given internally, and will act as a powerful alterative. The diet should be changed, and cleanliness and fresh air are indispensable.

\section{EATING THEIR FEATHERS.}

On this subject the National Live Stock Journal for Decemher, 1871, has the following: "Eating each other's feathers is a habit fowls often contract when confined in yards, but is not, perhaps, fully understood. 'It is a morbid appetite,' says a writer in the Cultivator, 'apparently induced in the outset by the impatience of the fowls under confinement.' It is well known that fowls are very fond of blood, and when moulting the new feathers are generally called bloodshot; that is, the ends of the quills, when quite young, have a drop or so of blood, which induces the fowl to pluck for the blood contained in them; and we have known it to be kept up till some individuals of the flock, who were made special victims, were almost entirely denuded of their feathers, and sometimes have even had their entrails torn out."

\section{INFLAMMATION, OR SWELLING OF THE EYES,}

Is said to be a specific inflammation of the lining of the membrane of the air passages of the nose. The disease arises from exposure to cold and damp weather or constitutional delicacy. There is no regular treatment prescribed for this disease that we are aware of, but dry shelter, stimulating, peppered food and corn may be given with ad- 
vantage. Twice each day give one grain of sulphate of iron, three of Cayenne pepper and a desert spoonful of cod-liver oil mixed in their meal or feed. If the head of the bird feels feverish, bathe with warm salted water or warm milk and water two or three times a day.

\section{MELANCHOLY AND MOPING.}

When a fowl hangs its wings and looks droopingly immediate attention should be given. If he appears purged, give a teaspoonful of brandy with a few drops of camphor in a tablespoonfnl of warm water. keeping the fowl in a clean, warm place, giving him only soft food, If this treatment is followed the bird will soon recover, unless it has been too long neglected.

\section{APOPLEXY}

Occurs from over feeding and can seldom be treated in time. It is more troublesome among hens, which are found dead on their nests or under their roosts. If perceived in time lessen the quantity of food. Stimulating food should not be given to fowls subject to this disease. It is recommended that bleeding the fowl under the wing will possibly effect a cure.

\section{CORNS.}

The larger varieties of games are particularly subject to corns, which are occasioned by roosting high or by long confinement in coops. These will be found in the fleshy part of the foot, often causing lameness. To remove, cut around the hard substance forming the corn, and apply equal parts of sweet oil and turpentine. Frequently they can be removed with a knife. Keep the foot soft and all trouble on this account will cease.

\section{CARE OF WOUNDED FOWLS.}

When fowls are injured immediate attention should be given to prevent the fever which generally follows the injury. When the fowl has been badly pecked and torn, the head should be washed in bloodwarm water, using a soft sponge, carefully removing the blood; grease 
the parts affected with salt butter. Give butter rolled into a pill the size of a marble; this tends to remove the blood and feathers in the throat, and serves as a slight physic. For a few days only food of a soft nature should be given; also a small quantity of nitre should be placed in the drinking water. Where fowls, either old or young, have been badly injured in the pit the closest attention is necessary. If the injury occurs in the winter season, warm quarters must be provided to avoid taking cold. As a general thing fowls injured with the steels more readily recuperate than those torn with the naked spur. The day after fighting "give the fowl a feed of bread and milk, warmed. The blood and feathers in the throat and mouth should be removed, and a few drops of wine given as stimulant. If fever is prevented from making its appearance the fowl can cafely be placed on the walk in a few days. It is not advisable, however, to place the cock on his walk after battle, during cold weather, as he is liable to take more cold, which usually results in his death.

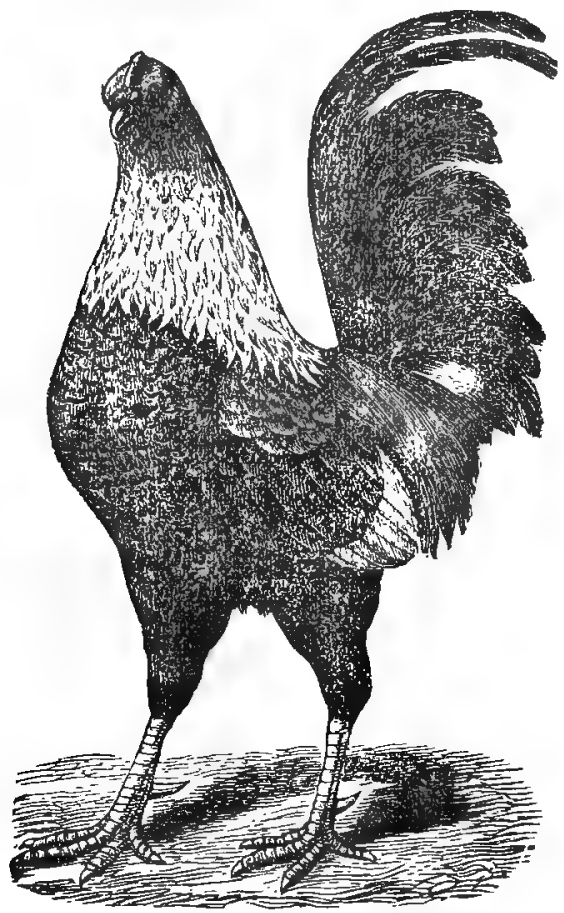

TARTAR GAME COCK. 


\section{THE STANDARD OF EXCELLENCE.}

Up to this point we have given a brief exposition of many subjects intimately connected with the breeding and management of Game Fowls, studiously avoiding everything: uninteresting to the cocker and fancier, yet evidently the Manual will hardly be complete if a briefspace were not devoted to those breeding standard or exhibition birds, and for their benefit we give the latest revised Standard of Excellence.

\section{BLACK-BREASTED RED GAMES.}

\section{DISQUALIKICATIONS.}

Color of legs or plumage not matching, when shown in pairs or trios; crooked backs; wry tails; malformeu breasts; duck-feet; adult cocks not dubbed, any artificial coloring; trimuning or plucking loul feathers.

\section{THE COCK.}

HEAD: Very rich, dark red, long, thin and tapering, and very strong at its junction with the neck. Beak, willow or dark horn-color, slightly curved, and strong at the base.

Comb, Wattles and Ear-lobes: Comb, in chickens that have not been dubbed, single, small and thin, low in front, serrated, erect and straight; mature birds to be neatly dubbed, and free from warty excrescences, small feathers, or ridges on the edges. Wattles, in chickens, brilliant red, very thin, and smooth in texture. Ear-lobes, rich red, small, and smooth in texture.

ExES : Large and prominent, bright, clear, deep bay, with a quick and fearless expression, and perfectly alike in color.

Neck: Rather long and nicely arched, the hackle being rich red, short and close, and free from black stripes. 
BACK : Rich, rark red, rather short, flat, broad across the shoulders, and narrowing to the tail ; the stern slender and neat, and the saddlefeathers very short and close, and, in color, rich red.

BREast AND BoDy: Breast, broad and full, and a rich black, free from any admixture of red, or any other color. Body, very firm and muscular, not soft or hollow on the sides, broadest at the shoulders and tapering towards the tail ; the under part rich, deep ulack.

Wings: Of medium length and powerful, the butts and shoulders slightly raised, as if for a sudden spring; the remainder not drooping but carried compactly against the sides, the points resting under the saddle feathers; the primaries bay on the outside web, and black on the inside web; the secondaries a rich, clear, bright bay on the outside web, and black on the inside web, with a rich metallic or greenish-black spot on the ends of the feathers; wing-butts, black; wingbows, rich, dark red, perfectly free from black feathers; wing-coverts, metallic or greenish-black, forming a wide bar across the wings, perfectly even and well defined, and not irregular on the edges.

TAIL: Rich black, of medium length, carried well together, and at a moderate elevation; sickle-feathers and tail-coverts a very rich metallic or greenish. black.

LEGS AND FEET: Thighs, black, rather long, round, stout, hard and firm, and placed well forward on the body. Shanks, in color, willow, olive, yellow, white or blue, rather long, bony, clean and strong, and standing well and evenly apart, the scales smooth and close, and the spurs set on low. Feet, broad, thin and flat; the toes long, straight and spreading, and well furnished with strong nails; the hind-toes set low on the feet, standing well backwards, and flat on the ground, and not merely touching with the points, or duck-footed.

HARDNass of Feather: Body-feathers, short, glossy, close, hard and firm; quills, very hard and strong.

\section{THE HEN.}

HEAD : Long, slender, tapering, very neat in appearance, and brown in color. Beak, horn-color, slightly curved, sharp at the point, and stout at the base.

Comb, Wattles and Ear-lobes: Comb, single, small and thin, low in front, evenly serrated, and perfectly erect and straight; in color, 
very bright red. Wattles, bright red, small, thin, and neatly rounded on the edges. Ear-lobes, bright red, very small and close to the face.

Eyes: Brilliant red or bay, large and prominent, with a quick and fearless expression, and exactly alike in color.

NECK: Long, the hackle a bright brownish-yellow, striped black, the feathers very short, giving the neck a slender and graceful appearance.

BACK: Brown, penciled with black, of moderate length, broad across the shoulders, flat, and narrowing to the tail.

BREAST AND BODY: Breast, broad, round and prominent, deep salmon-color, shading off to ashy-brown towards the thighs. Body, very firm and muscular, broadest at the shoulders, and tapering towards the tail, the general plumage a rich brown.

WINGS: Of medium length and powerful, the butts and shoulders carried somewhat high, making a flat back, the points not drooping, bat carried compactly against the sides; primaries and secondaries brown; wing-buws, shoulders and coverts brown, penciled with black, and perfectly free from red.

TAIL: Dark brown, approaching black, moderate in length, not carried over the back, but extending backwards at a slight elevation, the feathers not spread out, but held neatly together.

LeGs: Thighs, ashy-brown, stout and round, and the feathers short and close. Shanks, long, bony, clear and tapering, the scales narrow, smooth and close, and, in color, to match those of the cock when placed on exhibition. Feet, broad, flat and thin; toes, long, straight and spreading, and well furnished with strong nails, the hind-toes set low on the feet, standing well backwards, not duck-footed.

Hardness of Feather: Body-feathers, close, short hard and firm; quills, very hard and strong.

CARriage: Neat, upright, quick and active.

POINTS IN BLACK-BREASTED RED GAMES.

Symmetry,

Condition,

Station,
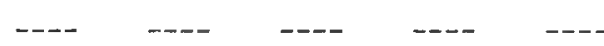

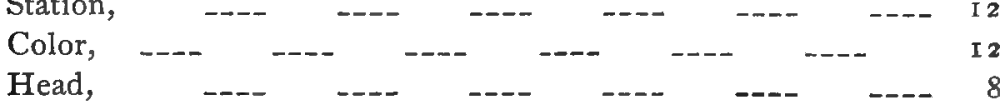

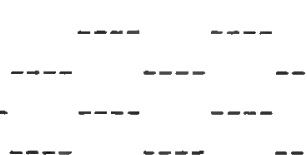

Comb, Wattles and Ear-lobes, Eyes,
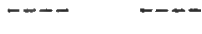


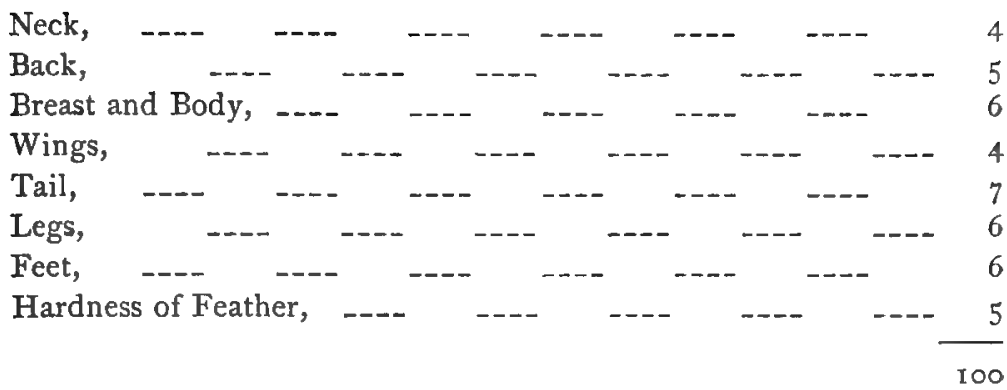

\section{BROWN-RED GAMES.}

\section{DISQ UALIFICATIONS.}

Color of legs or plumage not matching, when shown in pairs or trios; crooked backs; wry tails; malformed breasts; duck-feet; adult cocks not dubbed; any artificial coloring; trimming or plucking foul feathers.

\section{THE COCK.}

HEAD : Very dark red, long, thin and tapering, and very strong at its junction with the neck. Beak, nearly or quite black, slightly curved, and strong at the base.

Comb, Wattles and Ear-Lobes: Comb, in chickens that have not been dubbed, single, small and thin, low in front, serrated, erect and straight; mature birds to be neatly dubbed, and free from warty excrescences, small feathers, or ridges, on the edges. Wattles, in chickens, deep red or dark purple, very thin and smooth in texture. Earlobes, deep red or dark purple, small, thin, and smooth in texture.

Eyes: Dark brown or black, large, prominent and bright, with a quick and fearless expression, and perfectly alike in color.

Neck: Rather long and nicely arched, the hackle being short and close, and rich red in color, finely striped with black.

BReast AND Body: Breast, broad, full, round, and black in color, the shafts and margins of the feathers being reddish-brown, the color becoming darker as it approaches the thighs. Body, very firm and 
muscular, not soft or hollow on the sides, broadest at the shoulders and tapering towards the tail.

Wings: Of medium length and powerful, the butts and shoulders slightly raised, as if for a sudden spring; the remainder not drooping, but carried compactly against the sides, the points resting under the saddle-feathers; the primaries dusky-black; secondaries, black, with metallic lustre towards the ends of the feathers; wing-bows, dark crimson-red; wing-butts, black, or very dusky-brown; wing-coverts, rich, glossy black.

TAIL: Black, of medium length, carried well together, and at a moderate elevation; tail-coverts, rich, glossy black, and nicely curved.

LEGS: Thighs, dusky-black, rather long, round, stout, hard and firm, and pleced well forward on the body. Shanks, olive, dark willow or bronzy-black, rather long, bony, clean and strong, and standing well and evenly apart, the scales smooth and close, and the spurs set on low. Feet, broad, thin and flat; the toes long, straight and spreading, and well furnished with strong nails; the hind-toes set low on the feet, standing well backwards and flat on the ground, and not merely touching with the points, or duck-footed.

HARDNESS OF FEATHER: Body-feathers, short, hard and firm; quills, very hard and strong.

\section{THE HEN.}

HEAD : Dark, dusky-brown, approaching a dusky-black, long, slender, tapering, and very neat in appearance. Beak, black, or nearly so, slightly curved, sharp at the point and stout at the base.

Comb, Wattles and Ear-lobes: Comb, red or dark purple, single, small and thin, low in front, evenly serrated and perfectly erect and straight. Wattles, red or dark purple, small, thin and neatly rounded on the edges. Ear-lobes, red or dark purple, very small, and close to the face.

EyES. Dark brown or black, large, prominent and bright, with a quick, fiery expression, and perfectly alike in color.

NECK: Rich gold or bright lemon-color, striped with black, long feathers very short, giving the neck a slender and graceful appearance.

BACK: Very dark brown, approaching black, of moderate length, flat, broad across the shoulders, and narrowing to the tail. 
BREAST AND BODY: Breast, brilliant black, broad, round and prominent. Body, very firm and muscular, broadest at the shoulders, and tapering towards the tail.

Wings: Of medium length and powerful, the butts and shoulders carried somewhat high, so as to cause a flat back, the points not drooping, but carried compactly against the sides; primaries and secondaries, as well as wing-bows and coverts, brilliant black, duskyblack, or very dark brown.

TAIL: Black, moderate in length, not carried over the back, but extending backwards, the feathers not spread out, but held neatly together.

LEGS; Thighs, black, stout and round, and the feathers short and close. Shanks, long, bony, clean and tapering, the scales narrow, smooth and close, to match those of the cock when placed on exhibition. Feet, broad, flat and thin; toes, long, straight and spreading, well furnished with strong nails, the hind-toes set low on the feet, standing well backwards, and not duck-footed.

HaRdness of Feather: Body-feathers, close, short, hard and firm; quills, very hard and strong.

CARRIAGE : Neat, upright, quick and active.

POINTS IN BROWN-RED GAMES.

Symmetry,

Condition,

Station,

Color,
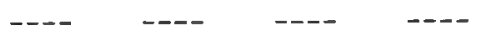

--1 2.-. 10

Head,

Comb, Wattles and Ear-lobes,

Eyes,

Neck,

Back,

Breast and Body,

Wings,
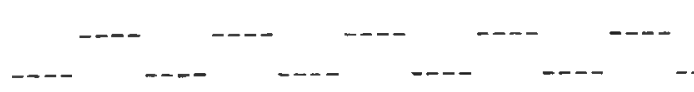

Tail,

Legs,

Feet,
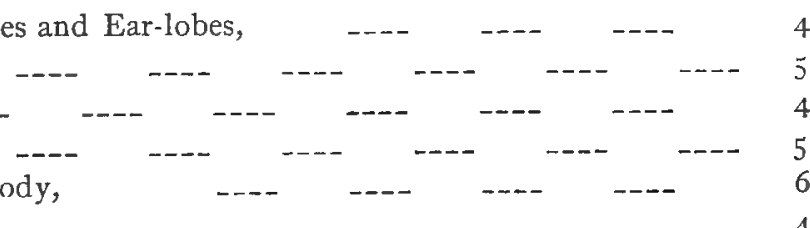

Hardness of Feather,

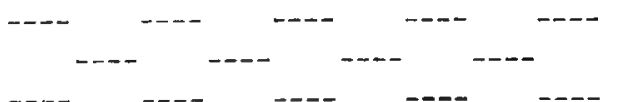




\section{GINGER-RED GAMES.}

\section{DISQUALIFICATIONS.}

Color of legs or plumage not matching, when shown in pairs or trios; crooked backs; wry tails; malformed breasts; duck-feet; adult cocks not dubbed; any artificial coloring; trimming or plucking foul feathers.

\section{THE COCK.}

HEAD: Red, long, thin and tapering, and very strong at its junction with the neck. Beak, olive or bronzy-black, slightly curved and strong at the base.

Comb, Wattles and Ear-lores: Comb, in chickens that have not been dubbed, single, small and thin, low in front, serrated, etect and straight; mature birds to be neatly dubbed, and free from warty excrescences, small feathers, or ridges on the edges. Wattles, red, very thin, and smooth in texture. Ear-lobes, red, small, thin, and smooth in texture.

Eyes: Brown or black, large, prominent and bright, with a quick and fearless expression, and perfectly alike in color.

NECK: Rather long and nicely arched, the hackle short and close, and a rich, clear red in color.

BACK: Rich red, rather short, flat, broad across the shoulders, and narrowing to the tail; the stern slender and neat, and the saddlefeathers very short and close, and a rich, clear red.

BREAST AND BoDY: Breast, in color, ginger-red, becoming darker towards the thighs, broad, round and full. Body, general plumage rich red, very firm and muscular, not soft or hollow on the sides, broadest at the shoulders and tapering to the tail.

Wings: Brownish-red, of medium length, and powerful, the butts and shoulders slightly raised, as if for a sudden spring; the remainder not drooping, but carried compactly against the sides, the points resting under the saddle feathers; primaries and secondaries, brownishred; wing-bows and shoulder-coverts, rich red.

TAIL: Black, of medium length, carried well together and at a moderate elevation; tail-coverts, rich black, the lesser coverts edged with red. 
LEGS: Thighs, dusky-red, rather long, round, stout, hard and firm, and placed well forward on the body. Shanks, olive, dark willow, or bronzy-black, rather long, bony, clean and strong, and standing well and evenly apart, the scales smooth and close, and the spurs set on low. Feet, broad, thin and flat; the toes long, straight and spreading, and well furnished with strong nails; the hind-toes set low on the feet, standing well backwards, and flat on the ground, and not merely touching with the points, or duck-footed.

HaRdness of FEathers: Body-feathers, short, hard and firm; quills, very hard and strong.

\section{THE HEN.}

HeAD: Yellowish-brown, long, slendering. tapering, and very neat in appearance. Beak, olive, or bronzy-black, slightly curved, sharp at the point and stout at the base.

Comb, Wattles and Ear-Lobes: Comb, purplish-red, single, small and thin, low in front, evenly serrated, and perfectly erect and straight. Wattles, dark-red, small, thin, and neatly rounded on the edges. Ear-lobes, dark-red, very small, and close to the face.

Eyes: Brown or black, large, prominent and bright, with a quick, fiery expression, and perfectly alike in color.

NECK: Golden-yellow, striped with black, long, the feathers very short, giving the neck a slender and graceful appearance.

BACK: Yellowish-brown, of moderate length, flat, broad across the shoulders, and narrowing to the tail.

BREAST AND BODY: Breast, broad, round and prominent, the higher part, near the throat, a yellowish-brown; the shafts, and a narrow margin of feathers, of a much lighter shade; the lower part and sides a dusky-brown, with a narrow margin of a golden-ginger shade. Body, very firm and muscular, broadest at the shoulders, and tapering to the tail ; the general color of the plumage a yellowish-brown.

WINGS: Of medium length and powerful, the butts and shoulders carried somewhat high, so as to cause a flat back, the points not drooping, but carried compactly against the sides; the primaries and secondaries, dark brown or black; wing-coverts, yellowish-brown.

TAIL: Black, moderate in length, not carried over the back, but extending backwards, the feathers not spread out, held neatly together. 
LEGS: Thighs, dusky-brown, stout and round, and the feathers short and close. Shanks, olive, dark willow or bronzy-black, long, clean, bony and tapering, the scales narrow, smooth and close, to match those of the cock when shown in pairs or trios. Feet, broad, flat and

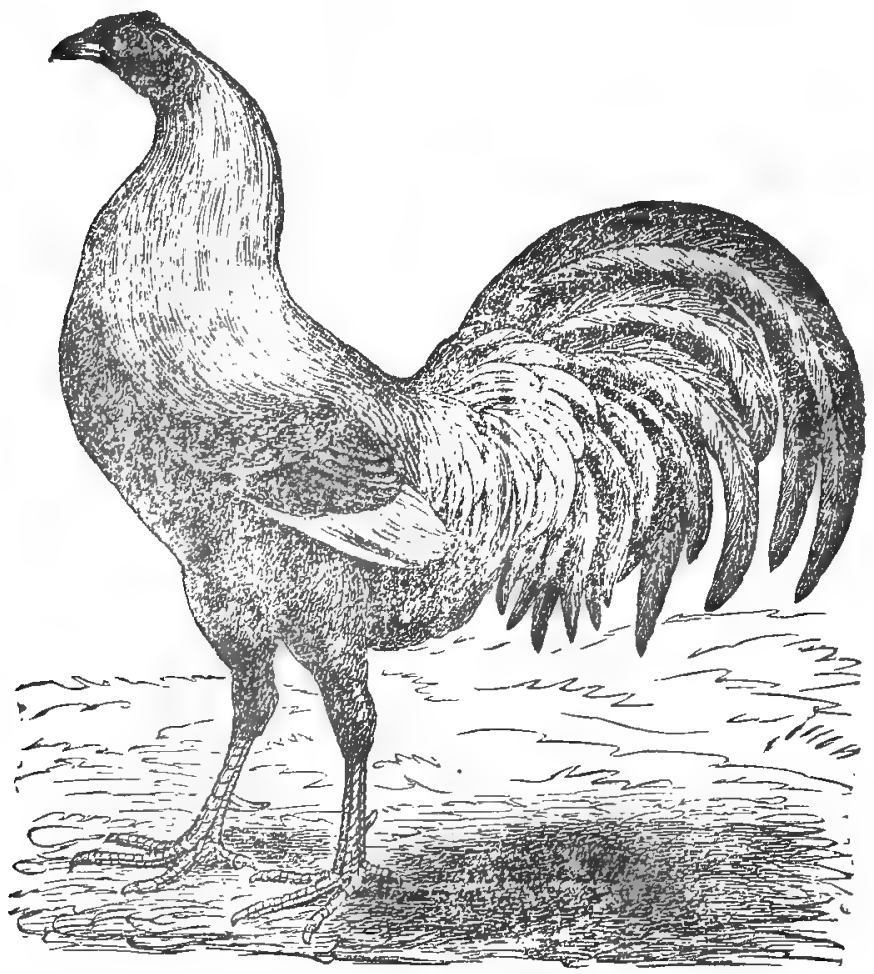

PIT FOWL.

thin; toes, long straight and spreading, well furnished with strong nails; the hind-toes set low on the feet, standing well backwards, and not duck-footed.

HaRdness of Feather: Body-feathers, close short, hard and firm; quills, very hard and strong.

CARriage; Neat, upright, quick and active. 
POINTS IN GINGER-RED GAMES.

Symmetry,

Condition,

Station,

Color,

Head,

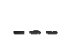

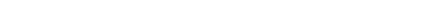

Comb, Wattles and Ear-lobes,

Eyes,

Neck,

Back,

Wings,

Tail,

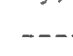

Legs,

Feet,

Hardness of Feather
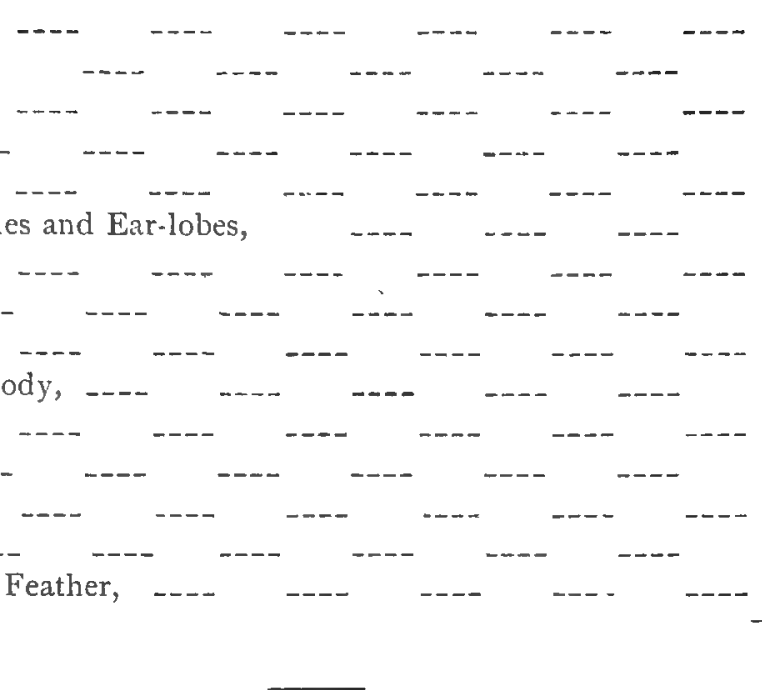

IO

\section{YELLOW DUCKWING GAMES.}

\section{DISUUALTFICATIONA:}

Adult cocks not dubbed; color of legs or plumage not matching, when shown in pairs or trio:; crooked baclis; wry tails; malformed hreasts; duck-feet; any artificial coloring; trimming or plucking foul feathers.

\section{THE COCK.}

Head: Straw-color or yellow, long thin and tapering, and rery strong at its junction with the neck. Beak, willow, olive or blue, slightly curved, and strong at the base.

Conb, Wattles and Ear-loees: Ccmb, bright red in chickens that have not been dubbed, single. small, and thin, low in front, serrated, erect and straight; mature birds to be neatly dubbed, and free from warty excrescences, small feathers or ridges on the edges. Wat- 
tles, brilliant red, very thin, and smooth in texture. Ear-lobes, brilliant, red, small, thin, and smooth in texture.

Eves; Red, or deep bay, large, prominent and bright, with a quick and fearless expression, and perfectly alike in color.

NECK : Rather long and nicely arched, the hackle a clear strawcolor, free from black stripes.

BACK : Rather short, flat, broad across the shoulders, and narrowing to the tail, the plumage a rich, uniform, bright copper or maroon, the more even, clear and unmixed in color the better; the stern slender and neat, and the saddle-feathers very short and close, and of straw color.

Breast and Body: Breast, rich black, broad, full and round. Body, very firm and muscular, not soft or hollow on the sides, broadest at the shoulders, and tapering to the tail ; the under part of the body a rich black.

Wings: Of medium length and powerful, the butts and shoulders slightly taised, as if for a sudden spring ; the remainder not drooping, but carried compactly against the sides, the points resting under the saddle feathers; primaries straw-white on the outside web, dark on the inside web; the secondaries white on the outside web, dark on the inside, and also at the ends of the feathers; wing-butts, black; wingcovests, steel blue or metallic black, forming a wide bar across the wings.

TALL Black, of medium length, carried well together, and at a moderate elevation; sickle feathers and tail-coverts a rich metallic or greenish-black.

LEGS. Thighs, rich black, rather long, round, stout, hard and firm, and placed well forward on the body. Shanks, willow, olive, yellow or blue, rather long, clean, bony and strong, and standing well and evenly apart; the scales smooth and close, and the spurs set on low. Feet, broad, thin and flat; the toes long, straight and spreading, and well furnished with strong nails; the hind-toes set low on the feet, standing well backwards, and flat on the gsound, and not merely touching with the points, or duck-footed,

Hardness of Feather: B Jdy-feathers, short, hard and firm; quilis, very hard and strong. 


\section{THE HEN.}

Head: Gray, long, slender, tapering and very neat in appearance. Beak, willow, olive or blue, slightly curved, sharp at the point and stout at the base.

Comb, WatTles and Ear-Lobes: Comb, bright red, single, small and thin, low in front, evenly serrated, and perfectly erect and straight. Wattles, bright red, small, thin, and neatly rounded on the edges. Ear-lobes, bright red, very small and close to the face.

Eyes: Red or deep bay, large, prominent and bright, with a quick and fiery expression, and perfectly alike in color.

NECK: White, striped with black, long, the feathers very short, giving the neck a slender and graceful appearance.

BACK: Bluish or slaty-gray, the shafts of feathers white, of moderate length, flat, broad across the shoulders, and narrowing to the tail.

Breast AND BoDy: Breast, salmon-red, shading off to ashy-gray toward the thighs, broad, round and prominent. Body, very firm and muscular, broadest at the shoulders and tapering to the tail.

WINGS: Of medium length and powerful, the butts and shoulders carried somewhat high, so as to cause a flat back, the points not drooping but carried compactly against the sides; primaries and secondaries a slaty or bluish-gray; wing-bows and wing-coverts a slaty or bluish-gray, the shafts of the feathers being white; red or brown on the wings very objectionable.

TAIL: Dark gray, the inside approaching black, moderate in length, not carried over the back, but extending backwards, the feathers not spread out, but held neatly together.

LEGS: Thighs, ashy-gray, stout and round, and the feathers short and close. Shanks, long, bony, clean and tapering, the scales narrow, smooth and close, and to match the cock in color when placed on exhibition. Feet, broad, flat and thin; toes, long, straight and spreading, well furnished with strong nails; the hind-toes set low on the feet, standing well backwards, and not duck-footed.

Hardness of Feather: Body-feathers, close, short, hard and firm; quills, very hard and strong.

CARRIAGE : Neat, upright, quick and active.

Symmetry,

POINTS IN YELLOW DUCKWING GAMES.

Condition,
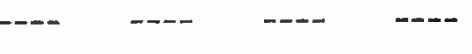


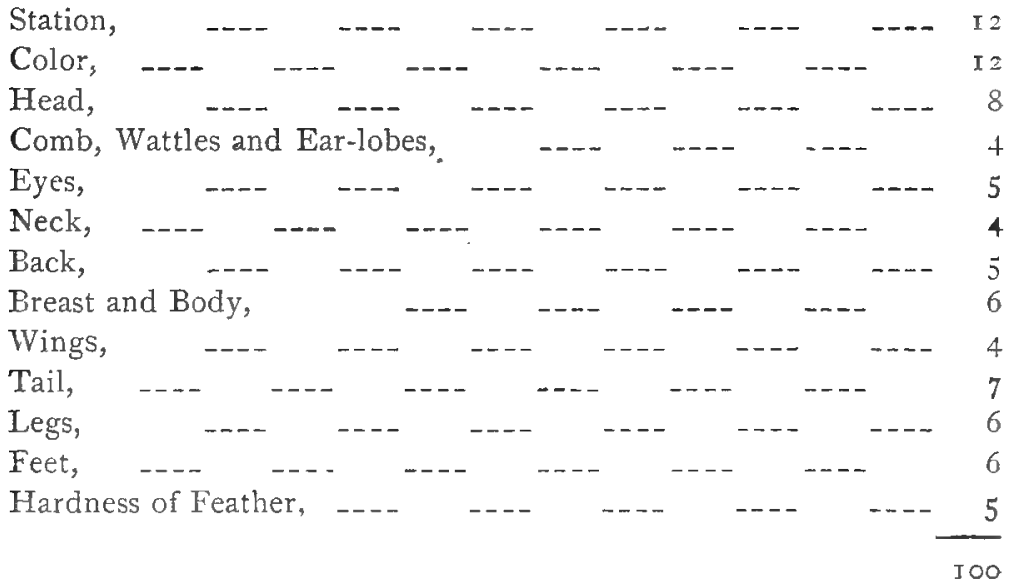

\section{SILVER DUCKWING GAMES.}

DISQUALIFICATIONS.

Adult cocks not dubbed, color of legs or plunage not matching, when shown in pairs or trios; crooked backs; wry tails; malformeu breasts; cluck-feet; any artificial coloring; trimminer or plucking foul feathers.

\section{THE COCK.}

HEAD: Silvery-white, long, thin and tapering, and very strong at its junction with the neck. Beak, olive or yellow, slightly curved, and strong at the base.

Conis, Wattles and EAR-Lobes: Comb, bright red in chickens that have not been dubbed, single, small and thin, low in front, serrated, erect and straight; mature birds to be neatly dubbed, and free from warty excrescences, small feathers, or ridges on the edges. Wattles, bright red, very thin, and smooth in texture. Ear-lobes, bright red, small, thin and smooth in texture.

Eyes: Red or deep bay, large, prominent and bright, with a quick and fearless expression, and perfectly alike in color. 
NECK : Rather long and nicely arched, hackle short and close, clear white, without any mixture of black or any other color.

BACK: Silvery-white, rather short, flat, broad across the shoulders, and narrowing to the tail; the stern slender and neat, and the saddlefeathers a clear white, and very short and close.

Breast and Bony: Breast, black, broad, full and round. Body, very firm and muscular, not soft or hollow on the sides, broadest at the shoulders and tapering towards the tail; the under part of the body black.

Wings: Of medium length and powerful, the butts and shoulders slightly raised, as if for a sudden spring; the remainder not drooping but carried compactly against the sides, the points resting under the saddle feathers; the primaries white on the outside web, and dark on the inside web; the secondaries a clear white on the outside web, black on the inside web and on the ends of the feathers; wing-bows, silvery-white.wing-butts, black, and wing-coverts, a steel-blue, forming wide bars across the wings.

TAIL: Black, of medium length, carried well together, and at a moderate elevation; tail-coverts, a metallic or greenish.black, and nicely curved.

LEGS AND FEET: Thighs, black, rather long, round, stout, hard and firm, and placed well forward on the body. Shanks, willow, olive, bronze or blue, rather long, bony, clean and strong, and standing well and evenly apart, the scales smooth and close, and the spurs set on low. Feet, broad, thin and flat; the toes long, straight and spreading, and well furnished with strong nails; the hind toes set low on the feet, standing well backwards, and flat on the ground, and not merely touching with the points, or duck-footed.

HARDNESS OF FEATHER: Body-feathers, short, hard and firm; quills, very hard and strong.

\section{THE HEN.}

HEAD : Silvery-gray, long, slender, tapering, very neat in appearance. Beak, willow or bronze, slightly curved, sharp at the point, and stout at the base.

Come, Wattles and Ear-loees: Comb, single, small and thin, low in front, evenly serrated, and perfectly erect and straight. Wattles, 
bright red, small, thin, and neatly rounded on the edges. Ear-lobes, bright red, very small and close to the face.

Eyes: Red or deep bay, large, prominent and bright, with a quick, fiery expression, and perfectly alike in color.

NECK: Silvery-white, striped black, long, the feathers very short, giving the neck a slender and graceful appearance.

BACK : Silvery or ashy-gray, the shatts of feathers white, flat, of moderate length, broad across the shoulders, and narrowing to the tail.

BREAST AND BODY: Breast, salmon, broad, round and prominent, Body, very firm and muscular, broadest at the shoulders, and tapering to the tail.

Wings: Of medium length and powerful, the butts and shoulders carried somewhat high, so as to cause a flat back, the points not drooping, but carried compactly against the sides; the primaries, secondaries and wing-coverts gray; wing-buws, ashy-gray, the shafts of feathers white; red or brown on the wings very objectionable.

TAJL: Dark gray, approaching black, moderate in length, not carried over the back, but extending backwards, the feathers not spread out, but held neatly together.

LEGS: Thighs, ashy-brown, stout and round, and the feathers short and close. Shanks, long, bony, clear and tapering, the scales narrow, smooth and close, and, in color, to match those of the cock when placed on exhibition. Feet, broad, flat and thin; toes, long, straight and spreading, and well furnished with strong nails, the hind-toes set low on the feet, standing well backwards, and not duck-footed.

HaRdness of FEATHer: Body-feathers, close, short hard and firm ; quills, very hard and strong.

CARRIAGE: Neat, upright, quick and active.

POINTS IN SILVER DUOIFWING GAMES.

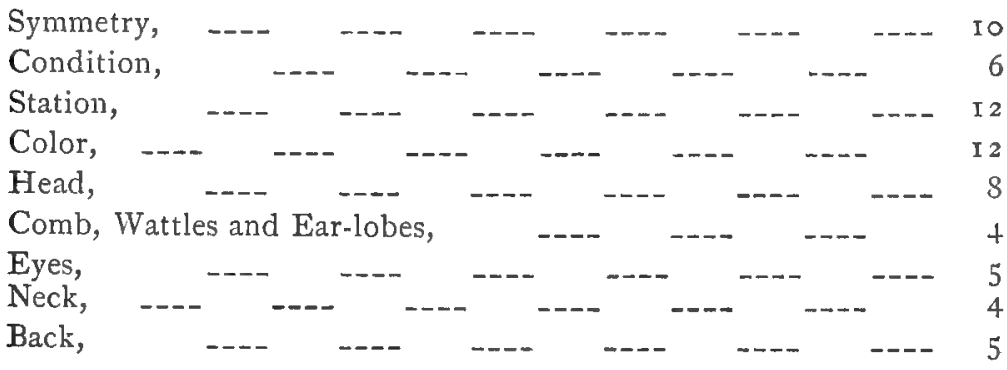




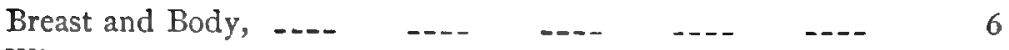

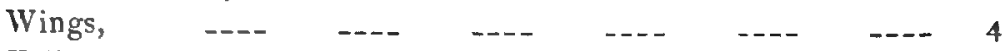

Tail, -.-- -..- -.-- -..

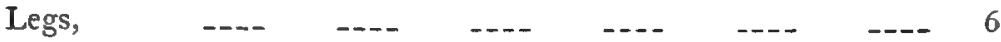

Feet, --- -.-- ---- -.-

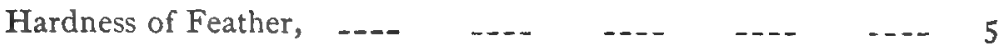

RED PILE GAMES.

DISQ TALIFICATIONS.

Adult cocks not dubbed; color of legs or plumage not matching, when shown in pairs or trios; crooked backs; wrs tails; malformed breasts; dnck-feet; artificial coloring; trimming or plucking foul feathers.

\section{THE COCK.}

HEAD: Deep chestuut red, long, thin and tapering, and very strong at its junction with the neck. Beak, slightly curved, and strong at the base.

Comb, Wattles axd Ear-lobes: Comb, rich, bright red, in chickens that have not been dubbed, small, single and thin, low in front, serrated, erect and straight; mature birds to be neatly dubbed, and free from warty excrescences, small feathers, or ridges, on the edges. Wattles, red, very thin and smooth in texture. Ear-lobes, red small, thin, and smooth in texture.

EYES: Red or brown, large, prominent and bright, with a quick and fearless expression, and perfectly alike in color.

NECK: Rather long and nicely arched, the hackle light chestnutred.

BAck: Uniform rich red, rather short, flat, broad across the shoulders and narrowing to the tail; the stern slender and neat, and the saddle-feathers light chestnut-red, and very short and close.

BREAST AND BODY: Breast, white, slightly penciled with chestnutred, broad, full, and round. Body, very firm and muscular, not soft 
or hollow on the sides, broaclest at the shoulders and tapering to the tail.

Wings: Of medium length and powerful, the butts and shoulders slightly raised, as if for a sudden spring; the remainder not drooping, but carried compactly against the sides, the points resting under the saddle-feathers; primaries white; secondaries, red on the outside web, and white on the inside web, with a white spot on the end of each feather; wing-bows, uniform rich red; wing-coverts, white, edged with red.

TAIL: White, of medium length, carried well together, and at a moderate elevation; sickle-feathers white and handsomely curved.

LEGS: Thighs, white, rather long, round, stout, hard and firm, and placed well forward on the body. Shanks, willow, yellow or white, rather long, bony, clean and strong, and standing well and evenly apart, the scales smooth and close, and the spurs set on low. Feet, broad, thin and flat; the toes long, straight and spreading, and well furnished with strong nails; the hind-toes set low on the feet, standing well backwards and flat on the ground, and not merely touching with the points, or duck-footed.

HaRdness of FEather: Body-feathers, short, hard and firm; quills, very hard and strong.

\section{THE HEX.}

HEAD: Long, slender, tapering, and very neat in appearance. Beak, willow or yellow, slightly curved, sharp at the point and stout at the base.

Сомв, WatTles and Ear-lobes: Comb, bright red, single, small and thin, low in front, evenly serrated and perfectly erect and straight. Wattles, bright red, small, thin and neatly rounded on the edges. Earlobes, bright red, very small, and close to the face.

Eves. Red or brown, large, prominent and bright, with a quick and fiery expression, and perfectly alike in color.

Neck: Long, the feathers very short, giving the neck a slender and graceful appearance; the hackle a light chestnut, with white in the center of the feathers.

BACK: Of moderate length, flat, broad across the shoulders, and narrowing to the tail. 
BREAST AND Boly: : Breast, broad, round, prominent and chest. mut-red on the front part, and mottled, shading to white on the lower part. Body, very muscular and firm, broadest at the shoulders, and tapering to the tail.

Wincs: White, slightly penciled with light chestnut-red, of medinm length and powerful, the butts and shoulders carried somewhat high, so as to cause a flat back, the points not drooping, but carried compactly against the sides; primaries and secondaries, white.

TAIL: White, moderate in length, not carried over the back, but extending backwards, the feathers not spread out, but held neatly together.

LEcis; Thighs, white, stout and round, and the feathers short and close. Shanks, long, bony, clean and tapering, the scales narrow, smooth and close, to match those of the cock when placed on exhibition. Feet, broad, flat and thin; toes, long, straight and spreading, well furnished with strong nails, the hind-toes set low on the feet, standing well backwards, and not duck-footed.

HARDNESS OF FEATHER: Body-feathers, close, short, hard and firm; quills, very hard and strong.

Carriage: Neat, upright, quick and active.

POINTA IN RED PILE GAMES.

symmetry,

Condition,

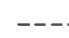

Station,

Color,
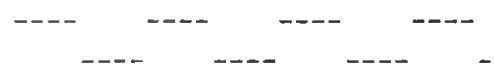

$---\quad---\quad$ IO

Head,
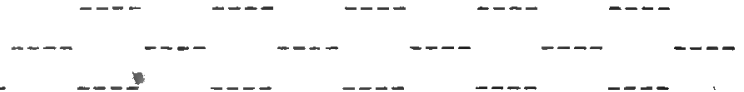

Comb, Wattles and Ear-lobes,

Eyes,

Neck,

Back,

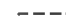

Breast and Body,

Wings,

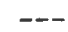

Tail,

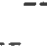

Legs,

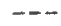

$--$
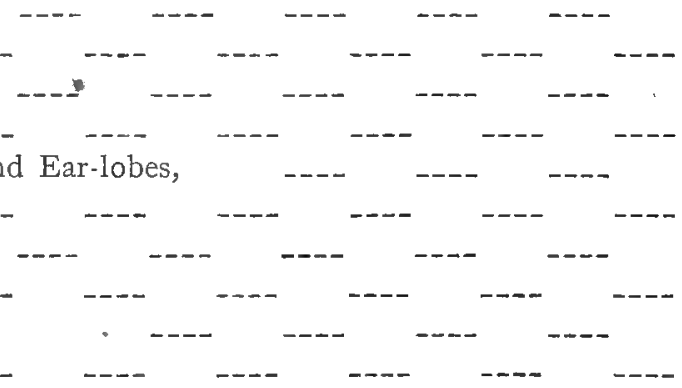

I 2 I 2

Feet,
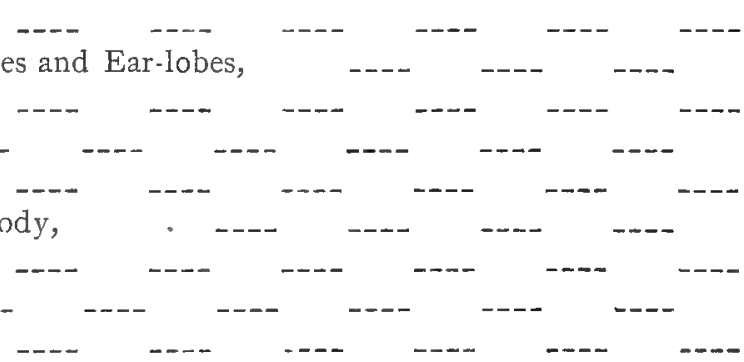

8

Hardness of Feather,
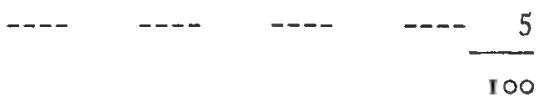


\section{WHITE PILE GAMES.}

\section{DISQUALIFICATIONS.}

Adult cocks not dubbed; color of legs or plimage not matching, when shown in pairs or trios; crooked backs; wry tails; malformed breastz; duck-feet; artificial coloring; trimming or plucking foul feathers.

\section{THE COCK.}

HEAD : Long, thin and tapering, and very strong at its junction with the neck. Beak, yellow, willow or white, slightly curved and strong at the base.

Comb, Wattles AND EAR-LOBEs: Comb, rich, bright red, in chickens that have not been dubbed, single, small and thin, low in front, serrated, erect and straight; mature birds to be neatly dubbed, and free from warty excrescences, small feathers, or ridges on the edges. Wattles, red, very thin, and smooth in texture. Ear-lobes, red, small, thin, and smooth in texture.

Eyes: Red, large, prominent and bright, with a quick and fearless expression, and perfectly alike in color.

NECK: Rather long and nicely arched, the hackle mainly white, and with but faint penciling.

BACK: Rather short, flat, broad across the shoulders, and narrowing to the tail, in color light red; the stern slender and neat, and the saddle-feathers short and close, mainly white, and with but slight penciling.

Breast and Body: Breast, white, broad, full and round. Body, very firm and muscular, not soft or hollow on the sides, broadest at the shoulders and tapering to the tail.

WINGS: Of medium length, and powerful, the butts and shoulders slightly raised, as if for a sudden spring; the remainder not drooping, but carried compactly against the sides, the points resting under the saddle feathers; primaries and secondaries, white; wing-coverts, a rich, bright red, or orange and port-wine color combined.

TAIL: Pure white, of medium length, carried well together and at a moderate elevation; sickle-feathers and tail-coverts white and handsomely curved. 
LEGS: Thighs, white, rather long, round, stout, hard and firm, and placed well forward on the body. Shanks, willow, yellow or white, and the colors preferred in the ordor in which they are named, rather long, bony, clean and strong, and standing well and evenly apart, the scales smooth and close, and the spurs set on low. Feet, broad, thin and flat; the toes long, straight and spreading, and well furnished with strong nails; the hind-toes set low on the feet, standing well backwards, and flat on the ground, and not merely touching with the points, or duck-footed.

HARDNeSS OF FEATHers: Body-feathers, short, hard and firm; quills, very hard and strong.

\section{THE HEN.}

HEAD : Long, slendering, tapering, and very neat in appearance. Beak, yellow, willow or white, in color, slightly curved, sharp at the point and stout at the base.

Comb, Wattles and Ear-lobes: Comb, bright red, single, small and thin, low in front, evenly serrated, and perfectly erect and straight. Wattles, bright red, small, thin, and neatly rounded on the edges. Ear-lobes, bright red, very small, and close to the face.

Eves: red, large, prominent and bright, with a quick, fiery expression, and perfectly alike in color.

NECK : White, long, the feathers very short, giving the neck a slender and graceful appearance.

BACK: Of moderate length, flat, broad across the shoulders, and narrowing to the tail; in color white.

Breast And BoDy: Breast, distinct chestnut-color, broad, round and prominent. Body, very firm and muscular, broadest at the shoulders, and tapering to the tail.

Wings: Of medium length and powerful, the butts and shoulders carried somewhat high, so as to cause a flat back, the points not drooping, but carried compactly against the sides; the primaries and secondaries white.

TAIL: Pure white, moderate in length, not carried over the back, but extending backwards, the feathers not spread out, held neatly together.

Legs: Thighs, white, stout and round, and the feathers short and close. Shanks, long, bony, clean and tapering, the scales narrow, 
smooth and close, and to match the cock's in color when placed on exhibition. Feet, broad, flat and thin; toes, long straight and spreading, well furnished with strong nails; the hind-toes set low on the feet, standing well backwards, and not duck-footed.

Hardness of FEATHER: Body-feathers, close short, hard and firm; quills, very hard and strong.

Carriage ; Neat, upright, quick and active.

POINTS IN WHITE PILE GAMES.

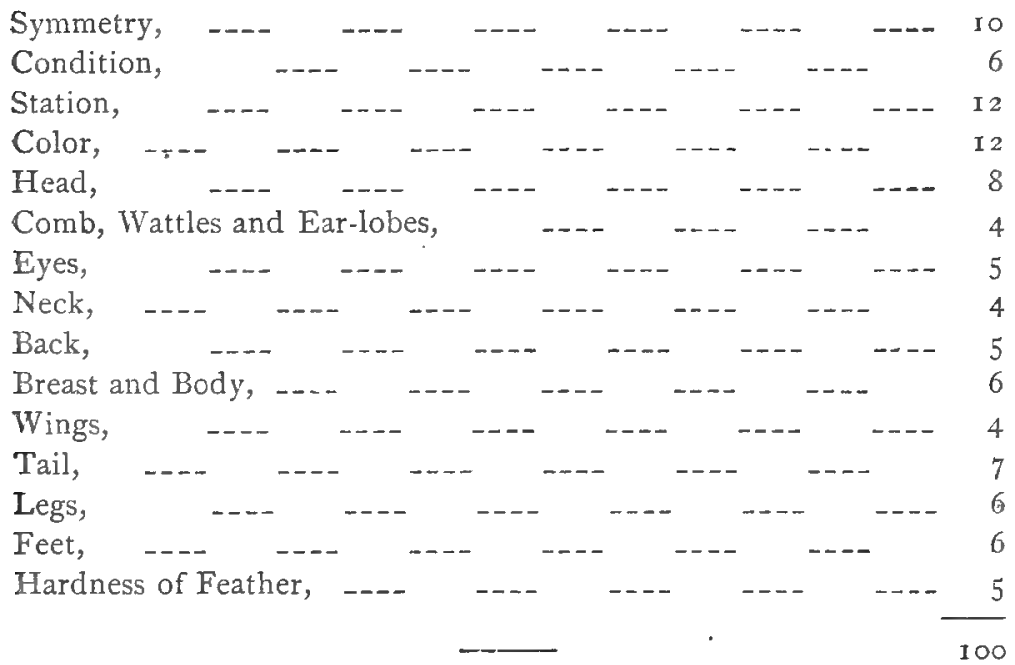

\section{WHITE GAMES.}

\section{DISQUALIFICATIONS.}

Adult cocks not dubbed; color of legs or plumage not matcbing, when shown in pairs or trios; crooked backs; wry tails; malformed breasts; duck-feet; trimming or plucking foul feathers.

\section{THE COCK.}

HEAD: A pure white, long, thin and tapering, and very strong at its junction with the neck. Beak, yellow or white, slightly curved, and strong at the base. 
Comb, Wattles and Ear-lobes: Comb, bright red, in chickens that have not been dubbed, single, small and thin, low in front, serrated, erect and straight; mature birds to be neatly dubbed, and tree from warty excrescences, small feathers, or ridges on the edges. Wattles, bright red, very thin, and smooth in texture. Ear-lobes, bright red, small, thin, and smooth in texture.

Eves: Red, large, prominent and bright, with a quick and fearless expression, and perfectly alike in color.

NECK: Rather long and nicely arched; the hackle short and close, pure white, and free from any tinge of yellow.

BACK : Rather short, flat, broad across the shoulders, and narrowing to the tail; the stern slender and neat, and the saddle-feathers very short and close, pure white, and free from yellow tinge.

BREAST AND BODY: Breast, pure white, broad, full and round. Body, very firm and muscular, not soft or hollow on the sides, broadest at the shoulders and tapering to the tail, and, in plumage, clear, pure white.

Wirgs: Of medium length and powerful, the butts and shoulders slightly raised, as if for a sudden spring; the remainder not drooping, but earried compactly against the sides, the points resting under the saddle-feathers; primaries, secondaries and wing-coverts pure white, free from yellowish tinge.

TAIL: Of medium length, carried well together, and at a moderate elevation; sickle-feathers and tail coverts pure, clear white, and handsomely curved.

LEGS: Thighs, rather long, round, stout, hard and firm, and placed well forward on the body. Shanks, yellow or white, rather long, bony, clean and strong, and standing well and evenly apart; the scales smooth and close, and the spurs set on low. Feet, broad, thin and flat; the toes long, straight and spreading, and well furnished with strong nails; the hind-toes set low on the feet, standing well backwards and flat on the ground, and not merely touching with the points, or duck-footed.

Hardness of Feather: Body-feathers, short, hard and firm; quills, very hard and strong. 


\section{THE HEN.}

HEAD: Long, slender, tapering, and very neat in appearance. . Beak, yellow or white, slightly curved, sharp at the point, and stout at the base.

Comb, Wattles and Ear-lobess; Comb, single, small and thin, low in front, evenly serrated, and perfectly erect and straight. Wattles, bright red, small, thin, and neatly rounded on the edges. Earlobes, bright red, very small and close to the face.

Eyes: Large, prominent and bright, with a quick, fiery expression, and perfectly alike in color.

NECK : Long, the feathers very short, giving the neck a slender and graceful appearance, the hackle clear white.

BACK: Of moderate length, flat, broad across the shoulders, and narrowing to the tail.

Breast AND Body: Breast, broad, round and prominent. Body, very muscular and firm, broadest at the shoulders, and tapering to the tail, and in plumage a clear, pure white throughout.

Wings: Of medium length and powerful, the butts and shoulders carried somewhat high, so as to cause a flat back, the points not drooping, but carried compactly against the sides; primaries secondaries and coverts all pure white.

TAlL: Clear white, moderate in length, not carried over the back, but extending backwards, the feathers not spread out, but held neatly together.

LEGS: Thighs, stout and round, and the feathers short and close. Shanks: yellow or white, long, bony, clean and tapering, the scales narrow, smooth and close, and to match the cock's in color when placed on exhibition. Feet, broad, flat and thin; toes, long, straight and spreading, and well furnished with strong nails; the hind-toes set low on the feet, standing well backwards, and not duck-footed.

Hardness of Feather: Body-feathers, close, short, hard and firm; quills, very hard and strong.

Carriage; Neat, upright, quick and active.

POINTS IX WHITE GAMES.

Symmetry,

Condition,

Station,
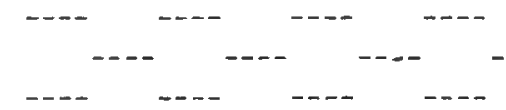


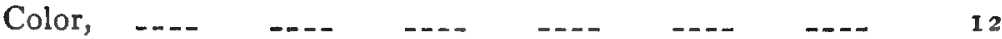

Head, -.- -

Comb, Wattles and Ear-lobes,

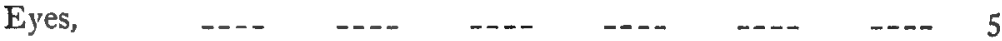

Neck, _..

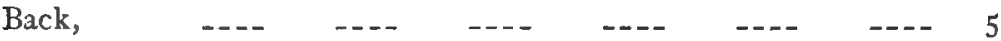

Breast and Body, ... _... _..

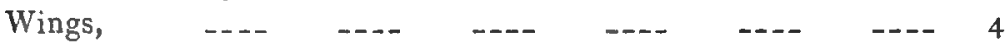

Tail, -.. $\ldots+\ldots-\ldots 7$

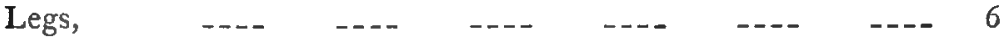

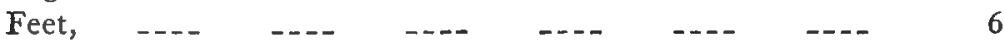

Hardness of Feather, _.. $\ldots \ldots \ldots \ldots$

100

\section{BLACK GAMES.}

\section{DISQUALIFICATIONS.}

Adult cocks not dubbed; color of legs or plumage not matching, when shown in pairs or trios; crooked backs; wry tails; malformed breasts; duci-feet; any artifi. cial coloring; trimming or plucktng foul feathers.

\section{THE COCK.}

HEAD: Rich, deep black, long, thin and tapering, and very strong at its junction with the neck. Beak, olive or bronzy-black, slightly curved, and strong at the base.

Comb, Wattles and EaR-Lobes: Comb, in chickens that have not been dubbed, bright red, single, small and thin, low in front, serrated, erect and straight; mature birds to be neatly dubbed, and free from warty excrescences, small feathers, or ridges on the edges. Wattles, bright red, very thin, and smooth in texture. Ear-lobes, bright red, small, thin, and smooth in texture.

Eyes: Black or brown, large, prominent and bright, with a quick and fearless expression, and perfectly alike in color. 
NECK: Rather long and nicely arched; the hackle short and close; and rich metallic black in color.

BACK: Rather short, flat, broad across the shoulders, and narrowing to the tail; the stern slender and neat, the saddle-feathers very short and close, and a rich, lustrous black.

BREAST AND BoDy: Breast, deep black, broad and full. Body, very firm and muscular, not soft or hollow on the sides, broadest at the shoulders, and tapering to the tail; plumage throughout a rich, deep black.

Wings: Of medium length and powerful, the butts and shoulders shghtly raised, as if for a sudden spring; the remainder not drooping, but carried compactly against the sides, the points resting under the saddle-feathers.

TAIL: Of medium length, carried well together and at a moderate elevation; sickle-feathers and tail-coverts a rich, glossy, or metallic black.

LEGs: Thighs, deep black, rather long, round, stout, hard and firm, and placed well forward on the body. Shanks, dark olive, leaden-black, or bronzy-black, rather long, bony, clean and strong, and standing well and evenly apart, the scales smooth and close, and the spurs set on low. Feet, broad, thin and flat; the toes long, straight and spreading, and well furnished with strong nails; the hind. toes set low on the feet, standing well backwards, and flat on the ground, and not merely touching with the points, or duck-footed.

HaRdness of FEATHER: Body-feathers, short, hard and firm; quills, very hard and strong.

\section{THE HEX.}

HEAD: Long, slender, tapering, and very neat in appearance. Beak, dark olive or bronzy-black, slightly curved, sharp at the point and stout at the base.

Comb, Wattles and Ear-lobes: Comb, single, small and thin, low in front, evenly serrated, and perfectly erect and straight. Wattles, bright red, small, thin, and neatly rounded on the edges. Earlobes, bright red, very small and close- to the face.

ErES: Black or brown, large, prominent and bright, with a quick, fiery expression, and perfectly alike in color. 
NEck: Long, the feathers very short, giving the neck a slender and graceful appearance.

BACK: Of moderate length, flat, broad across the shoulders, and narrowing to the tail, and, in color, a rich, lustrous black.

BREAST AND BODY: Breast, broad, round and prominent. Body, very firm and muscular, broadest at the shoulders and tapering to the tail, and the plumage throughout a rich, glossy black.

Wings: Of medium length and powerful, the butts and shoulders carried somewhat high, so as to cause a flat back, the points not drooping but carried compactly against the sides; primaries and secondaries, deep black; wing-coverts a rich, glossy black.

TAIL: Moderate in length, not carried over the back, but extending backwards, the feathers not spread out, but held neatly together, and a pure, deep black in color.

LEGS: Thighs, stout and round, and the feathers short and close. Shanks, dark olive or leaden black, long, bony, clean and tapering, the scales narrow, smooth and close, and to match the cock in color when placed on exhibition. Feet, broad, flat and thin; toes, long, straight and spreading, well furnished with strong nails; the hindtoes set low on the feet, standing well backwards, and not duck-footed.

HaRdNess of FEather: Body-feathers, close, short, hard and firm; quills, very hard and strong.

Carriage: Neat, upright, quick and active.

POINTS IN BLACK GAMES.

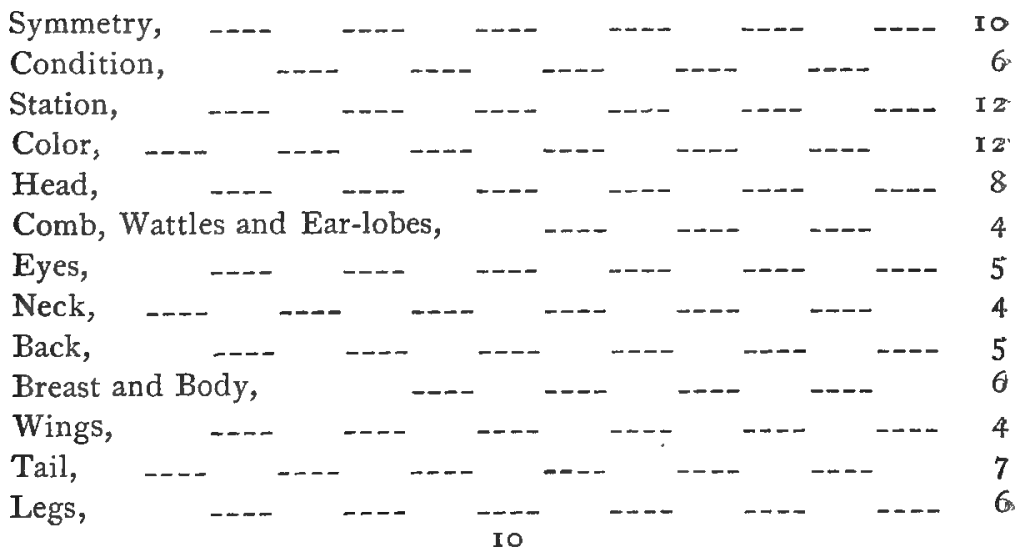




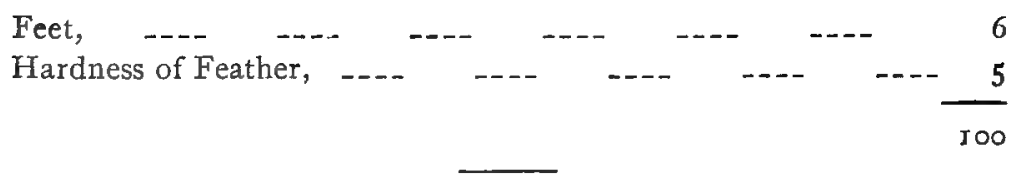

BLUE GAIMES.

DISQUALIFICATIONS.

Adult cocks not dubbed, color of legs or plumage not matching, when shown in pairs or trios; crooked backs; wry tails; malformed breasts; duck-feet; any artificial coloring; trimming or plucking foul feathers.

\section{THE COCK.}

HEAD : Very dark blue, shaded with black, long, thin and tapering, and very strong at its junction with the neck. Beak, black or brownish-black, slightly curved, and strong at the base.

COMB, WATTLES AND EAR-LOBES: Comb, in chickens that have not been dubbed, dark red or purple, single, small and thin, low in front, serrated, erect and straight; mature birds to be neatly dubbed, and free from warty excrescences, small feathers, or ridges on the edges. Wattles, dark red, very thin, and smooth in texture. Ear-lobes, dark red or purple, thin, and smooth in texture.

Eyes: Black, large, prominent and bright, with a quick and fearless expression, and perfectly alike in color.

NECK: Blue, shaded with black, rather long and nicely arched; the hackle short and close.

BACK: Dark blue, rather short, flat, broad across the shoulders, and narrowing to the tail; the stern slender and neat, the saddle-feathers blue, tinged with golden-red or yellow, and very short and close.

BREAST AND Body: Breast, broad, full and round. Body, very firm and muscular, not soft or hollow on the sides, broadest at the shoulders, and tapering to the tail, and in color of plumage deep blue throughout.

Wrngs: Of medium length and powerful, the butts and shoulders slightly raised, as if for a sudden spring; the remainder not drooping, 
but carried compactly against the sides, the points resting under the saddle-feathers; primaries and secondaries, dark blue; wing-coverts, blue, tinged with golden-red or yellow.

TAIL: Dark blue, of medium length, carried well together and at a moderate elevation; tail-coverts nicely curved, and deep blue in color.

LEGS: Thighs, rather long, round, stout, hard and firm, and placed well forward on the body. Shanks, blue-black or olive, rather long, bony, clean and strong, and standing well and evenly apart, the scales smooth and close, and the spurs set on low. Feet, broad, thin and flat; the toes long, straight and spreading, and well furnished with strong nails; the hind-toes set low on the feet, standing well backwards, and flat on the ground, and not merely touching with the points, or duck-footed.

Hardness of Feather: Body-feathers, short, hard and firm ; quills, very hard and strong.

\section{THE HEN.}

HEAD: Very dark blue, shaded with black, long, slender, tapering, and very neat in appearance. Beak, black or brownish-black, slightly curved, sharp at the point and stout at the base.

Comb, Wattles and Ear-lobes: Comb, dark red or purple, single, small and thin, low in front, evenly serrated, and perfectly erect and straight. Wattles, dark red, small, thin, and neatly rounded on the edges. Ear-lobes, dark red, very small and close to the face.

Eves: Black, large, prominent and bright, with a quick, fiery expression, and perfectly alike in color.

NECK : Blue, shaded with black, long, the feathers very short, giving the neck a slender and graceful appearance.

BACK: Dark blue, of moderate length, flat, broad across the shoulders, and narrowing to the tail.

BREAST AND Body: Breast, broad, round, prominent. Body, very firm and muscular, broadest at the shoulders, and tapering to the tail; the plumage throughout a rich, dark blue.

-Wings: Of medium length and powerful, the butts and shoulders carried somewhat high, so as to cause a flat back, the points not drooping, but carried compactly against the sides; primaries and secondaries, dark blue; wing-coverts, dark blue, bordering on black. 
TAIL: Moderate in length, dark blue, not carried over the back, but extending backwards, the feathers not spread out, but held neatly together; the tail-coverts dark blue, bordering on black.

LEGS; Thighs, dark blue, stout and round, and the feathers short and close. Shanks, blue-black or olive, long, bony, clean and tapering, the scales narrow, smooth and close, and to match the cock's in color when placed on exhibition. Feet, broad, flat and thin; toes, long, straight and spreading, well furnished with strong nails, the hind-toes set low on the feet, standing well backwards, and not duckfooted.

HARDNESS of FEATHER: Body-feathers, close, short, hard and firm; quills, very hard and strong.

CARRIAGE: Neat, upright, quick and active.

\section{POIN'S IN BLUE GAMES.}

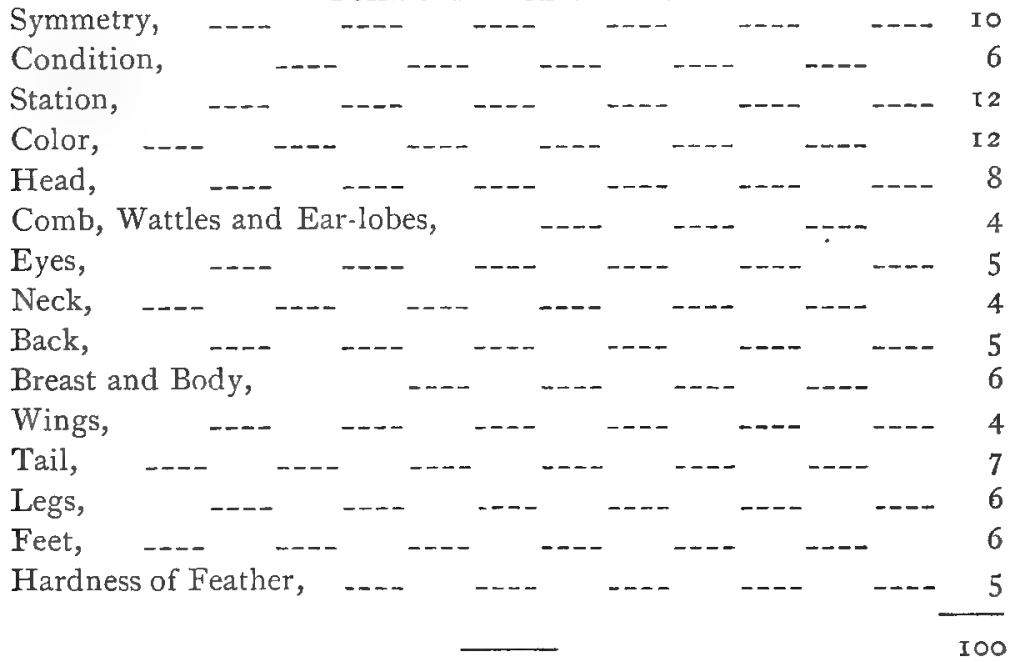

\section{GRAY GAMES.}

DISQUALIFICATIONS:

Adult cocks not dubbed; color of legs or plumage not matching, when shown in pairs or trios; crooked backs; wry tails; malformed breasts; duck-feet; anj artificial coloring; trimming or plucking foul feathers. 


\section{THE COCK.}

HEAD : Silvery-gray, long, thin and tapering, and very strong at its junction with the neck. Beak, dark willow or horn-color, slightly curved, and strong at the base.

Comb, Wattles and Ear-lobes: Comb, in chickens that have not been dubbed, single small, and thin, low in front, serrated, erect and straight; mature birds to be neatly dubbed, and free from warty excrescences, small feathers, or ridges, on the edges. Wattles, red or purple, very thin and smooth in texture. Ear-lobes, dark red or purple, small, thin, and smooth in texture.

Eyes: Deep bay or brown, large, prominent and bright, with a quick and fearless expression, and perfectly alike in color.

NECK: Rather long and nicely arched, the hackle short and close, and, in color, silvery-gray.

BACK : Silvery-gray, rather short, flat, broad across the shoulders, and narrowing to the tail; the stern slender and neat, and the saddle-feathers very short and close, and gray in color.

BREAST AND BODY: Breast, broad, full, and round; in color, black; the shafts of feathers silvery-gray, the color growing darker as it approaches the lower part of the thighs. Body, very firm and muscular, not soft or hollow on the sides, broadest at the shoulders and tapering to the tail.

WINGS: Of medium length and powerful, the butts and shoulders slightly raised, as if for a sudden spring; the remainder not drooping, but carried compactly'against the sides, the points resting under the saddle-feathers; primaries, dusky-black; secondaries, black, with metallic lustre towards the ends of the feathers; wing-butts, black or dark gray; wing-bows, silvery-gray; wing-coverts, rich, glossy black.

TAIL: Black, of medium length, carried well together, and at a moderate elevation.

LEGS: Thighs, dusky-black, rather long, round, stout, hard and firm, and placed well forward on the body. Shanks, dusky-willow or bronzy-black, rather long, bony, clean and strong, and standing well and evenly apart, the scales smooth and close, and the spurs set on low. Feet, broad, thin and flat; the toes long, straight and spreading, and well furnished with strong nails; the hind-toes set low on the feet, standing well backwards and flat on the ground, and not merely touching with the points, or duck-footed. 
HARdNESS OF FEATHER: Body-feathers, short, hard and firm ; quills, very hard and strong.

\section{THE HEN.}

HEAD: Dusky-gray, long, slender, tapering, and very neat in appearance. Beak, dark willow or bronzy-black, slightly curved, sharp at the point and stout at the base.

Comb, Wattles and EAR-Lobes: Comb, single, small and thin, low in front, evenly serrated and perfectly erect and straight; color, dark red or purple. Wattles, red, purple, small, thin and neatly rounded on the edges. Ear-lobes, dark red or purple, very small, and close to the face.

EyEs : Deep bay or brown, large, prominent and bright, with a quick, fiery expression, and perfectly alike in color.

NECK: Silvery-gray, striped with black, long, the feathers very short, giving the neck a slender and graceful appearance.

BACK : Very dark gray, of moderate length, flat, broad across the shoulders, and narrowing to the tail.

Breast and BoDy: Breast, broad, round and prominent. Body, very firm and muscular, broadest at the shoulders, and tapering to the tail.

Wings: Of medium length and powerful, the butts and shoulders carried somewhat high, so as to cause a flat back, the points not drooping, but carried compactly against the sides.

TAIL: Black, moderate in length, not carried over the back, but extending backwards, the feathers not spread out, held neatly together.

LEGS: Thighs, very dark, stout and round, and the feathers short and close. Shanks, dark willow, approaching black, long, bony, clean and tapering, the scales narrow, smooth and close, and to match the cock's in color when placed on exhibition. Feet, broad, flat and thin; toes, long straight and spreading, well furnished with strong nails; the hind-toes set low on the feet, standing well backwards, and not duck-footed.

HARDNEsS of FEATHER: Body-feathers, close short, hard and firm; quills, very hard and strong.

CARrIage; Neat, upright, quick and active. 
POINTS IN GRAY GAMES.

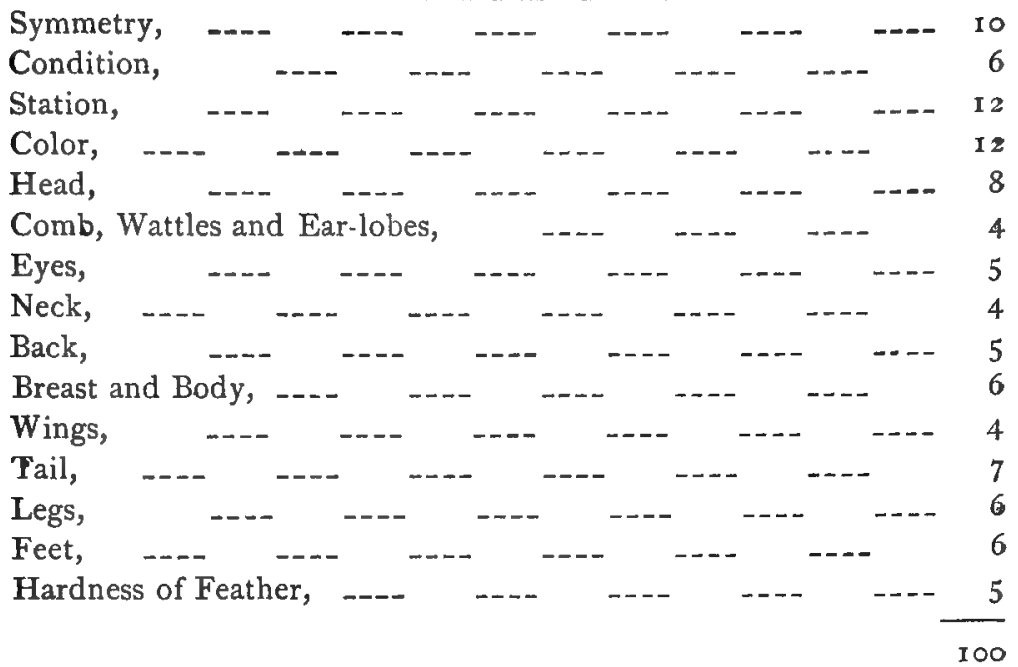

\section{SPANGLED GAMES.}

\section{DISQUALIFICATIONS.}

Adult cocks not dubbed; color of legs or plumage not matching, when shown in pairs or trios; crooked backs; wry tails ; malformed breasts; duck-feet; trimming or plucking foul feathers.

\section{THE COCK.}

HEAD: Long, thin and tapering, and very strong at its junction with the neck. Beak, yellow, willow or bronzy-black, slightly curved, and strong at the base.

Comb, Wattles and Ear-Lobes: Comb, in chickens that have not been dubbed, single, small and thin, low in front, serrated, erect and straight; mature birds to be neatly dubbed, and tree from warty excrescences, small feathers, or ridges on the edges. Wattles, red, very thin, and smooth in texture. Ear-lobes, red, small, thin, and smooth in texture. 
Eves: Red, bay or dark, large, prominent and bright, with a quick and fearless expression, and perfectly alike in color.

NECK: Rather long and nicely arched; the hackle short and close, and, in colors, either black and white, red and white, blue and white, buff and white, or any clearly defined combination.

BACK : Rather short, flat, broad across the shoulders, and narrowing to the tail; the stern slender and neat, and the saddle-feathers very short and close, and of any well-defined combination of spangles.

BREAST AND BoDY: Breast, broad, full, round, and well spangled. Body, very firm and muscular, not soft or hollow on the sides, broadest at the shoulders and tapering to the tail; the general plumage being black and white, red and white, blue and white, buff and white, or any other clearly defined and duly fixed combination of colors.

WINGS: Of medium length and powerful, the butts and shoulders slightly raised, as if for a sudden spring ; the remainder not drooping, but carried compactly against the sides, the points resting under the saddle-feathers.

TAIL: Of medium length, carried well together, and at a moderate elevation; tail-coverts nicely curved.

LEGS: Thighs, rather long, round, stout, hard and firm, and placed well forward on the body. Shanks, yellow, willow, olive or bronzyblack, rather long, bony, clean' and strong, and standing well and evenly apart; the scales smooth and close, and the spurs set on low. Feet, broad, thin and flat; the toes long, straight and spreading, and well furnished with strong nails; the hind-toes set low on the feet, standing well backwards and flat on the ground, and not merely touching with the points, or duck-footed.

HARDNESS OF FEATHER: Body-feathers, short, hard and firm; quills, very hard and strong.

\section{THE HEN.}

Head : Long, slender, tapering, and very neat in appearance. Beak, yellow, willow, olive or bronzy-black, slightly curved, sharp at the point, and stout at the base.

Comb, Wattles and Ear-Lobes; Comb, single, small and thin, low in front, evenly serrated, and perfectly erect and straight. Wattles, red, small, thin, and neatly rounded on the edges. Ear-lobes, red, very small and close to the face. 
EyES : Red, bay or dark, large, prominent and bright, with a quick, fiery expression, and perfectly alike in color.

NECK: Long, the feathers very short, giving the neck a slender and graceful appearance; the plumage spangled, black and white, red and white, blue and white, buff and white, or any other well-defined combination.

BACK: Of moderate length, flat, broad across the shoulders, and narrowing to the tail.

BREAst And Body: Breast, spangled, broad, round and prominent. Body, very muscular and firm, broadest at the shoulders, and tapering to the tail, the plumage throughout handsomely spangled.

IVINGS: Of medium length and powerful, the butts and shoulders carried somewhat high, so as to cause a flat back, the points not drooping, but carried compactly against the sides.

TAIL: Moderate in length, not carried over the back, but extending backwards, the feathers not spread out, but held neatly together.

LEGS: Thighs, stout and round, and the feathers short and close. Shanks: yellow, willow, olive or bronzy-black, long, bony, clean and tapering, the scales narrow, smooth and close, and to match the cock's in color when placed on exhibition. Feet, broad, flat and thin; toes, long, straight and spreading, and well furnished with strong nails; the hind-toes set low on the feet, standing well backwards, and not duck-footed.

HaRdness of FEather : Body-feathers, close, short, hard and firm; quills, very hard and strong.

CARriage; Neat, upright, quick and active.

POINTS IN SPANGLED GAMES.

Symmetry,

Condition,
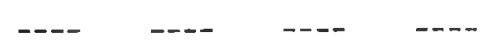

Station,
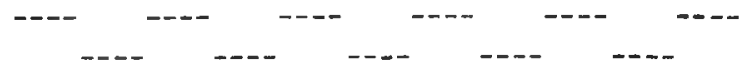

Color,
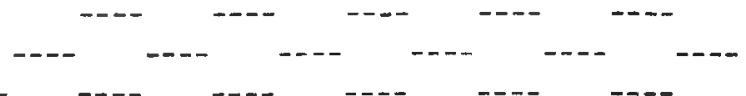

Head,
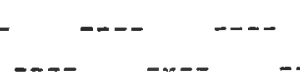

Comb, Wattles and Ear-lobes, Eyes,

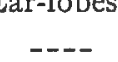

Neck,

Back,
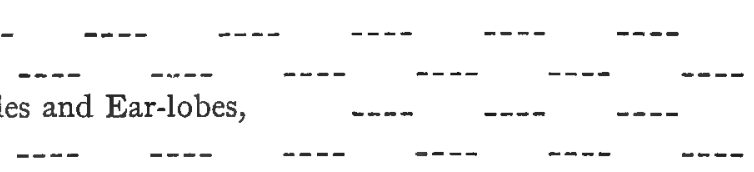

Breast

Wings,

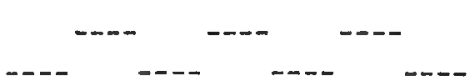


COCKER'S MANUAL.

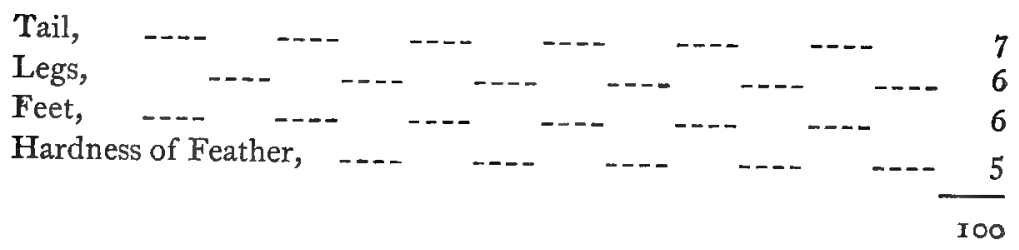




\section{THE POULTRY WORLD, \\ HARTFORD, CONN.}

\section{H. F. STODDARD, - - - FDITOR.}

This is an elegantly illustrated and carefully conducted quarto Monthly Magazine for the Fancier, the Family, the Breeder of Fowls, and the Market Poulterer, to whose interests its pages are especially devoted.

"The Poultry World" aims to maintain its reputation as the leading American journal of its class, and its circulation is admitted to be by far the largest of any strictly poultry publication in the country.

Its Seventh Volume, for the year 1878 , will be an advance upon all previous issues. and in that volume a highly attractive feature is presented, in our series of original

\section{Superior Chromo Illustrations}

of modern Standard specimens of Fowls; twelve of which elegant full page pictures are furnished to "The Poultry World" subscribers at a cost of only 75 cents annually, in addition to the regular price of the Magazine.

As an Advertising Medium for Breeders, Dealers, Fanciers, and Poultry men generally, those who have good surplus stock to sell will readily appreciate the advantages offered by means of the present very large and constantly increasing circulation of "The Poultry World" amongst the Farmers, Fanciers, Fowl-raisers, etc., who desire to purchase such stock.

Our Magazine goes largely into every State and Territory in the United States and Canadas, each month. Advertisements are received at reasonable rates, corsidering the wide-spread distribution these cards and notices obtain. And as we devote our pages exclusively to the interests of poultrymen, it will be seen that this paper is beyond comparison the best channel through which advertisers may reach the buying class.

TERMS. - \$1.25 for first year's subscription. 75 cents additional for the I2 Chromos. $\$ 1.00$ a year, after first year, to same address. Clubs of two or more (when desired) sent to separate addresses, at $\$ 1.00$ each. These rates include postage. back numbers always on hand-ro cts. each. Back Volumes \$1.00 each.

H. H. STODDARD, "Poultry World," Hartford, Conn. 


\section{GAME FOWLS FOR SALE,}

Of the following well-known varieties:

Black Reds, Tartars,

Virginia Grays. Rattlers,

\section{Duckwings.}

Brown Reds, Cencers,

Parties ordering fowls of me will receive nothing but choice, healthy birds. I can also furnish other strains of Games not above mentioned. Fowls carefully boxed and shipped on receipt of price.

$$
\text { NO FOWIS SENT C. O. D. }
$$

Send stamp for circular and prices. Address,

WM. JAS. HEALEY, Mineral Point, Wis.

\section{IHI A IRIRTY IK. WIAISIH, \\ YORK, PENNSYLVANIA,}

Breeder and Shipper of
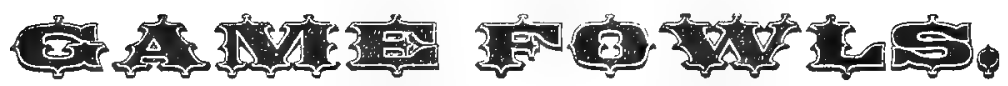

Yellow Duckwing, Black-Breasted Reds, Stonefence, etc., etc. Send for Prices.

\section{LOUIS SENDKER,}

Lock Box 643,

Importer and Breeder of

PIT G A M FOWLS.

Warranted Dead Game or money refunded.

Eggs and Chicks in season. Cocks and Hens at any time. Send stamp for Circulars and Prices. 


\section{IE. SIINSAIBAUGII,}

STIAOUSE, ITEBRASRA,

Breeder and Shipper of Superior

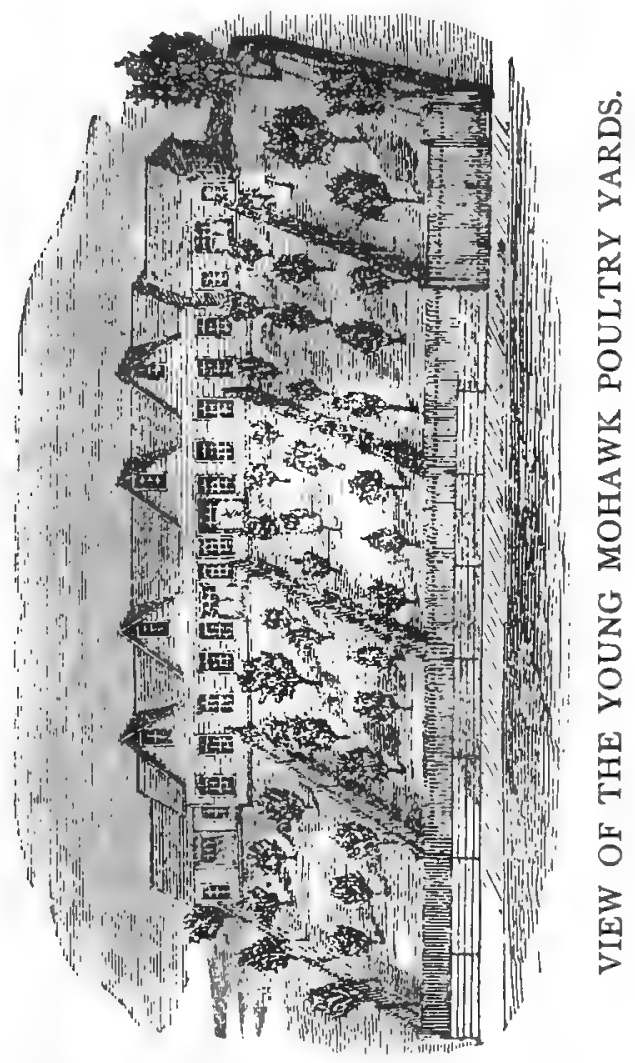

Light Brahmas, Dark Brahmas, Partridge Cochins, Plymouth Rock, Gold-Laced Sebright Bantams, Imperial Pekin Ducks.

I have about 400 Chicks of the above varieties, and I will sell Choice Specimens for breeding or exhibitions after Septernber 1st, at reasonable prices. Write for just what you want. All letters and postal cards cheerfully anwered. 


\section{American Poultry Journal}

\section{And Record.}

A splendid 32-page, Illustrated Monthly Magazine, devoted to the breeding and management of

\section{Poultry, Pigeons, Rabbits and Pet Stock.}

It has the Largest Corps of Practical Breeders as Editors and Correspondents of any Journal of its class in America, and is

\section{The Finest Poultry Journal in the World.}

Subscription, \$1.25 per year for plain edition; 2.00 per year for the Chromo-plate edition (each number containing a beautiful eight to ten color plate of prize fowls), strictly in advance. Send I 3 cents for specimen copy of Plain Edition, or zo cents for specimen copy of Chromo Edition.

No attention paid to postal cards asking for specimen numbers.

\section{Published by C. J. WARD, Editor and Manager,}

I 82 and 184 Clark Street, Chicago, Ill.

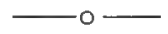

I also furnish the following goods at prices annexed:

CRUSHED RAW BONE: 25 Ith. bag, \$I.50; 50 th. bag, \$2.50; I00 lbs., \$4.00; per bbl., 200 玷s., $\$ 7.00$.

CRUSHED OYSTER SHELLS; I00 $\mathrm{tb}$. bag, $\$ 2.50$; per bag of 200 tbs, $\$ 4.00$.

COOKED BEEF MEAL (an excellent thing): 6 cents per pound. AMERICAN POULTRY FOOD: Trial Packages, 40 cents; Large Packages, \$1.00-sent by mail, post-paid. Five Pound Boxes (by express), $\$ 1.50$-expressage to be paid by person ordering.

Also, ROUP PILLS and CHOLERA PILLS at 50 cents, 75 cents and $\$$ I.00 per box, post-paid. 


\section{THE AMERICAN}

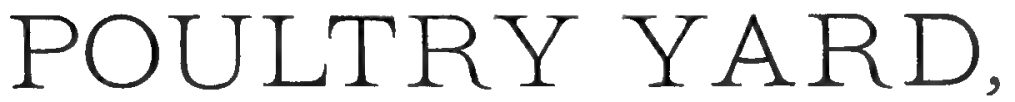

A New, Stylish, Well-filled, Nicely Illustrated, and Carefully Edited

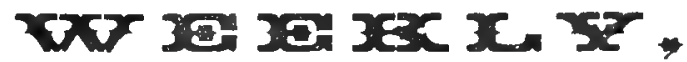

Will henceforth be pablished and sent out by us from Hartford, Conn., at

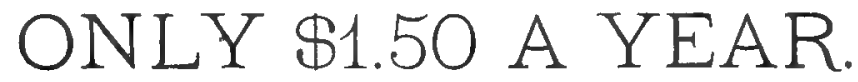

WE HAVE PLACED the SUBSCRIPTION PRICE DOWN LOW

In order that we may make it an inducement for Fanciers and Poul-

terers, Farmers, Families, Mechanics, Amateurs-every one who

keeps fowls, who thinks of breeding chickens, or who feels

any interest in fowl-raising in this country-may

SUBSCRIBE FOR IT.

New or Old subscribers to THE POULTRY WORLD are invited to order вотн papers (our Monthly Magazine and the Weekly), at $\$ 2.00$ for the year. The regular price for both is $\$ 2.75$.

THE AMERICAN POULTRY YARD and twelve

Chromos will be sent annually, to one address, for

\$2.25. Both The Poultry World and the

Weekly, with the I 2 Chromos, at $\$ 2.75$.

Half-yearly, or yearly advertisers have the privilege of changing the matter in their advertisements every three months, without

additional cost. No extra charge for cuts or displayed type, which we furnish, of any style and variety of fowls desired.

\section{A Live Weekly Poultry Paper}

Is now to be published, which we shall aim to make a welcome visitor to the fireside of farmer, poulterer, fancier, dealer, family or amateur, at $\$ \mathrm{I} .50$.

H. H. STODDARD, - - - HARTFORD, CONN. 


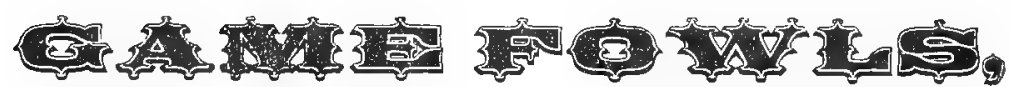

\section{The Best of American and Imported Stock.}

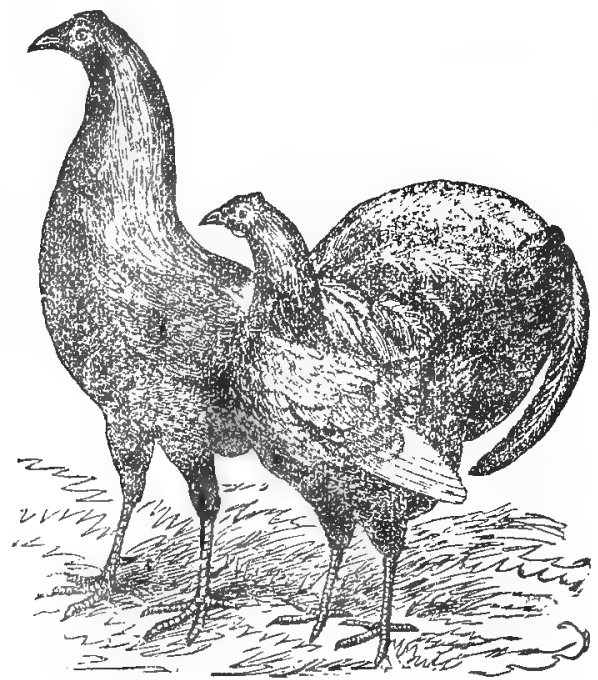

Having greatiy increased my stock of Games, I can now offer to Fanciers and Cockers a selection from

\section{Nearly all the Leading Varieties.}

Also, a number of Crossed Fowl, bred especially for the Pit.

Persons can have fowls combining beauty with strength, courage with skill, and perseverence with gameness, as it is a pride in me to produce WINNING FOWL. My fowls have been repeatedly tested, and in point of courage, ferocity, and celerity of action, have no superiors.

All purchasers guaranteed satisfaction.

For further particulars address

P. O. Box, No. 974.

\section{F. H. GRAY,}

Battle Creek, Mich. 


\section{GAMS
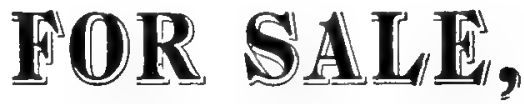

From Allen's Celebrated

Black-Red, Brown-Red \& Duckwing Games.

23 PAIRS of my Games were pronounced the best lot ever seen on exhibition, as exhibited by one exhibitor, at the Centennial. They were awarded the

\section{CENTENNIAL GRAND MEDAL,}

Also were recommended the GOLD MEDAL, by the International Judge, TWO SILVER, and FIVE BRONZE, for being very superior specimens of the varieties to which they belong. They were exhibited six times last season and received

81 First Premiums, 48 Second Premiums,
22 Third Premiums,

I Fourth Premium.

At the Provincial Exhibition this season, they received 7 First and 2 Second Premiums.

By this, judge of their merit, as they are only exhibited at first-class shows.

Game Fowl Chicks, at from $\$$ Io to $\$ 25$ each.

Eggs in Season, Setting, eleven eggs, \$6.

Game Bantam's, Setting, eleven eggs, \$4.

Terms-Cash. Parties ordering will please note this, as no order will be filled until terms are complied with.

Address,

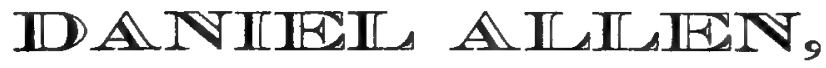

Enclose stamp for answer.

Galt, Ontario, Canada.

(See page 35 for illustration of Duck wing Games.) 
NEW SERIES.

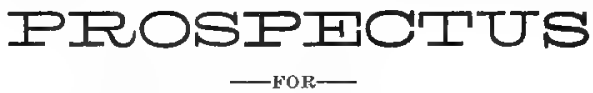

\title{
Familiar Science
}

\section{and Fanciers' Journal.}

\section{(Established 1873.)}

\author{
An Illustrated Magazine covering departments as follows:
}

EDITORIAL, wherein our views upon questlons and issues concerning, or of interest to, our readers will be given candidly and freely, uninfluenced by clique or ring.

CORRESPONDENCE,-the department of our subsoribers-wherein their experiences may be exchanged, different theories advanced and discussed, and the results of their research and experiments be recorded. The life of a fancy is in its members being acquainted and familiaxized with each other, so this department must recommend itself to all.

THE NATURALIST will be devoted more especially to Ornithology, Botany and Oology, studies now receiving almost universal attention. While a certain regárd must be had for scientific names and technical phrases to insure accuracy, still our aim in this department will be to treat these subjects in a familiar manner that shall be acceptable to the general readers as well as the advanced student.

HOME AND ITS PETS will treat of the Window Garden, the Aquarium, the Aviary, and the many Pets children fancy. It will aim to cover all that combine to make "bome" a center of interest, something more than a sheltering roof. A. feature in this departnient will also be the Domestic column, a collection of old, varied, and tested recipes.

POULTRY AND PIGEONS. In this department, we intend "Seasonable Hints" to be the concentration of a volume of timely iuformation. Besides this we shall furnish the latest news from all quarters, with a careful trealment of all theories and experiments that are engaging popular attention.

THE EXCHANGE' AND MART, our Advertising Supplement, will be all it has been in the past, We shall endeavor to keep it free from dishonest parties. The Exchange and Want columns, that bave proved so acceptable during the hard times, and have done much to familiarize fanciers with each other, will be continued.

OUR LIST OF CONTRIBUTORS will include the names of William Wood, M. D., Prof, A. N. Raub, Wm. E. Flower, "Huon," Thos. G. Gentry, Harry A. Slocum, E. A. Samuels, V. M. Firor, Plof. G O. Brown, Dr. A. M. Dickie, "Barb," Jas. M" MeCann, "P. B.," Rev. W. G. Todd, H. Woodward. Edw. Harris, Andrew Sugden, A. E. Abbott Prof, Horsford, "W.," C. L. Maynard, "Peter Peppercorn," P. Welch, "Pacific" "Washening," Charles Wylls, Fred T. Jencks, John Van Opstal, Geo, M. Twitobell, Wm. T. Rogers, Fenry Erdman, artist.

Receiving regularly, besides the leading Americen periodicals, the best of the German, French and English devoted to our specialties, we are enabled to have our selections applicable and of the higest order.

With the Fifth Volume, the Journal will be enlarged and improved. Its field is the broad one of fancies, hobbies. Devoted to no one in particular, it will give precedence to that which for the time being most engages the popular mind. Thanking pur patrons for the generous support of the past, we ask its continuance. We direct the attention of all fanciers, whatever may be their hobby, to the Journal as a papex giving the latest and best information, one out-spoken and independent, a paper untranmeled by individual interest, conducted "Not for itself, but for all."

\section{JOSEPH M. WADE, Springfield, Mass.}

Terms of Subscription, pre-paid by mail, \$1.50 per annuru. Single copies, 15 cents. General Adrertising Rates, 25 cents per line. Exchanges and Wants, four lines, or forty words, 25 cents each insertion. 


\section{GERMAN ROUP PILLS.}

THE STANDARD SPECIFIC REMEDY FOR

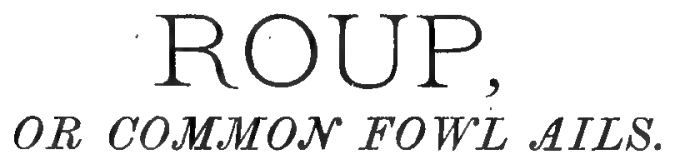

- -

THE GERMAN ROUP PILLS (Kunkel's Original Recipe), have deservedly acquired a world-wide reputation, through their extraordinary

\section{Efficacy, Adaptedness, Operative and Restorative Qualities,}

where they are judiciously administered to ordinary sick fowls. The combination of Health-giving Ingredients embodied in the peculiar prescription from which the universally approved and promptly effective German Roup Pills are manufactured, has proved indeed a wondrously successful and reliable discovery, that in thousands of instances has been voluntarily proclaimed by prominent and experienced Fowl Fanciers, Breeders, Amateurs, Dealers and Poulterers, in every section of the United States and the Canadas, to be for a general fowl medicine

UNRIVALED, AS WELL AS ALTOGETHER UNEXCELABLE.

After five years of steady success, the subscriber has become proprietor of the now celebrated German Roup Pills, and they will be manufactured under his supervision hereafter, at Hartford, Conn.

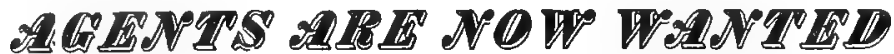

in good locations, for the sale of these reliable Roup Pills. Liberal discount, at wholesale.

Sample Boxes mailed, post-paid, to any address, for 50 cents.

Larger sized boxes (containing more than double the quantity), for

$\$ 1.00$. For explanatory circulars, testimonials, etc., address

\section{H. H. STODDARD,}

"Poultry W Orld,"

HARTFORD, CONN. 










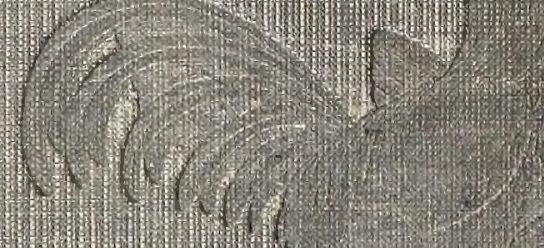

(1)

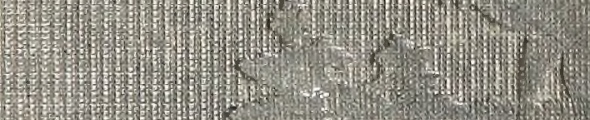
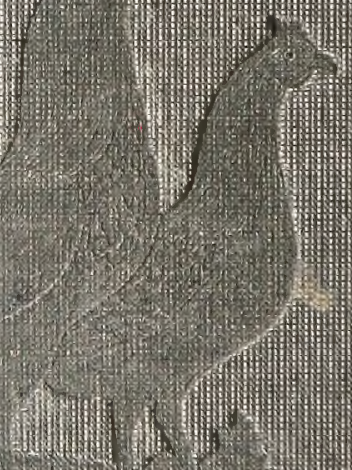